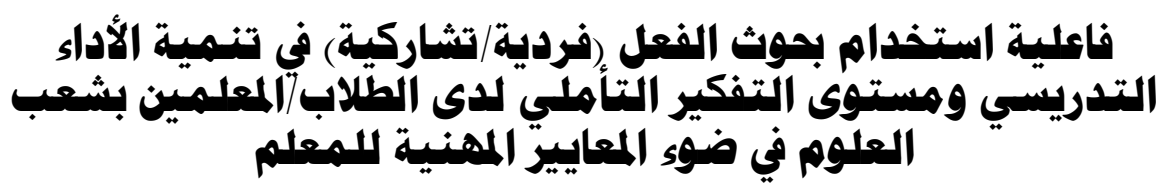

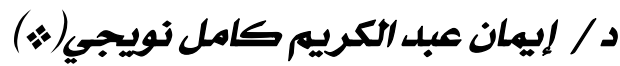

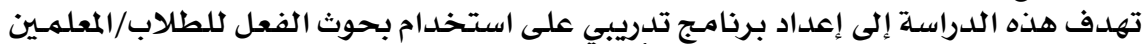

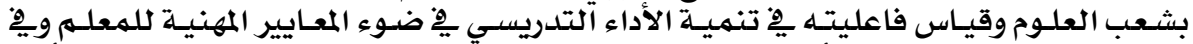

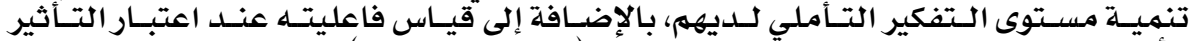

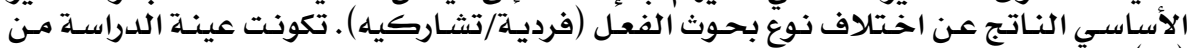

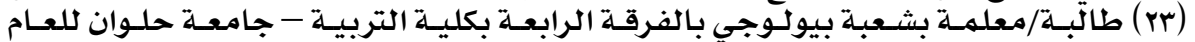

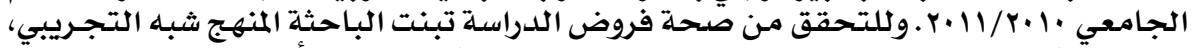

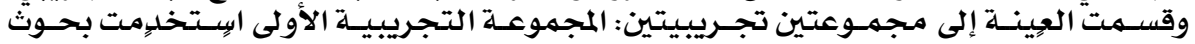

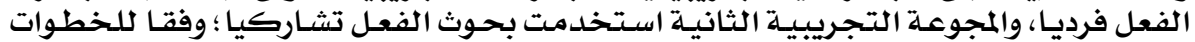

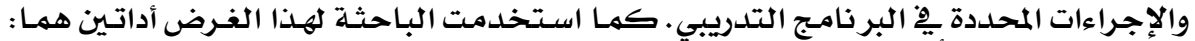

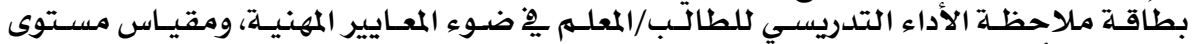

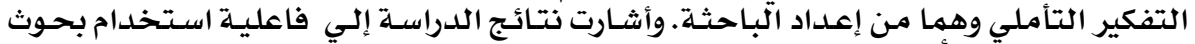

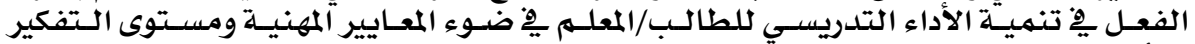

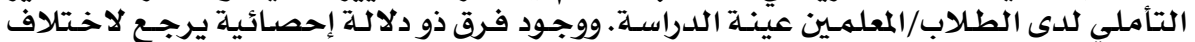

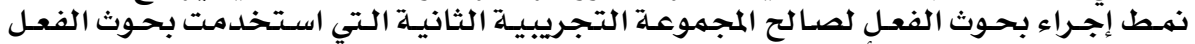

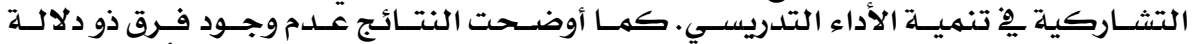

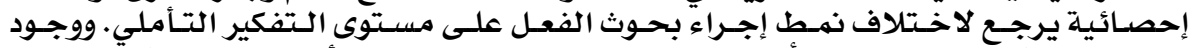

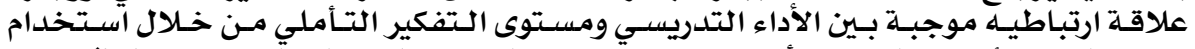

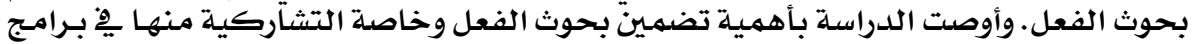

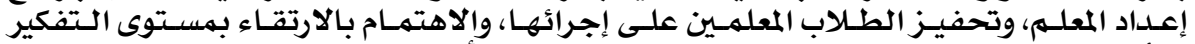

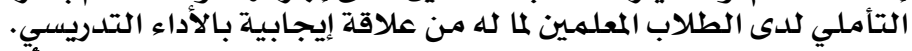

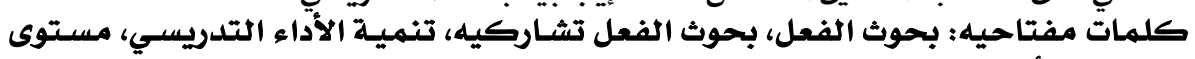

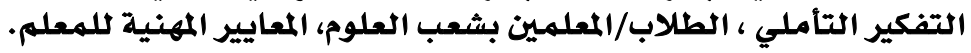

The Effect of Using Action Research (Individual/Collaborative) on

Improving the Teaching Performance and Reflective Thinking Level for The Science Student-Teacher in the light of Professional

\title{
Abstract:
}

\section{Standards for Teacher}

The main aim of this study was to determine the effect of using a training program based on action research on improving teaching performance and reflective thinking level for the science student-teachers in the light of professional standards for teachers. In addition, it was measured its effectiveness when considering the main effect was a result of the difference in the type of action research (individual versus collaborative). The sample of the study consisted of (23) fourth year, Biology student-teachers faculty of Education, Helwan University of the academic year 2010/2011. To validate the hypothesis of the study the researcher adopted a quasi-experimental

(*) مدرس المناهج وطرق تدريس العلوم بكلية التربية - جامعة حلوان 


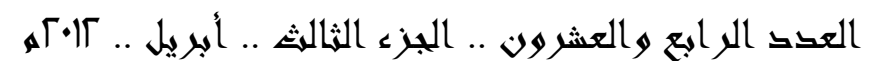

approach, and the sample was divided into two experimental groups: the first experimental group used the action research individually and the second experimental research used a collaborative action research, according to the steps and procedures specified in the training program. Data was collected by using two instruments: the Teaching Performance Observation Checklist in the light of professional standards for teacher, and Reflective Thinking Level Scale.The results showed the effectiveness of using the action research in the development of the teaching performance of the biology student-teacher (study sample) in the light of professional standards, and the reflective thinking level. Also there were statistically significant differences between the two experimental groups due to the effect of the type of using action research In favor of the second experimental group that used collaborative action research in improving teaching performance. The results also showed no statistically significant differences due to the different type of using action research at the level of reflective thinking. In addition, there was a positive correlation between teaching performance and the level of reflective thinking through the use of action research. Finally, based on the result reached and conclusion made, a set of recommendations and suggestions for further research were provided.

Key word : Action Research, Collaborative Action Research, Teaching Performance, Reflective Thinking Level, Science Student-Teacher, Professional Standards for Teacher

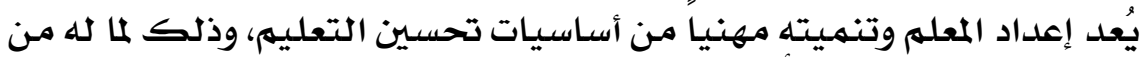

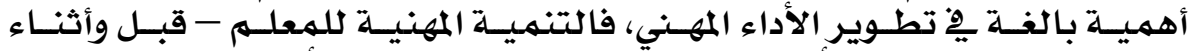

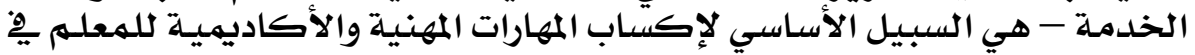

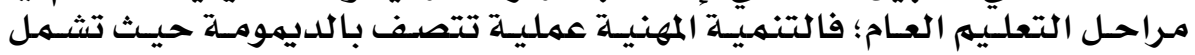

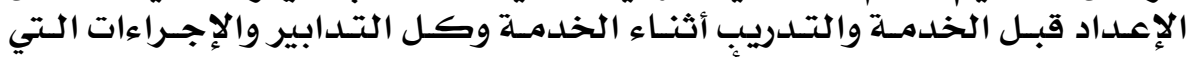

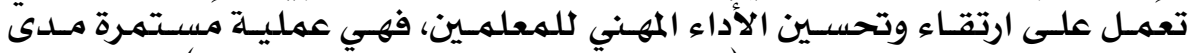

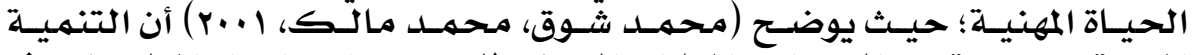

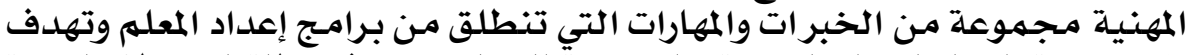

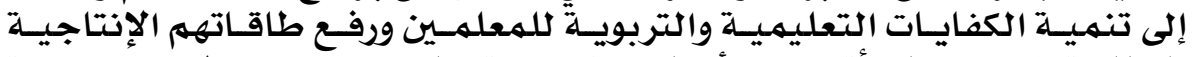

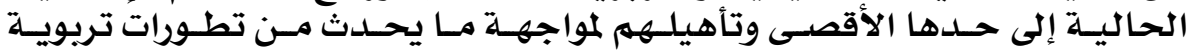

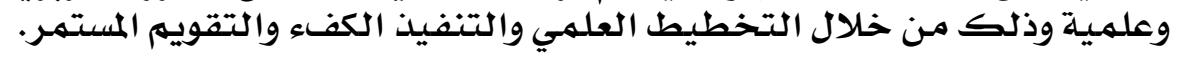

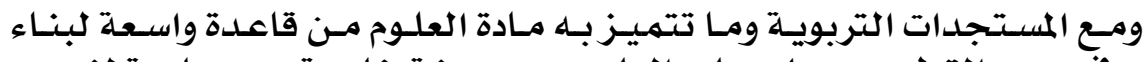

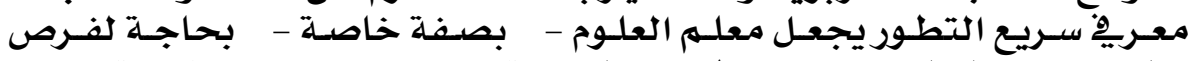

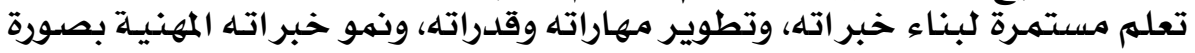

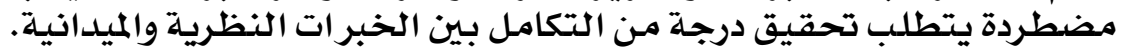

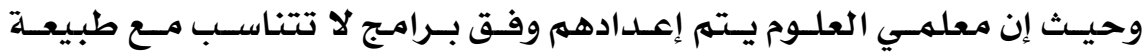

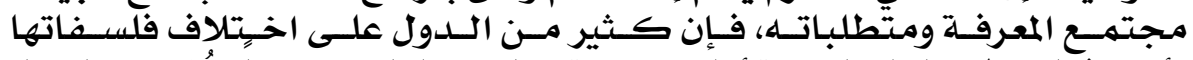

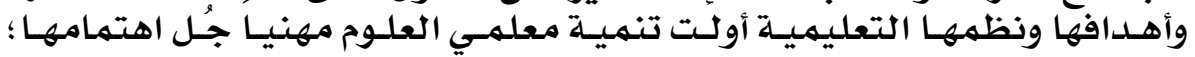




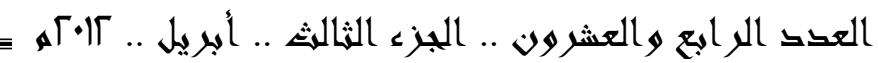

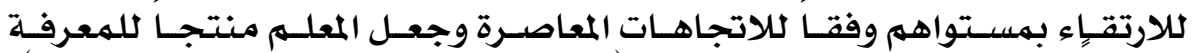

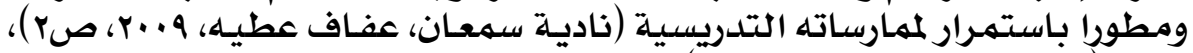

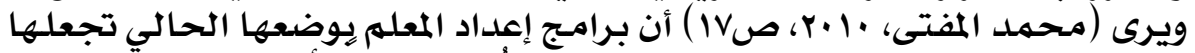

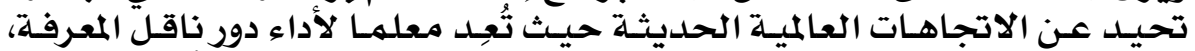

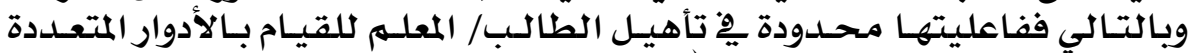

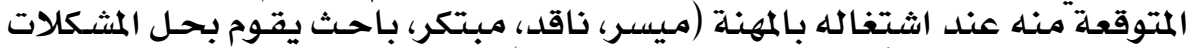

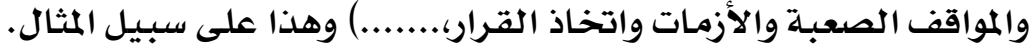

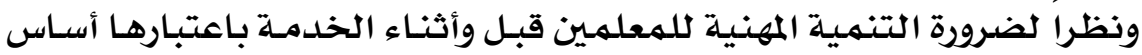

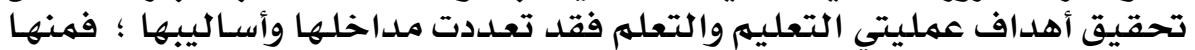

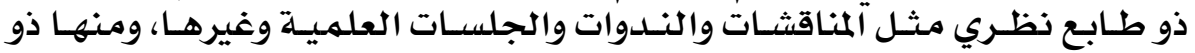

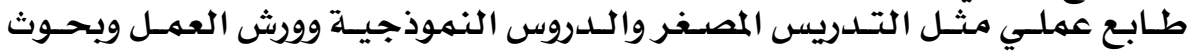
الفعل وغيرهيا.

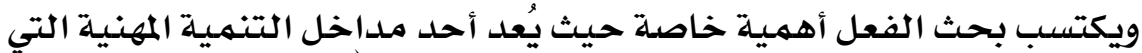

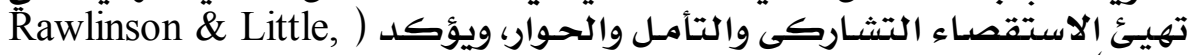

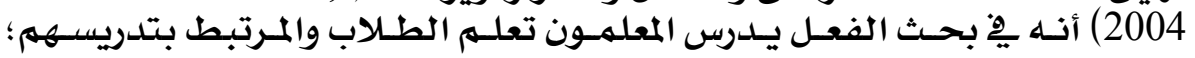

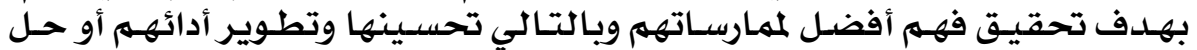

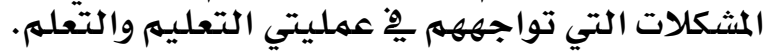

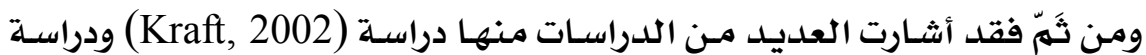

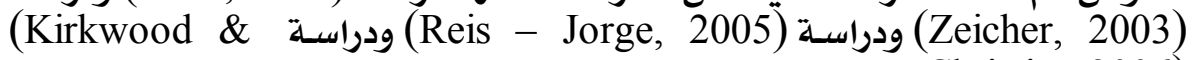
إلى Christie, 2006)

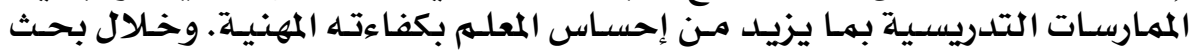

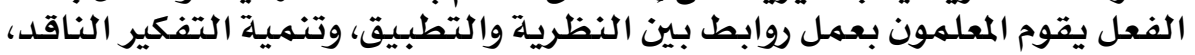

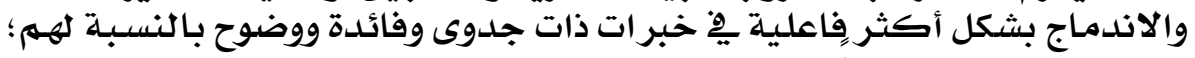

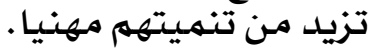

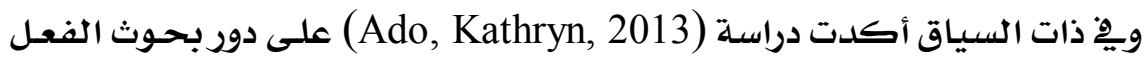

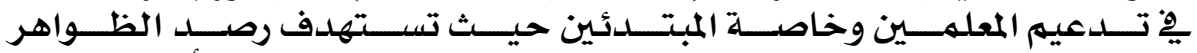

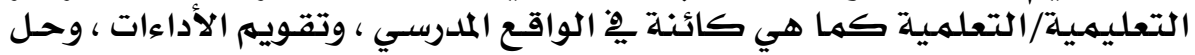

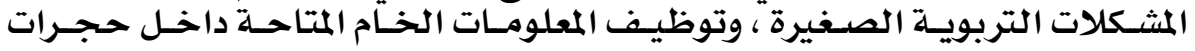

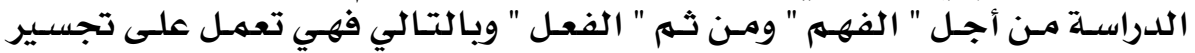

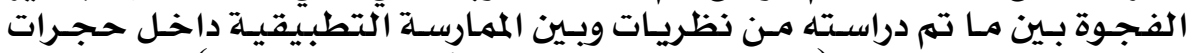

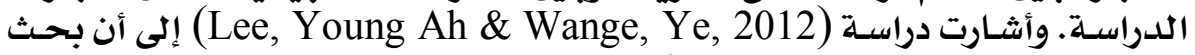

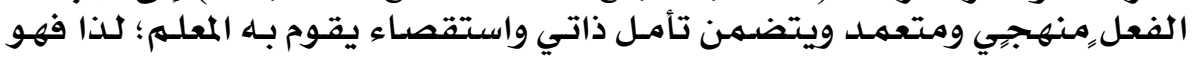

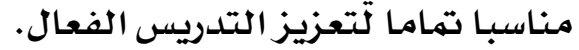

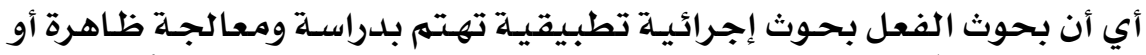

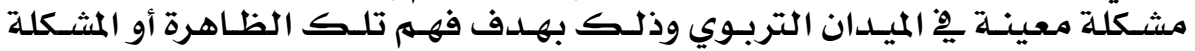

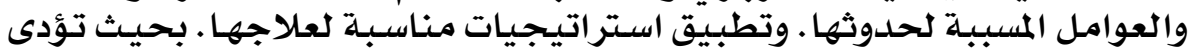

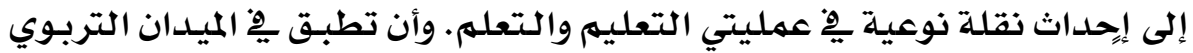

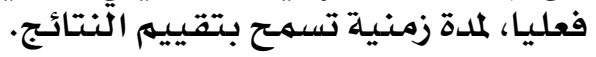




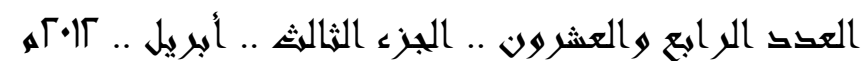

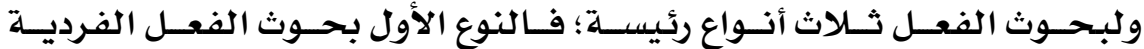

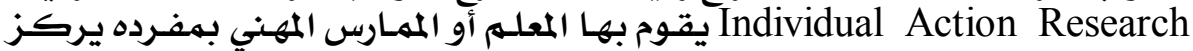

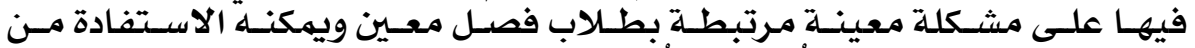

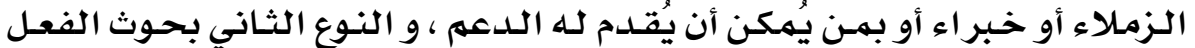

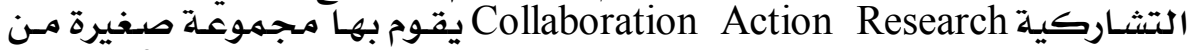

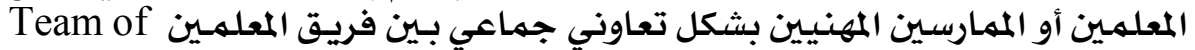

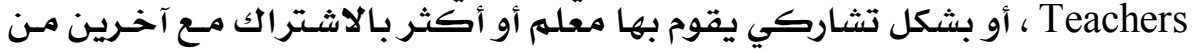

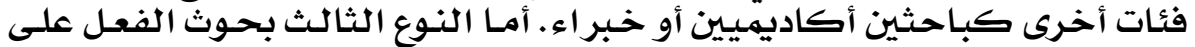

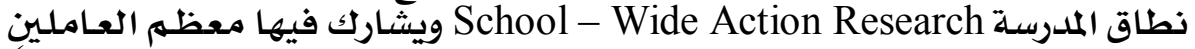

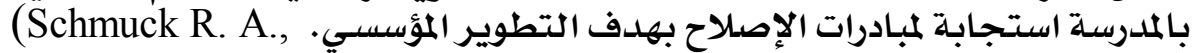
2009, p.p. 202-205)

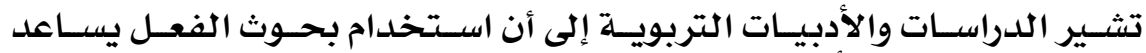

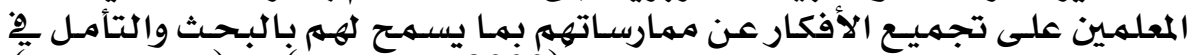

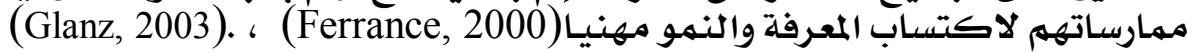

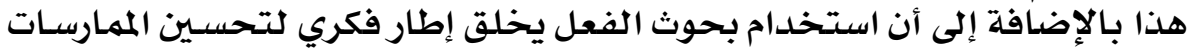

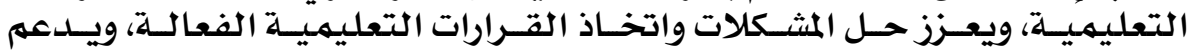

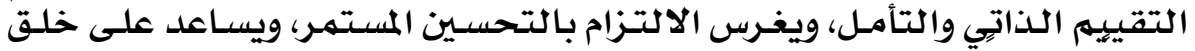

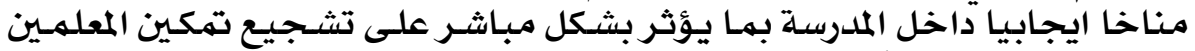
. Teacher Empowerment

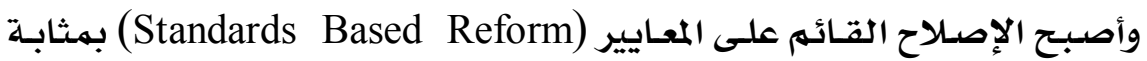

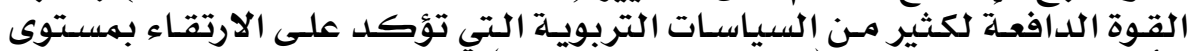

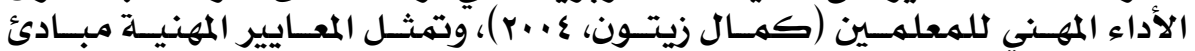

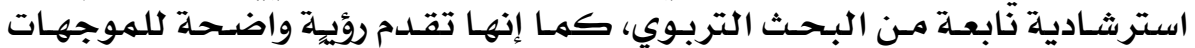

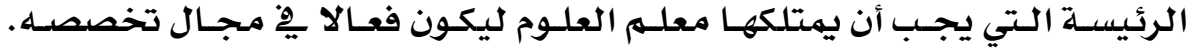

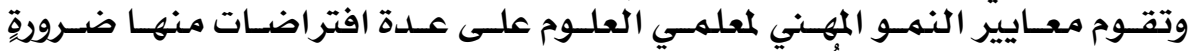

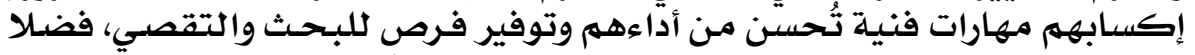

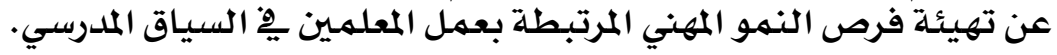

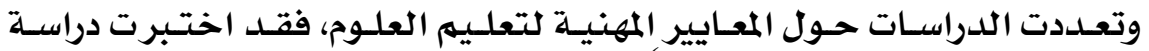
(Klieger \& Yakobovitch, 2011)

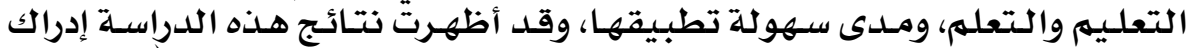

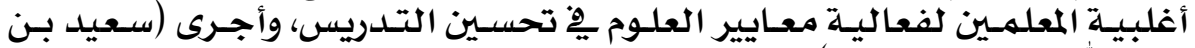

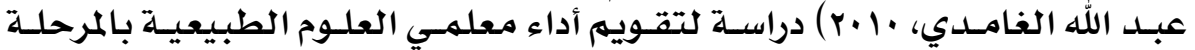

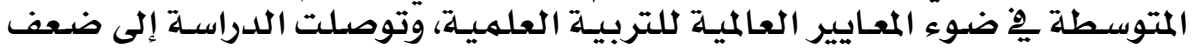

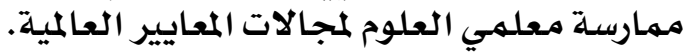

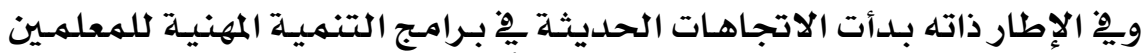

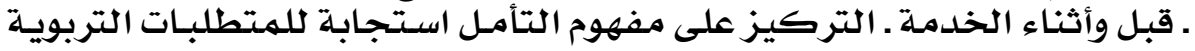

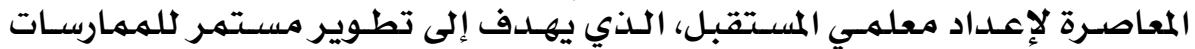

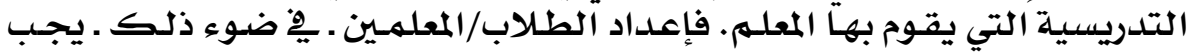




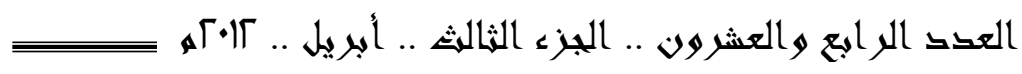

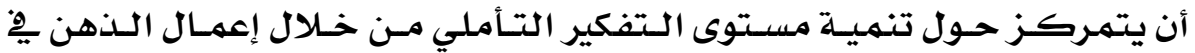

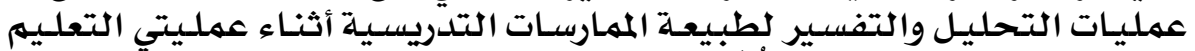

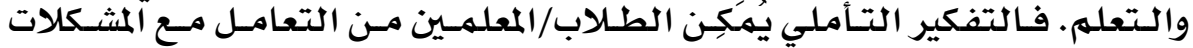

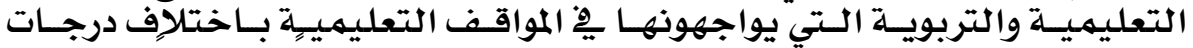

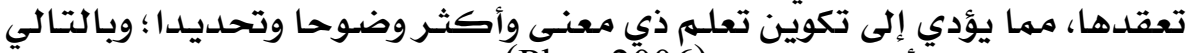

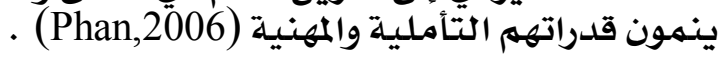

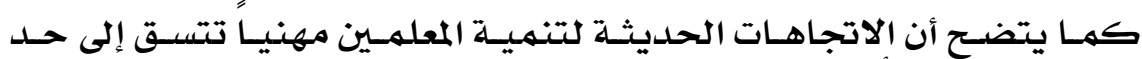

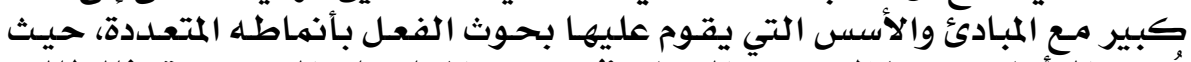

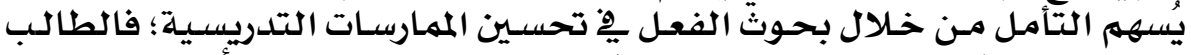

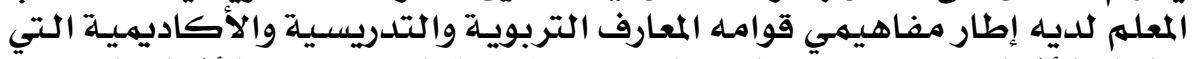

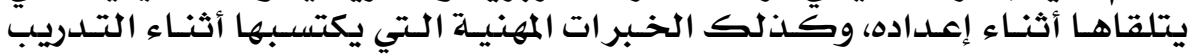

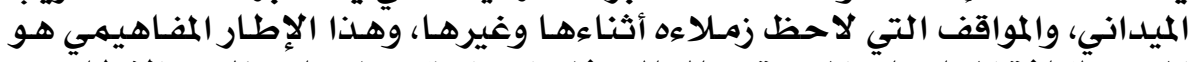

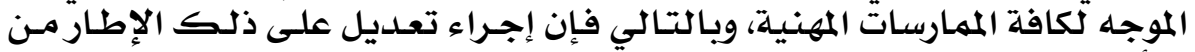

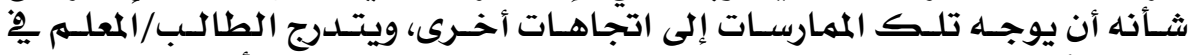

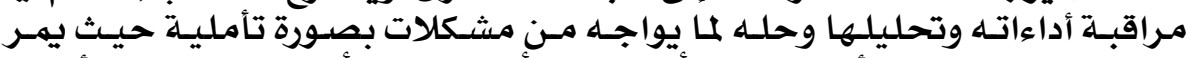

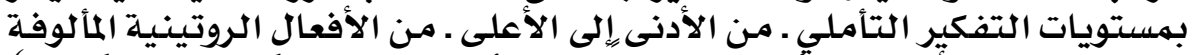

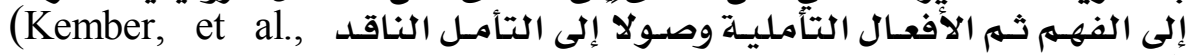
.2000)

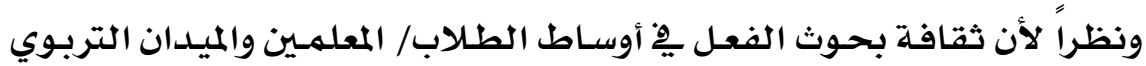

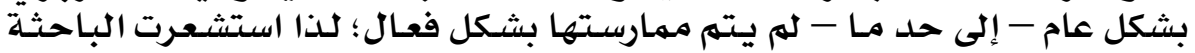

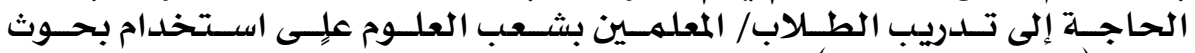

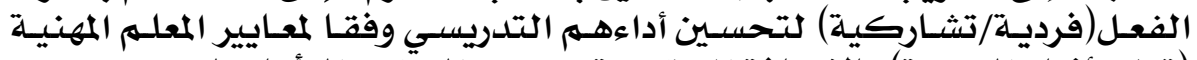

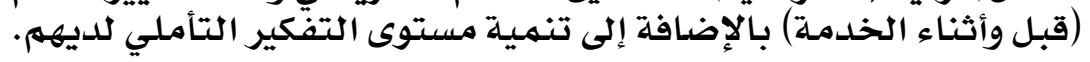

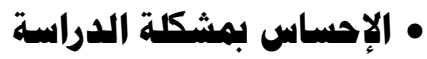

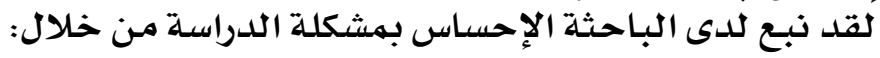

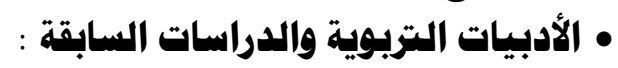

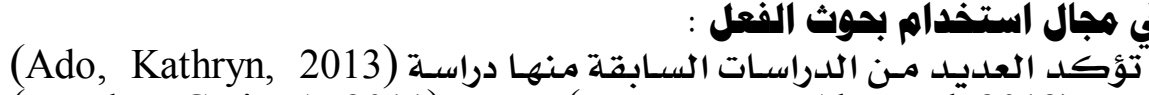

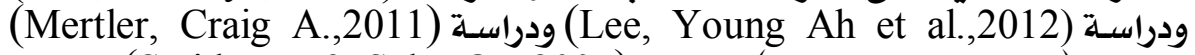

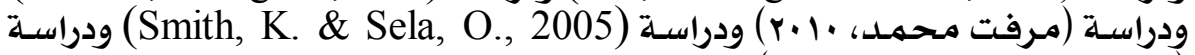

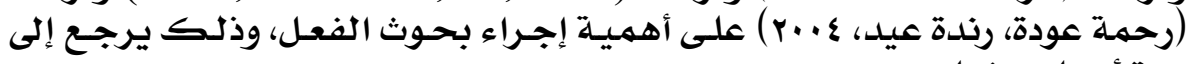

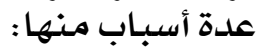

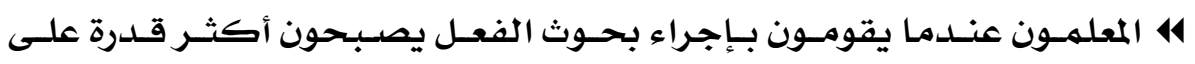

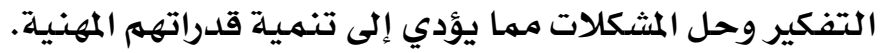

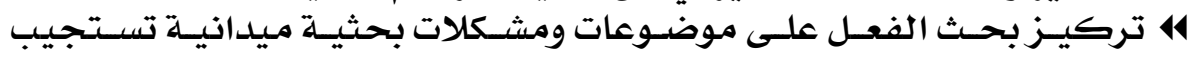

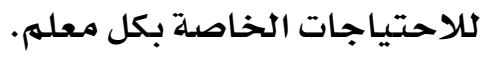
41 تساعد بحوث الفعل على اكتتشاف طبيعة المهمارسات وتحسينها. 


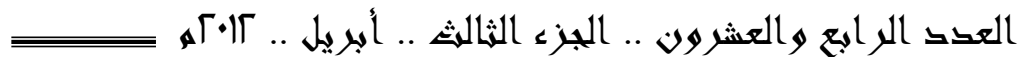

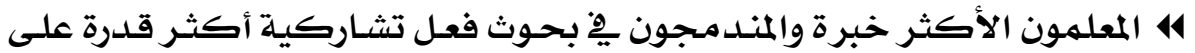

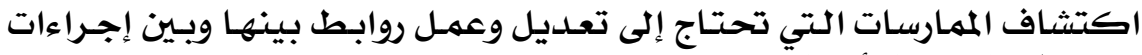

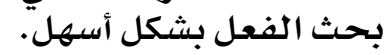
4 بحوث الفعل التشاركية تدعم ممارسات الطلاب/المعلمين والمعلمـين المبتدئين

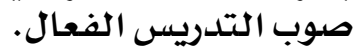

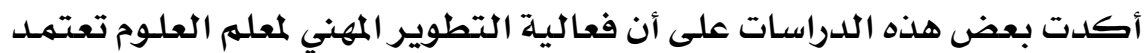

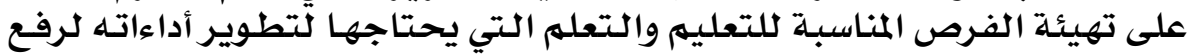

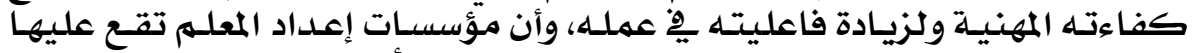

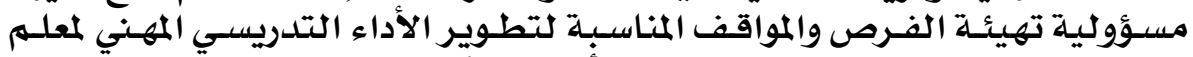

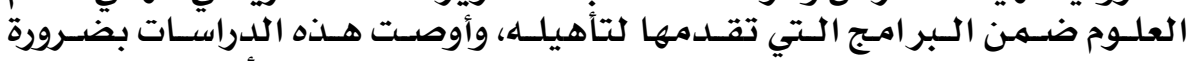

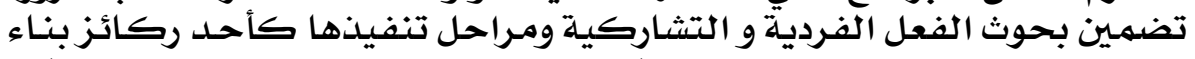

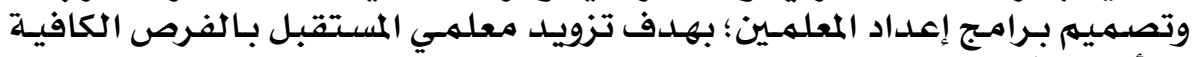

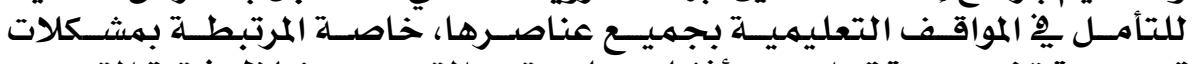

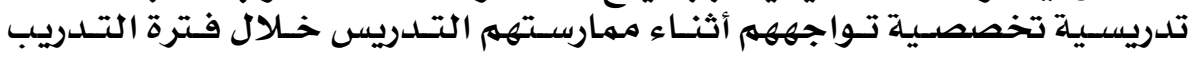
الميداني.

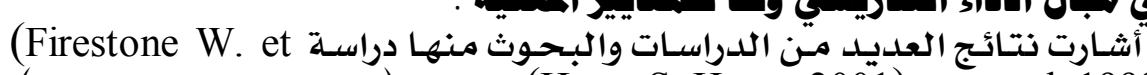

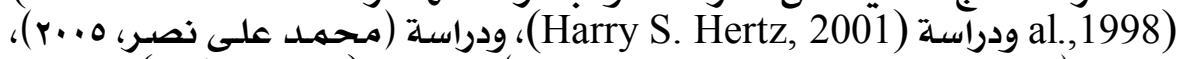

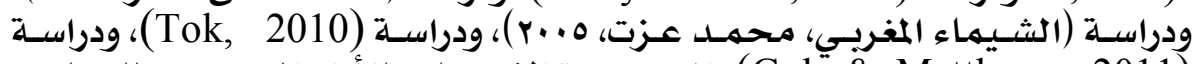
إلى ضرورة الاهتمام بالأداء التدريسي للمعلدم: (Goh \& Matthews, 2011)

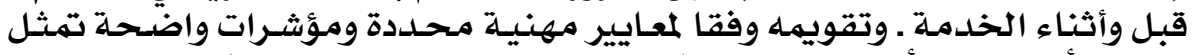

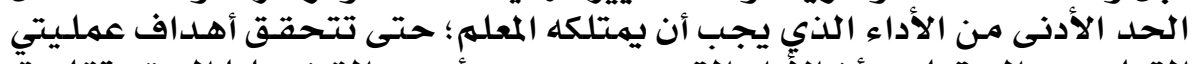

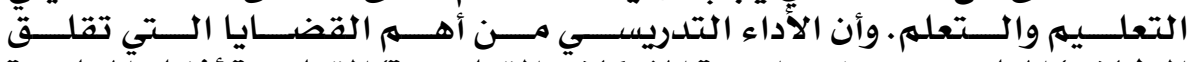

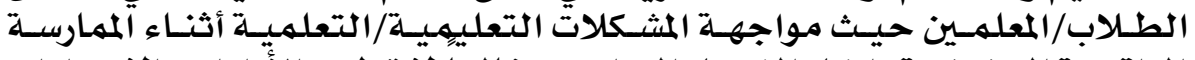

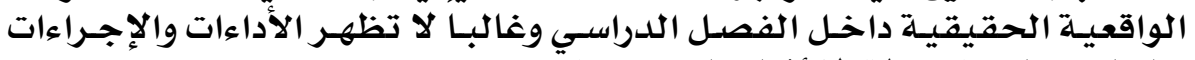
والسلوكيات المرتبطة إلا أثناء التدريب الميتداني.

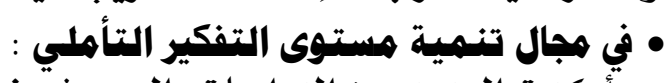

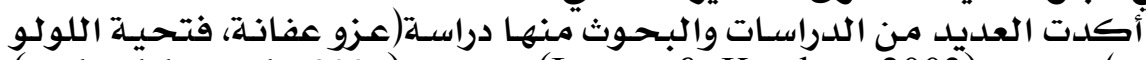

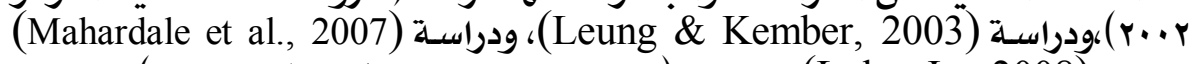

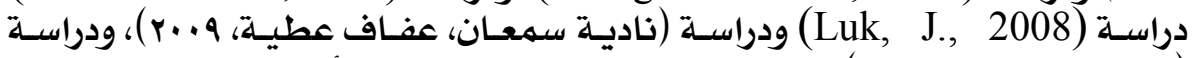

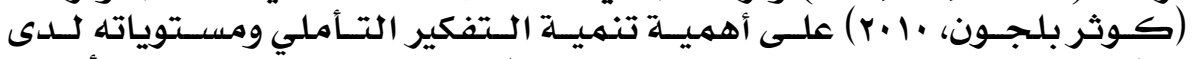

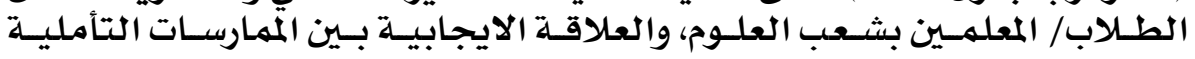

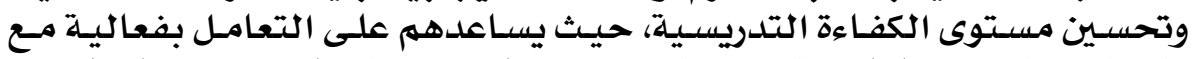

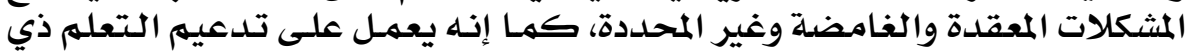

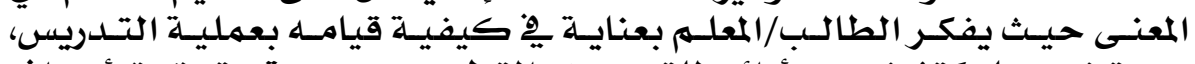

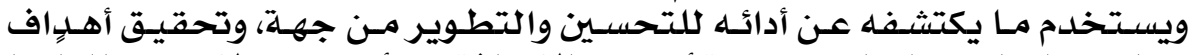

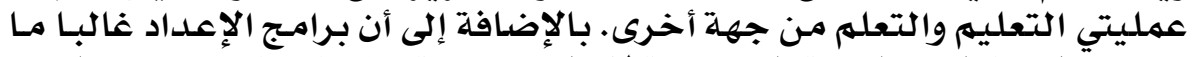

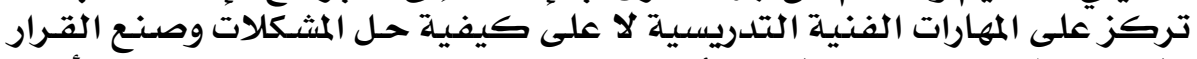

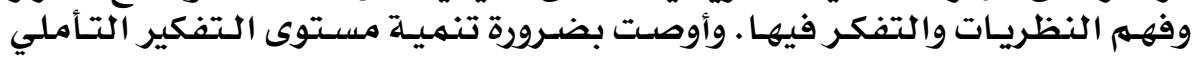

\section{Y1.}




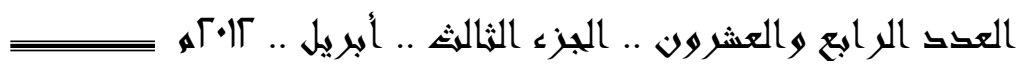

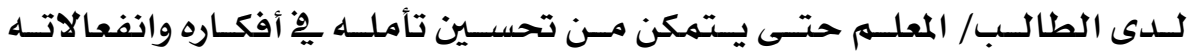

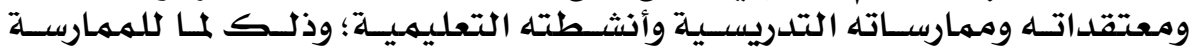

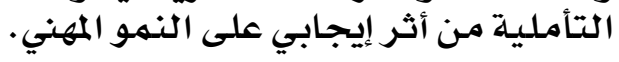

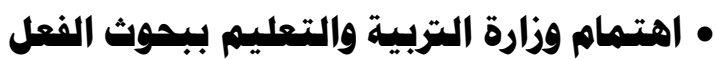

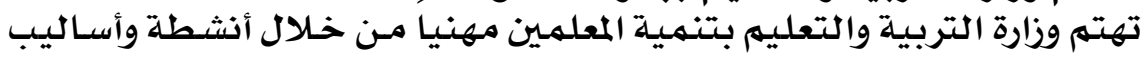

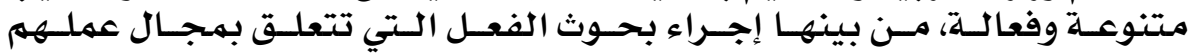

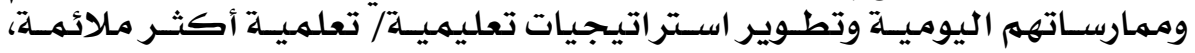

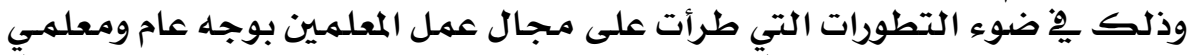

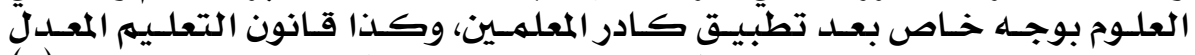

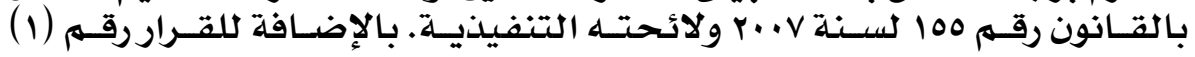

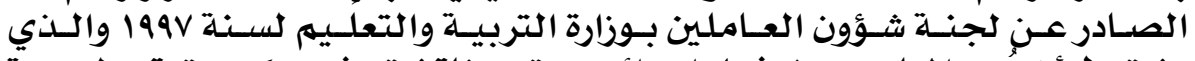

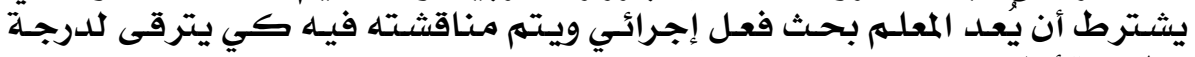

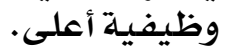

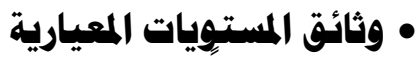

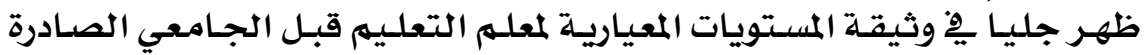

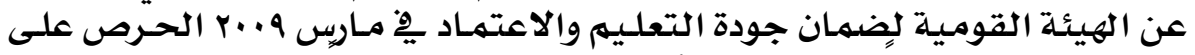

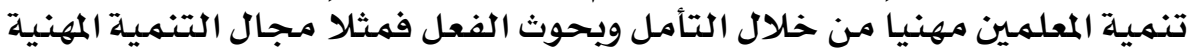

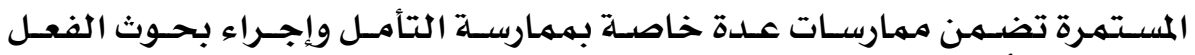

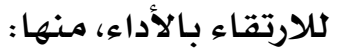

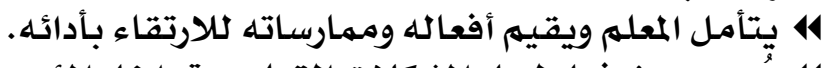

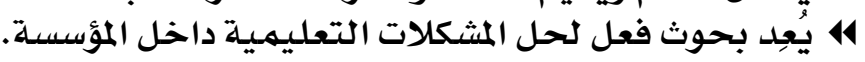

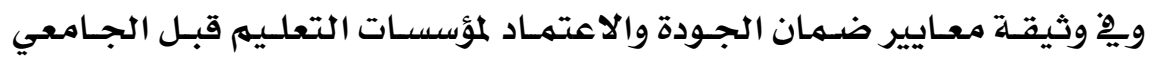

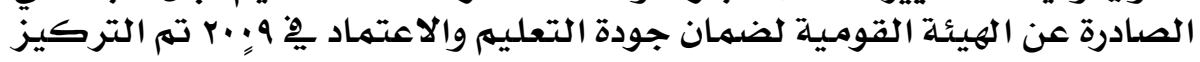

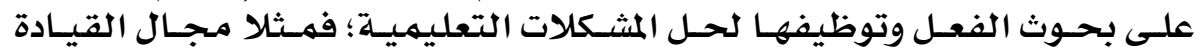

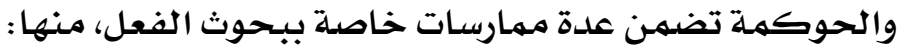

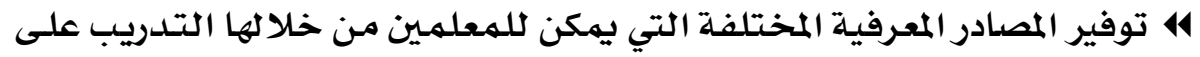

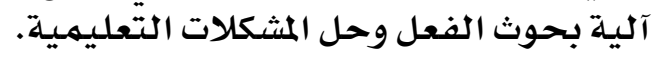

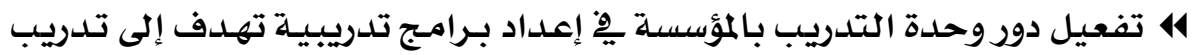

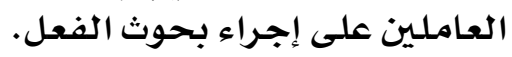

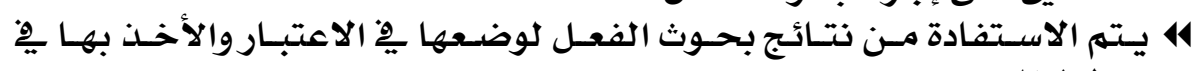
خطط التحسين.

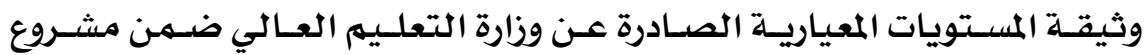

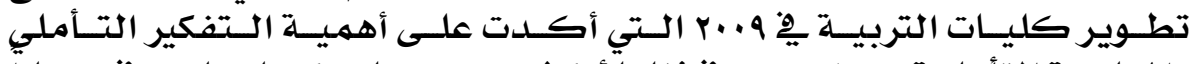

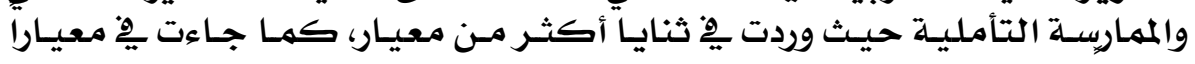

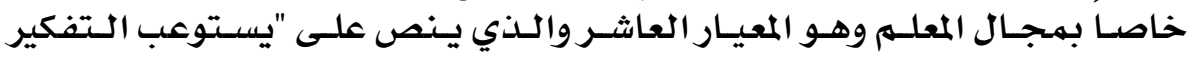

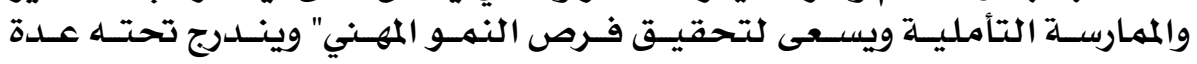
مؤشرات.

\section{YII}




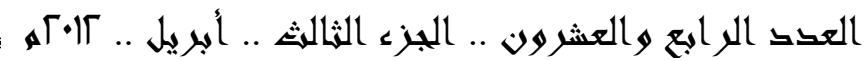

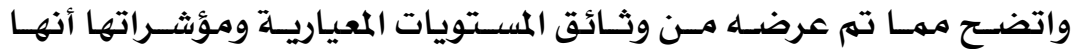

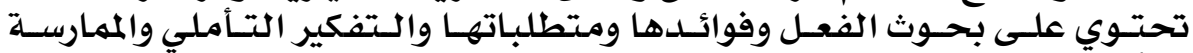

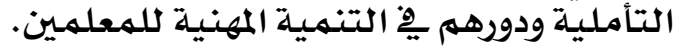

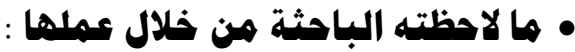

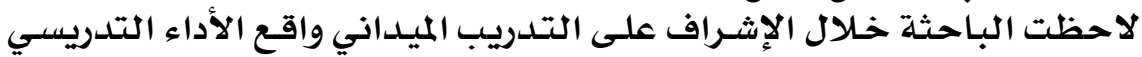

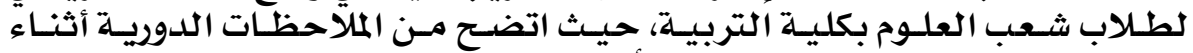

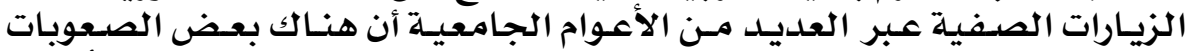

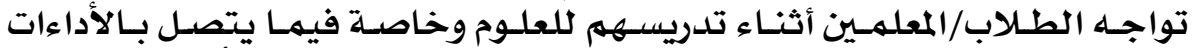

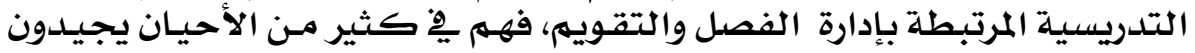

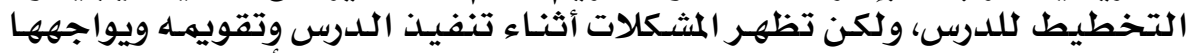

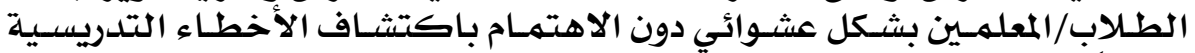

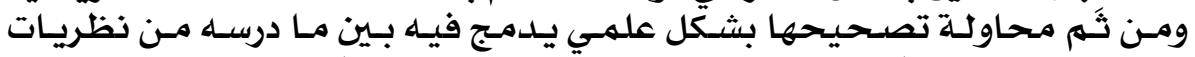

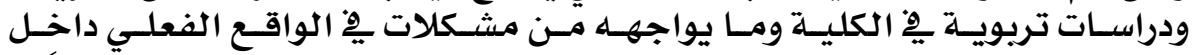

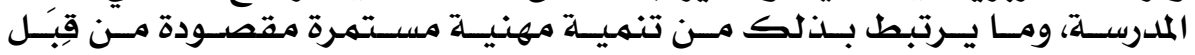

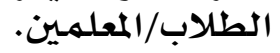

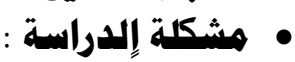

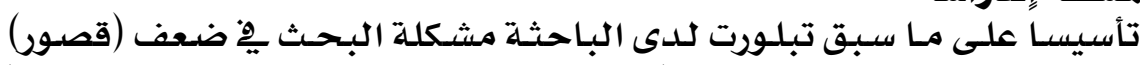

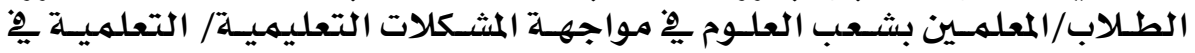

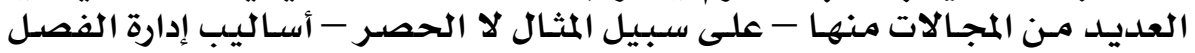

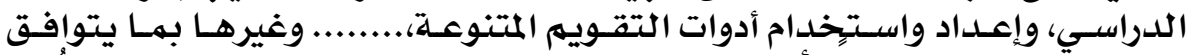

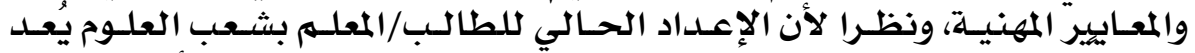

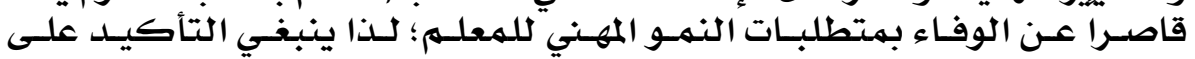

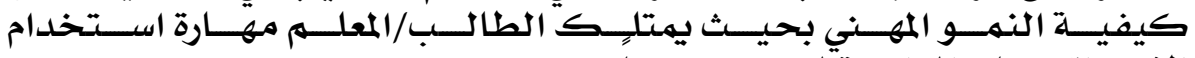

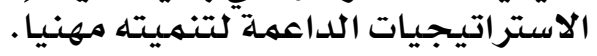

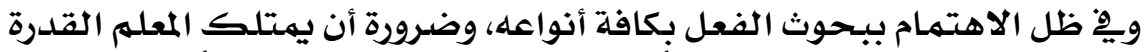

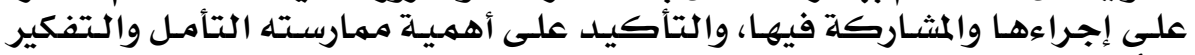

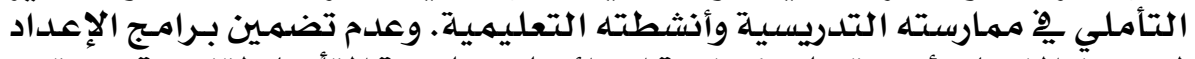

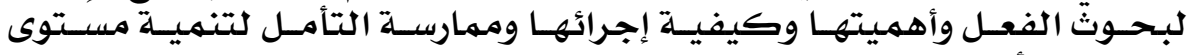
التفكير التأملي. التفعل

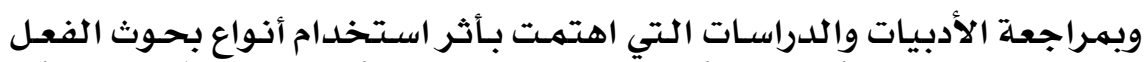

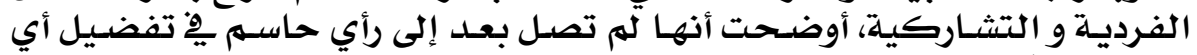

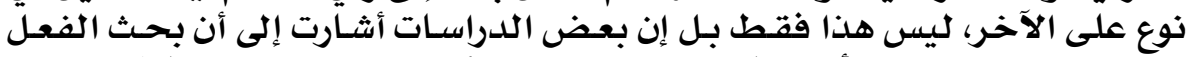

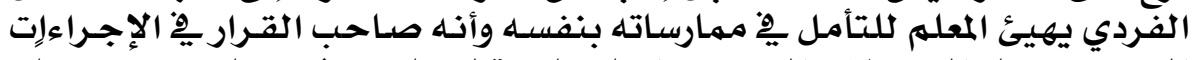

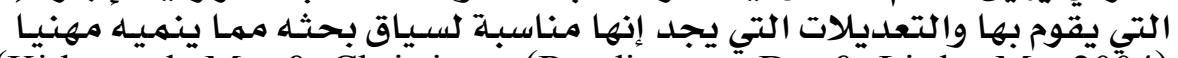
(Kirkwood, M., \& Christie, ، (Rawlinson , D., \& Little, M., 2004) بينهـا أثـارت دراسـات أخـرى إلى أن العهـل (Ado, Kathryn, 2013)،D.,2006)

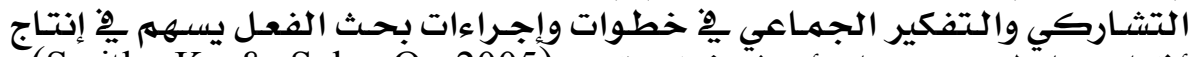

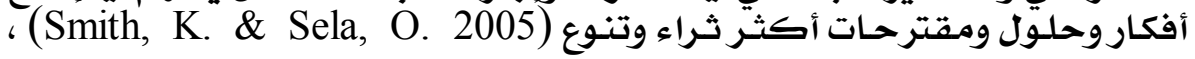




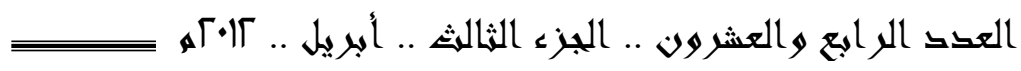

(Brownstein， Erica. et. al., 2013)

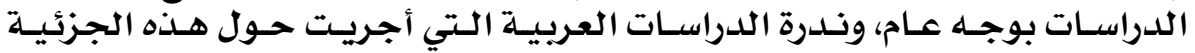

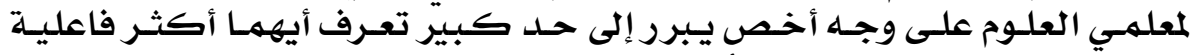

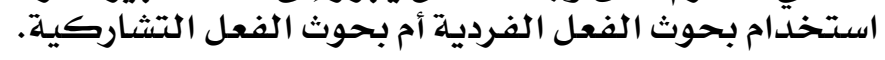

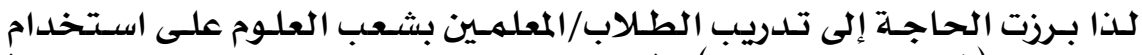

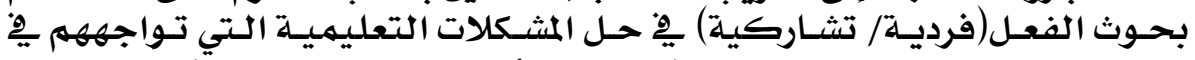

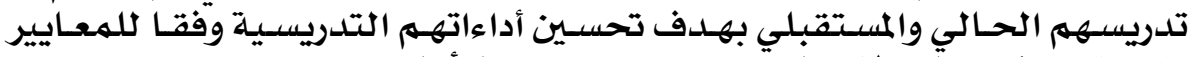
المهنية، وحثهم على الارتقاء بمستوى تفكيرهم التأملي.

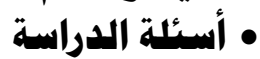

تحدد السؤال الرئيس للدراسة كما يلي: الرئية

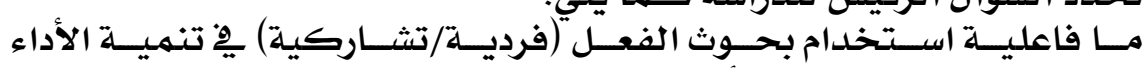

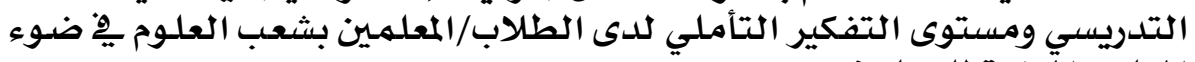
المعايير المهنية للمعلهم المكير

ويتفرع عن هذا السؤال الرئيس الأسئلة الفرعية التالية:

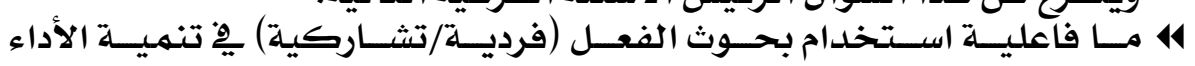

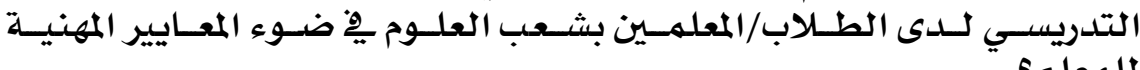
4 ما فاعلية استخلدام بحوث الفعل (فردية/تشاركية) ِِّ تنمية مستوى التفكير

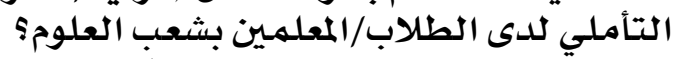

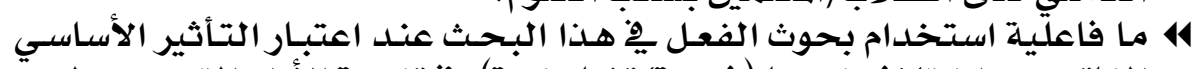

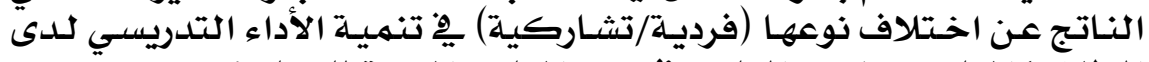

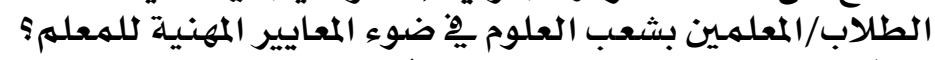

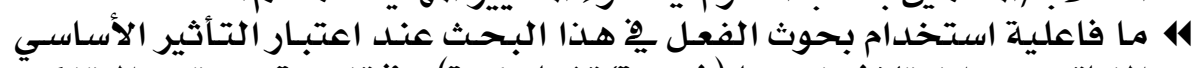

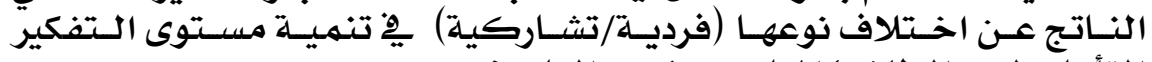

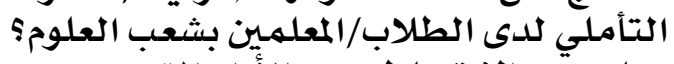

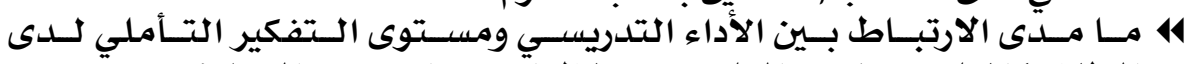

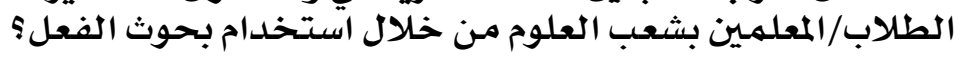

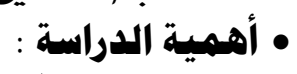

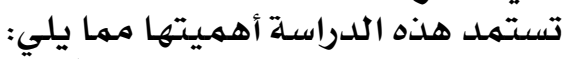

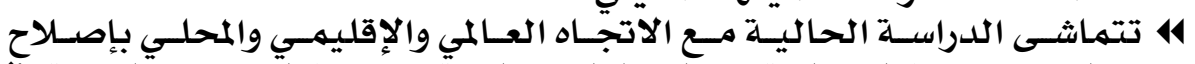

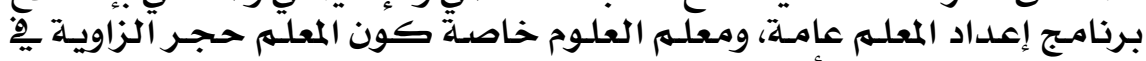

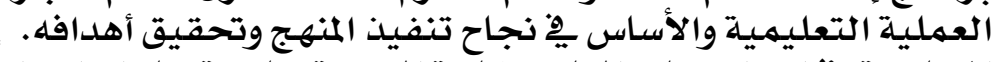

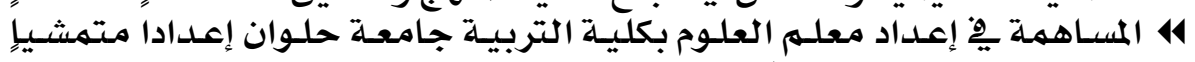

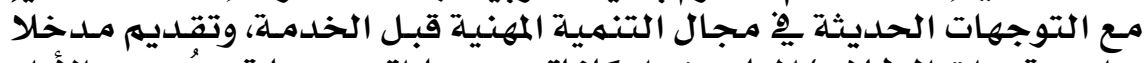

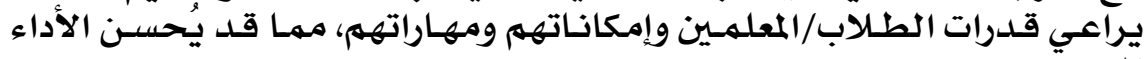

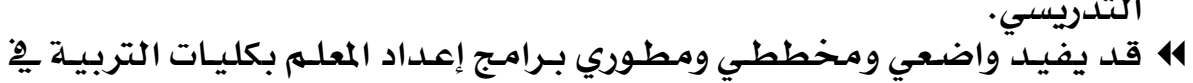

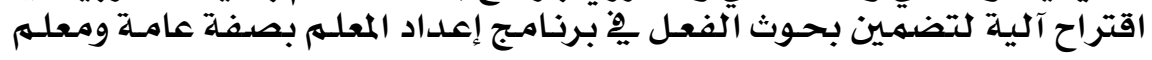

\section{YIY}




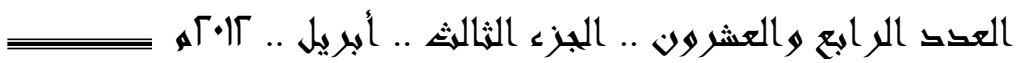

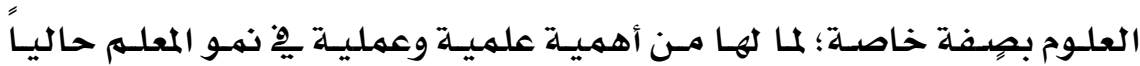
ومستقبلا.

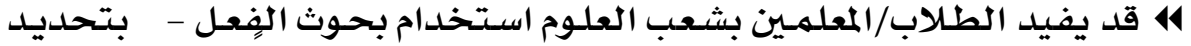

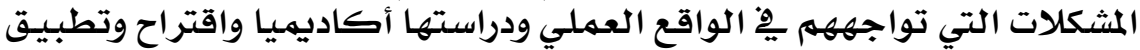

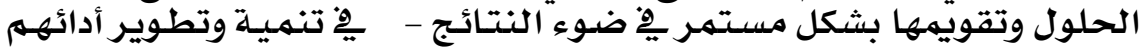

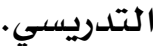

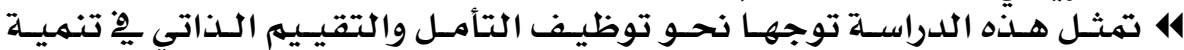

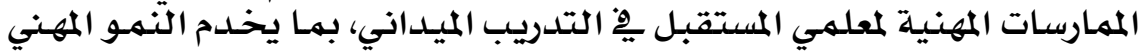

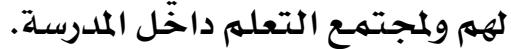

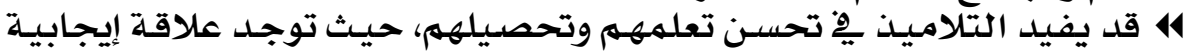

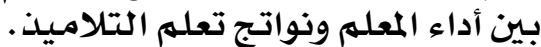

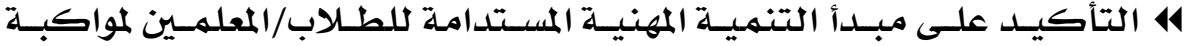
المستحدثات التربوية والعلميـة التبلية.

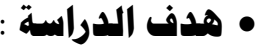

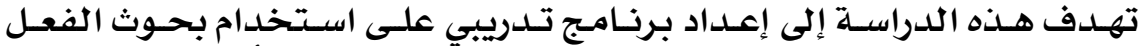

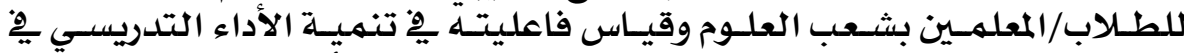

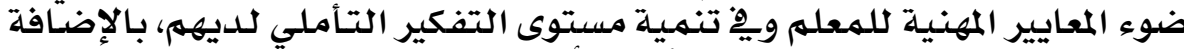

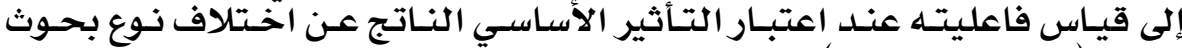
الفعل (فردية/تشاريتهية الفيدة).

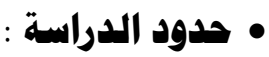

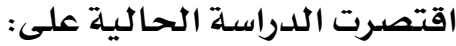

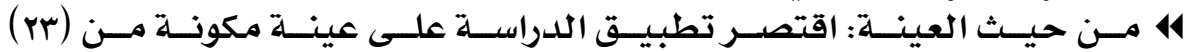

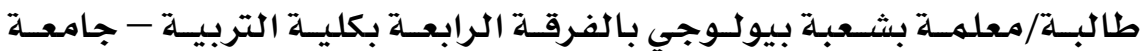

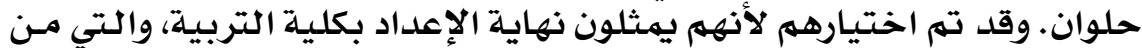

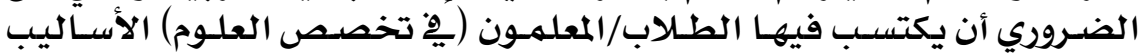

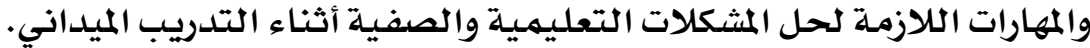

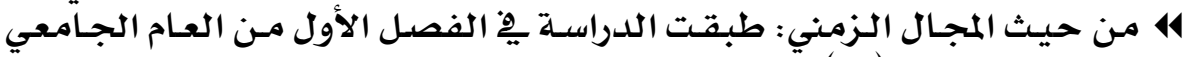

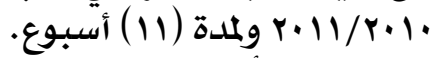

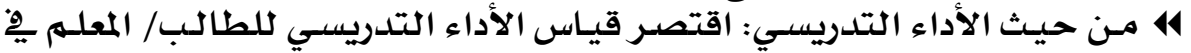

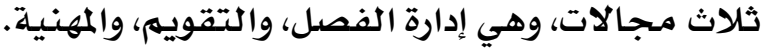

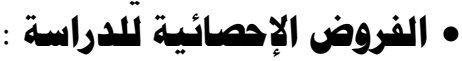

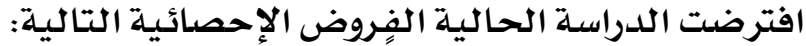

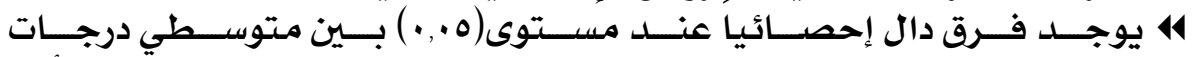

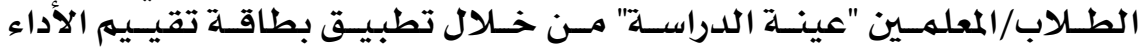

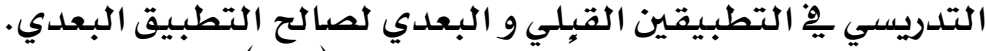

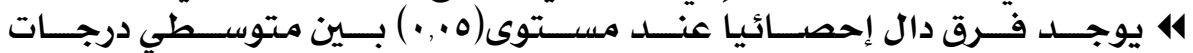

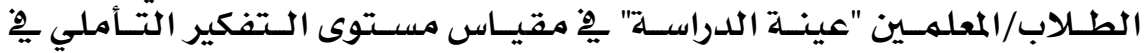

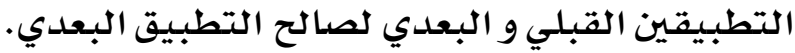




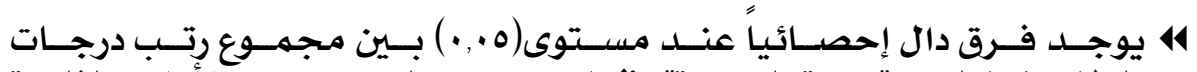

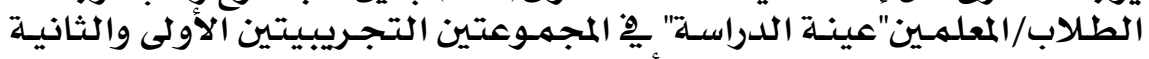

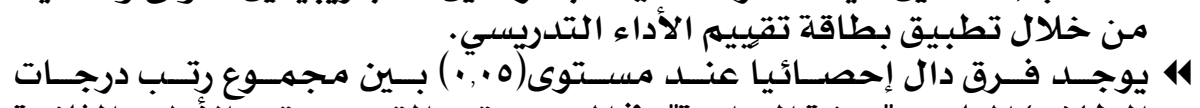

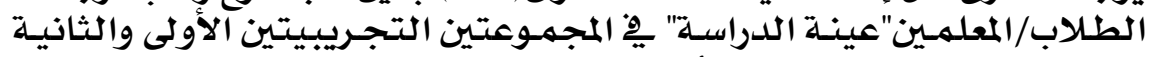

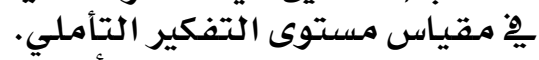

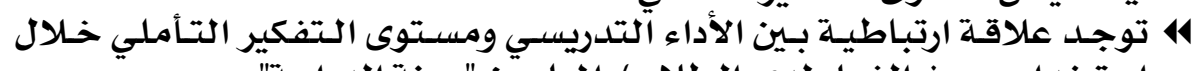

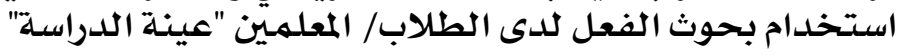

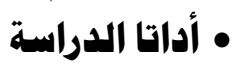
14 بطاقة ملاحظة الأداء التدريسي للطالب/المعلم يّْة ضوء المعايير المهنية (إعداد • ه مقياس مستة) هنتوى التفكير التأملي (إعداد الباحثة)

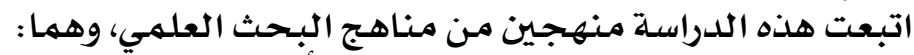

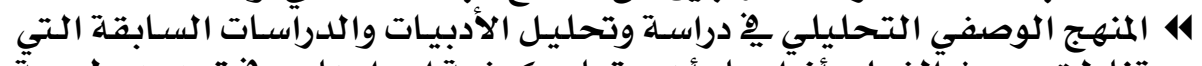

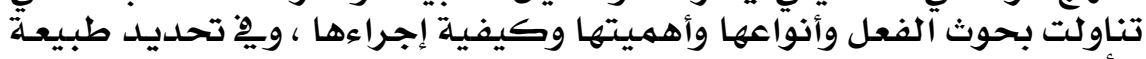

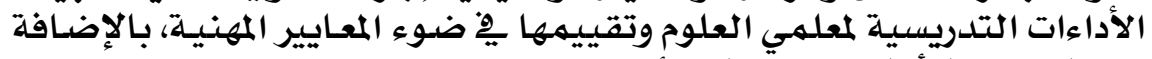

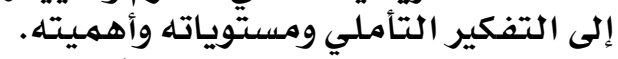

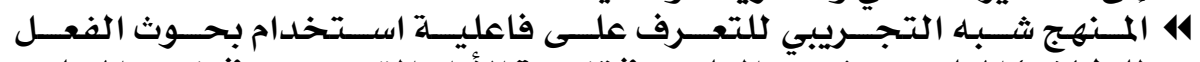

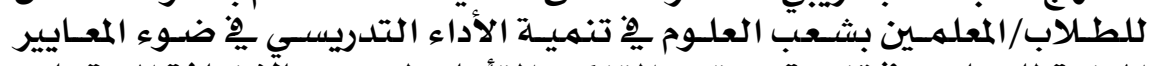

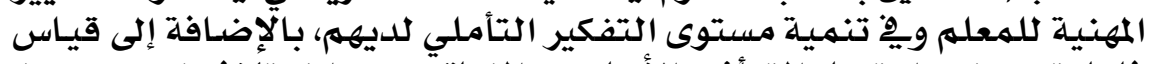

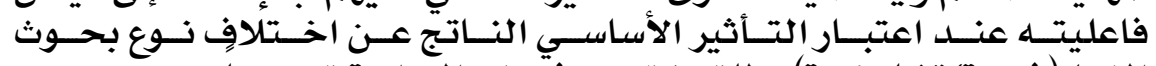

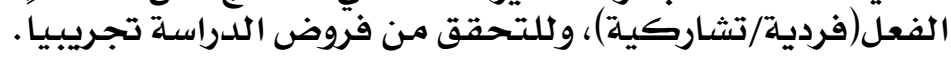

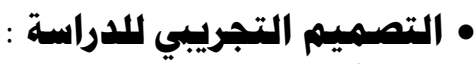

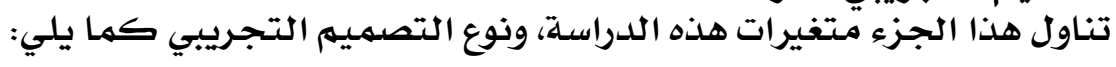

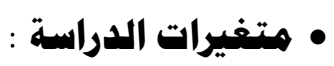

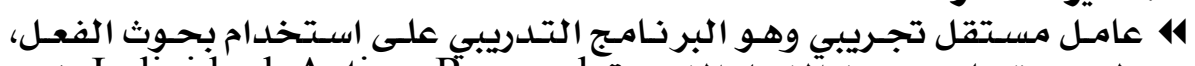

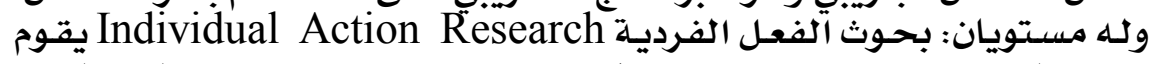

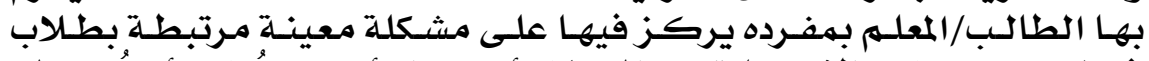

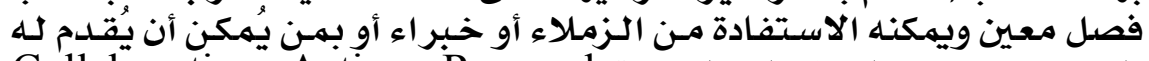

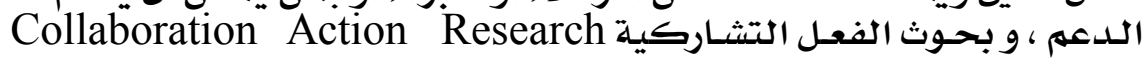

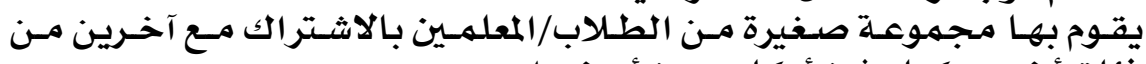

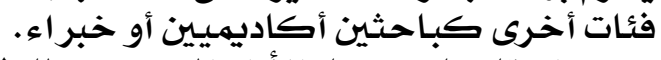

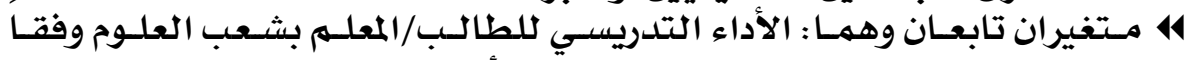

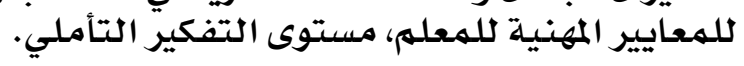

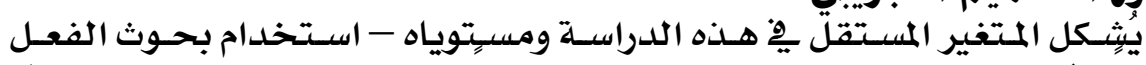

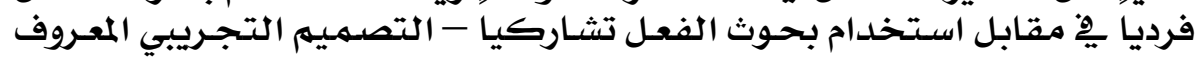

\section{Y $\odot$}

\section{دوأسأت عربية في أنتبية وعتم ألنفسي (ASEP)}




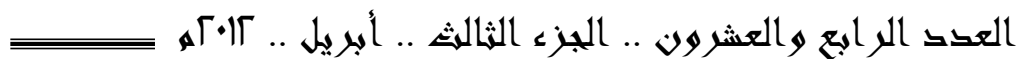

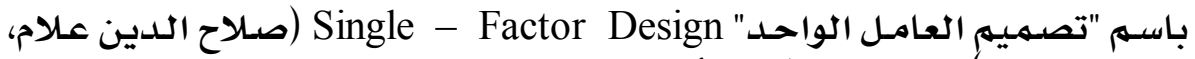

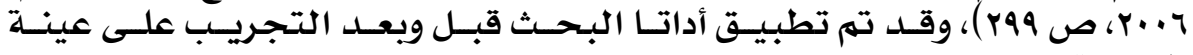

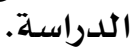

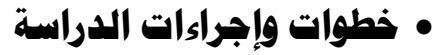

اللإجابة عن أسئلة الدراسـة والتحقق مـن صـحة فروضها تم إتبـاع الخطوات

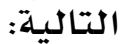

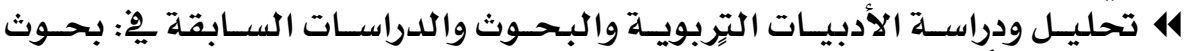

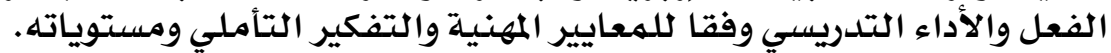

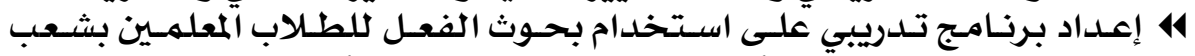

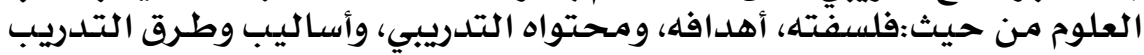

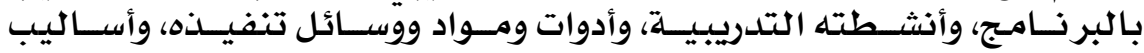

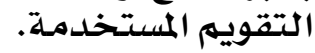
414 إعداد أداتا الدراسة والتأكسد من صدقدهما وثباتهما.

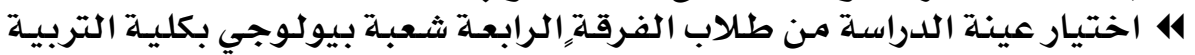

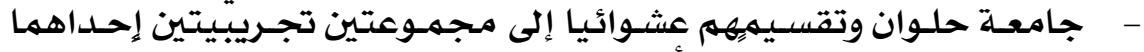

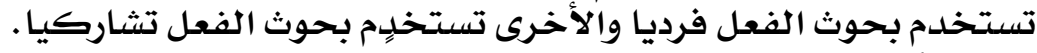

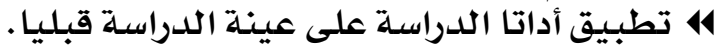

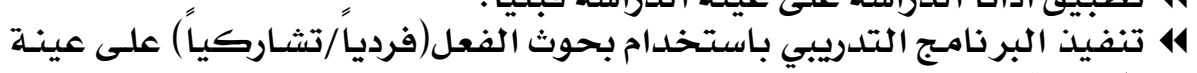

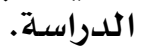

4 الطبيق أداتا الدراسة على عينة الدِراسة بعدياً.

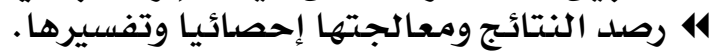

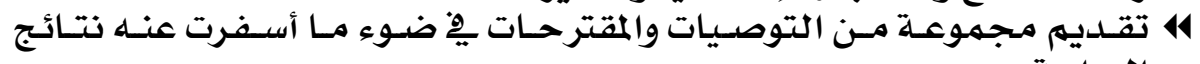

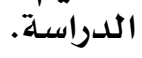

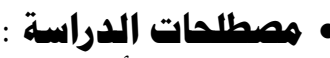

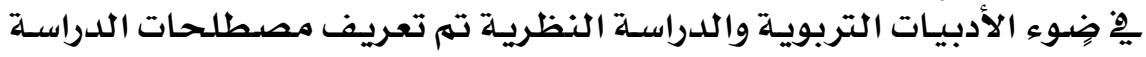
إجرائيا كما يلي: الادبيات

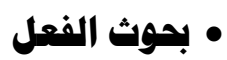

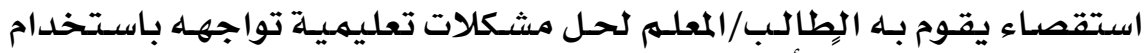

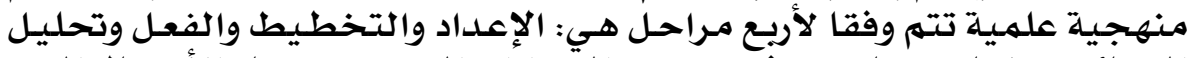

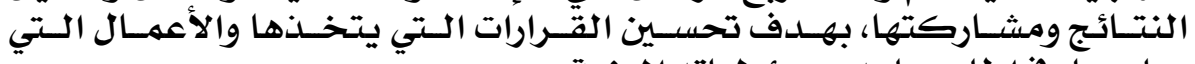

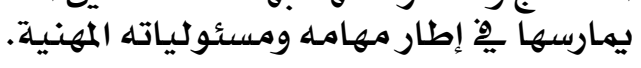

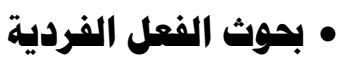

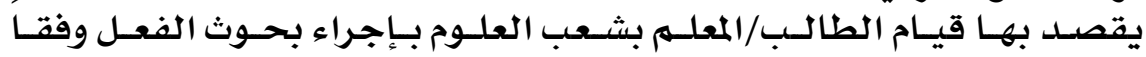

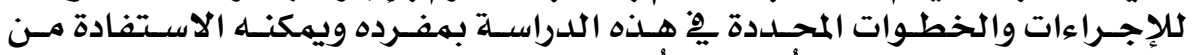

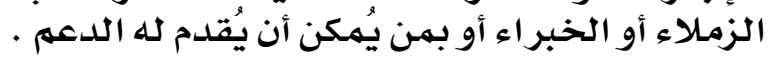

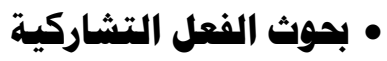

\section{Y) 7}




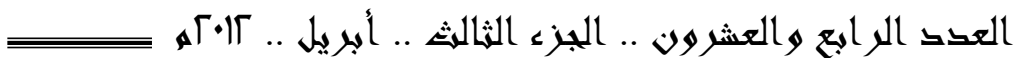

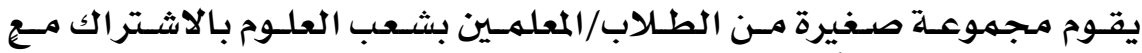

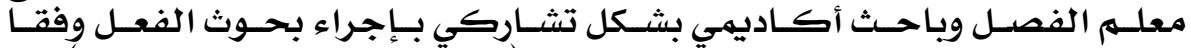

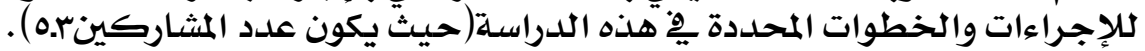

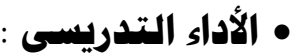

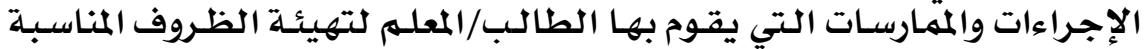

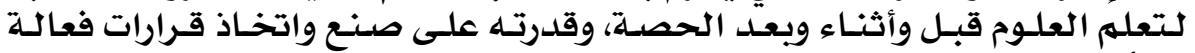

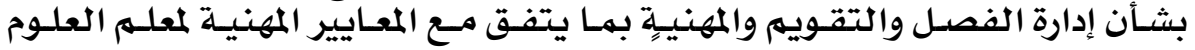

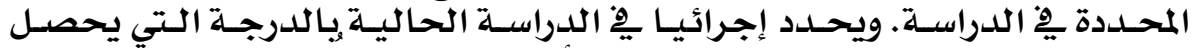

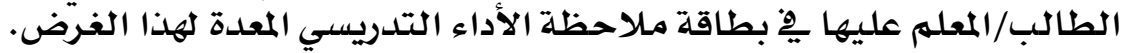

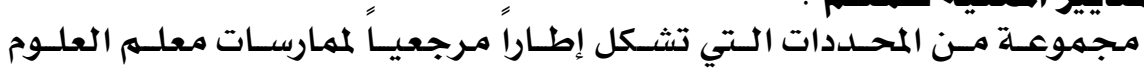

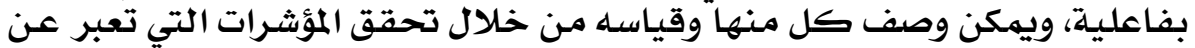

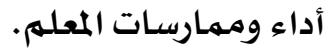

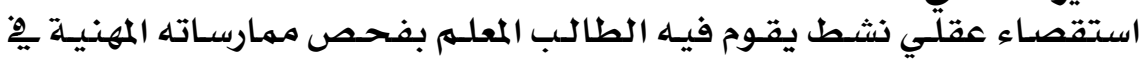

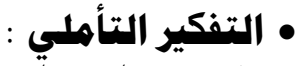

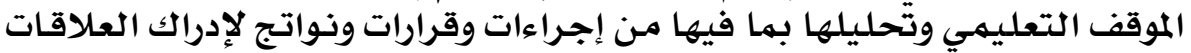

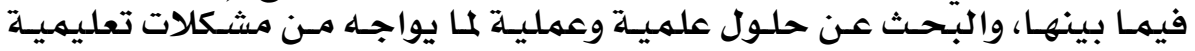

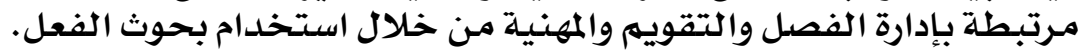

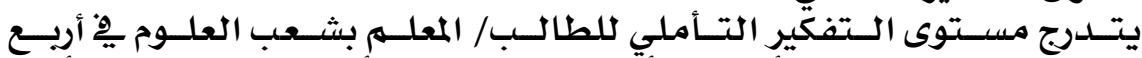

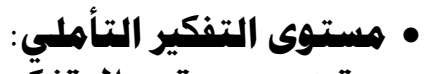

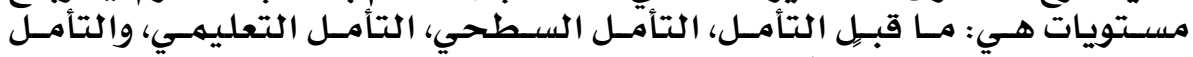

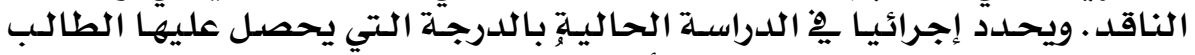

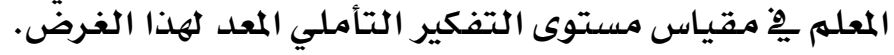

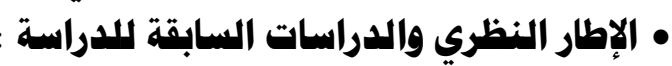

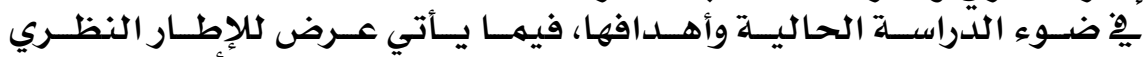

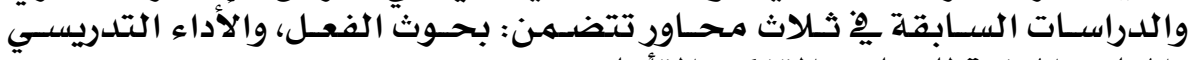

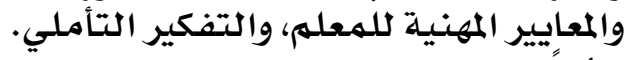

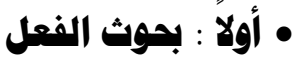

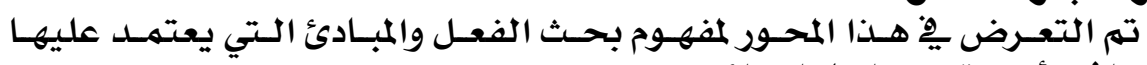

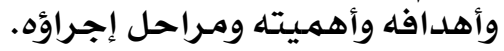

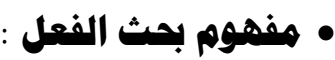

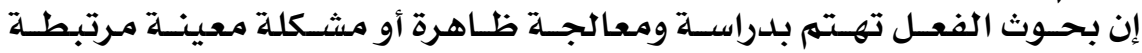

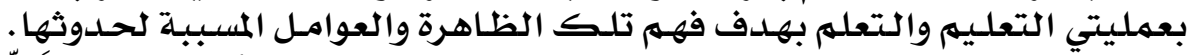

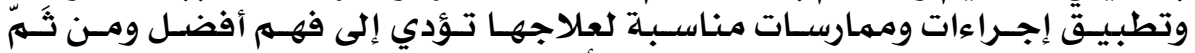

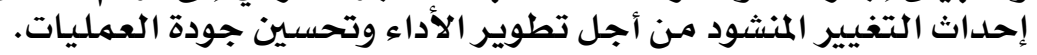

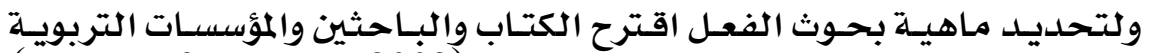

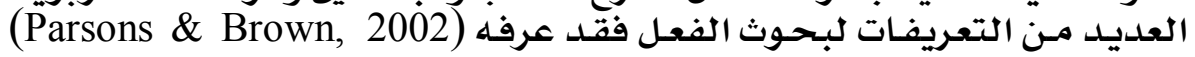

\section{YIV}




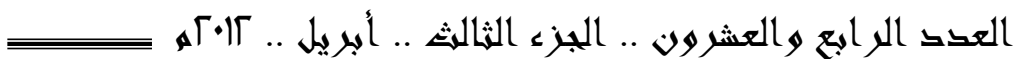

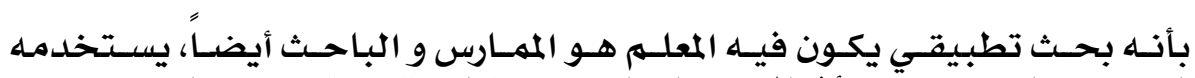

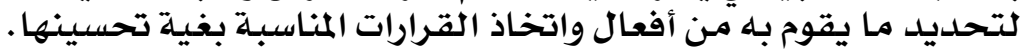

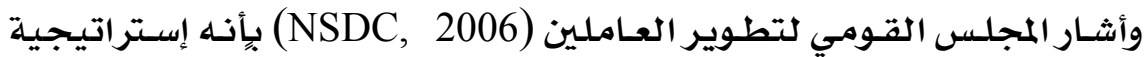

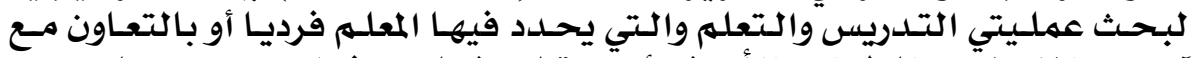

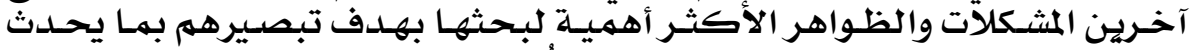

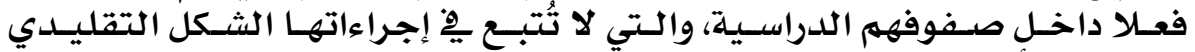

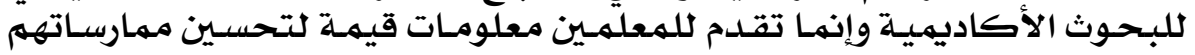

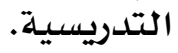

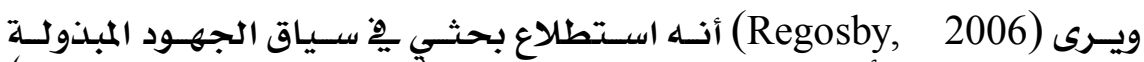

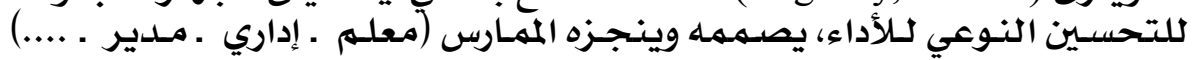

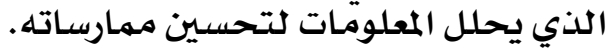

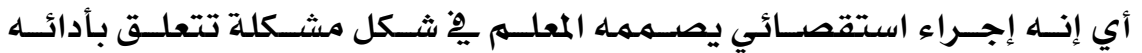

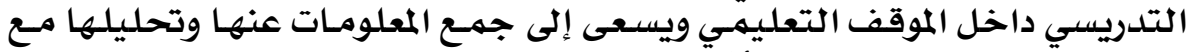

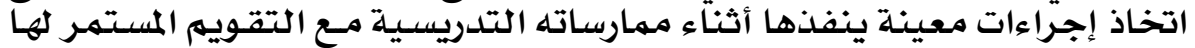

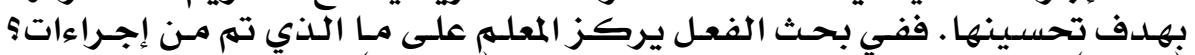

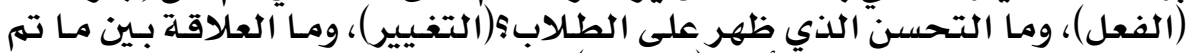

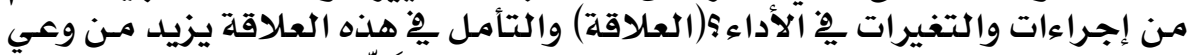

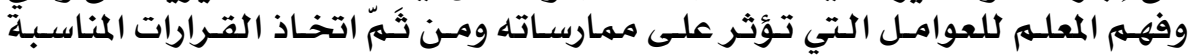
لتحسينها.

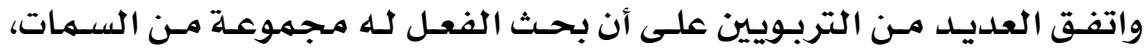
ومنها: (Schmuck,2006) (Johnson, 2008) (Mertler \& Charles, 2011) (Mills, : 2011)

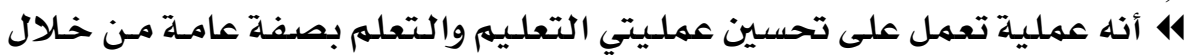

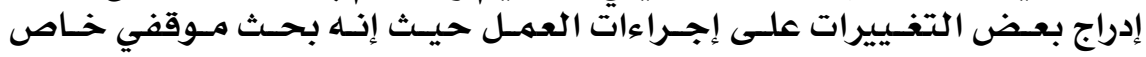

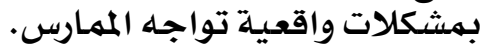

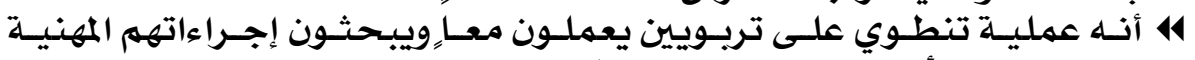

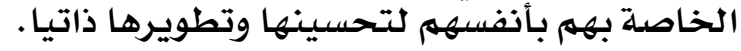

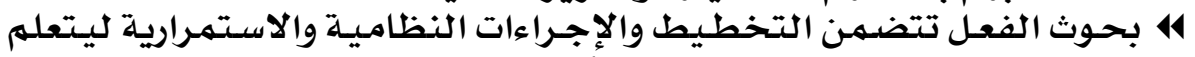

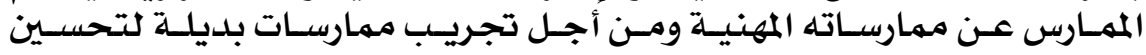

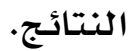
414 Teachers for Teachers

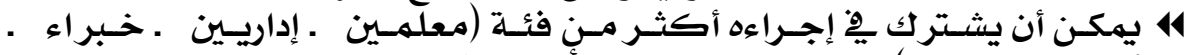

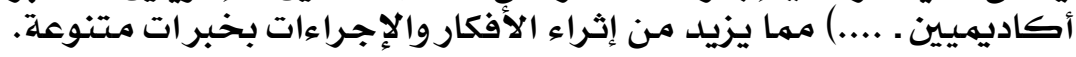

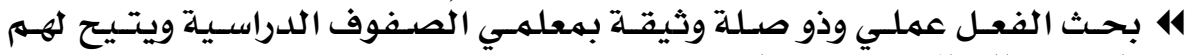

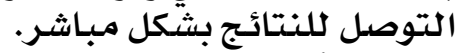

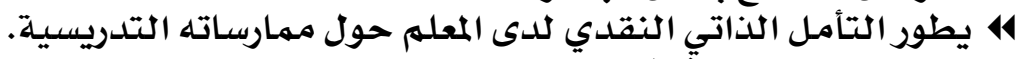

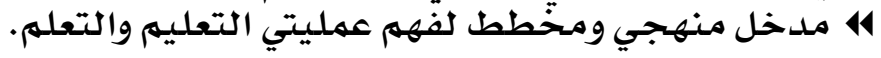


4 هو العملية التي تتطلب منا اختبار أفكارنا ومعتقداتنا حول عمليتي التعليهم والتعله. 4 هو عملية دورية من التخطيط والفعل والتطوير والتأمل.

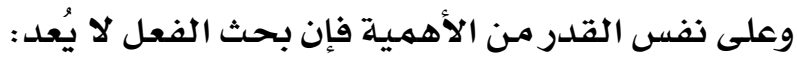

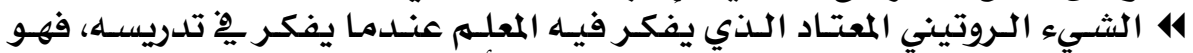

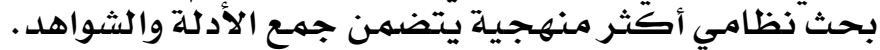

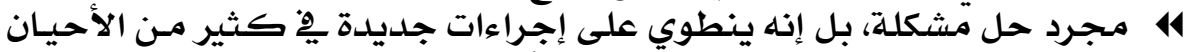

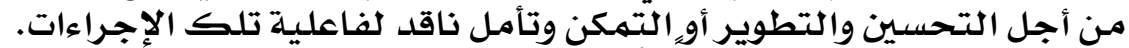

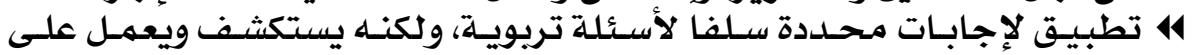

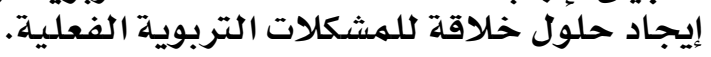

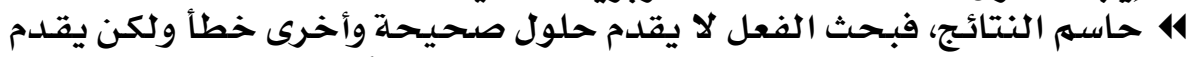

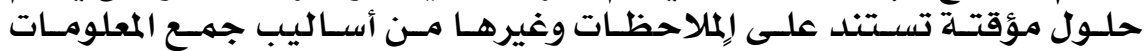

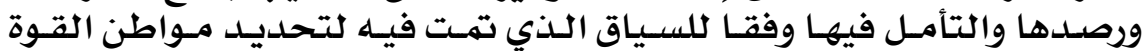
والضعف. واندان

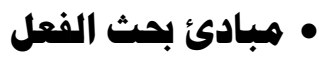

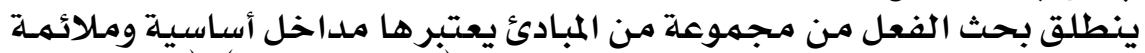

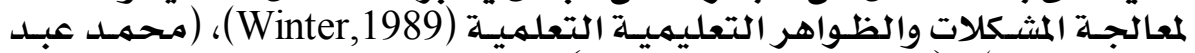

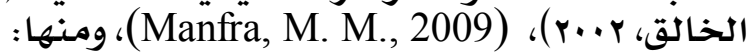

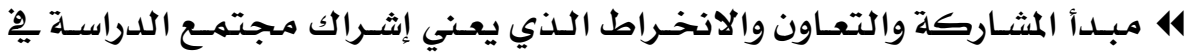

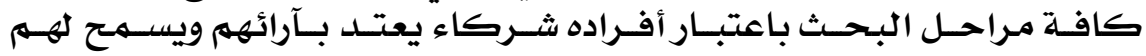

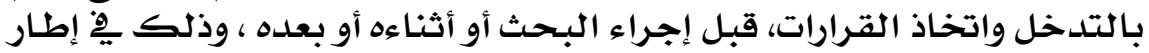

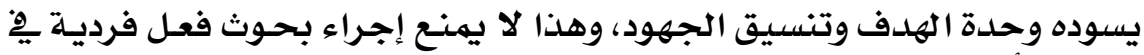

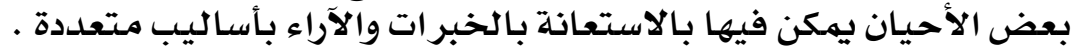

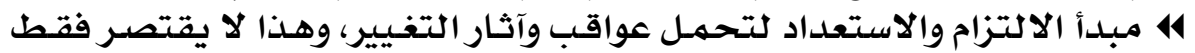

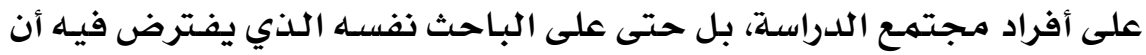

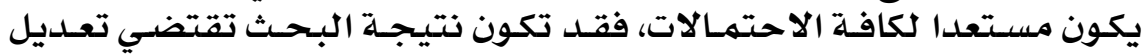

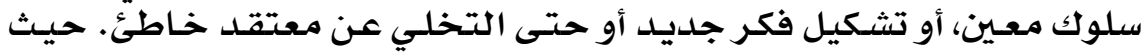

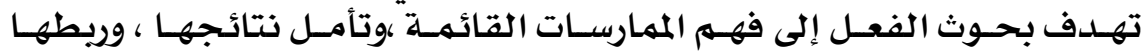

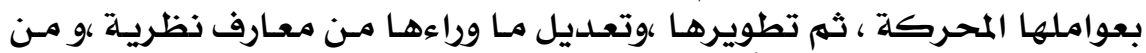

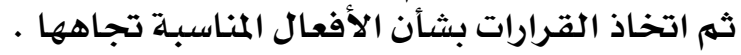

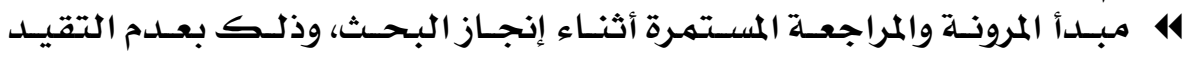

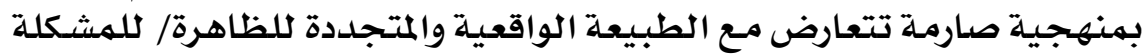

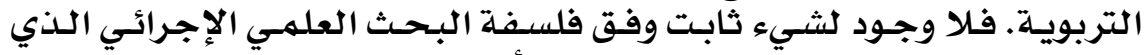

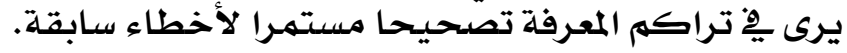

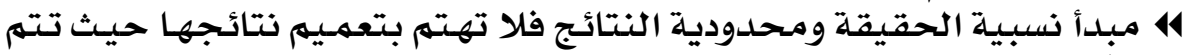

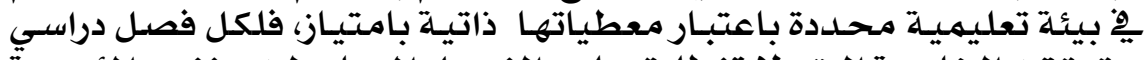

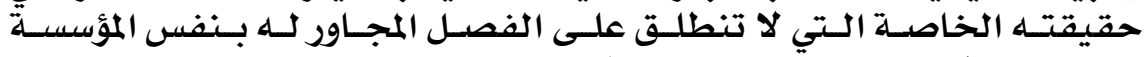
التعليمية، فالكل نسبي واهلي الكل متنحول.

\section{Y19}




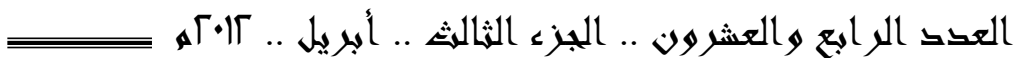

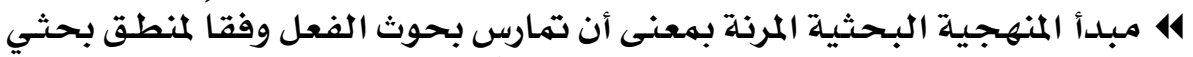

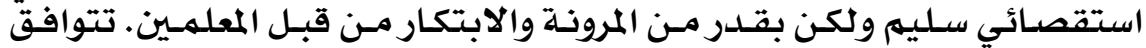

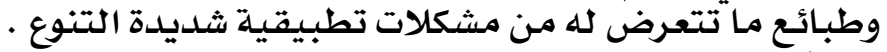

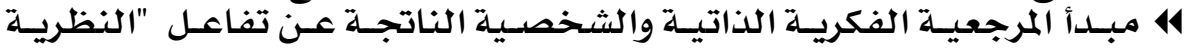

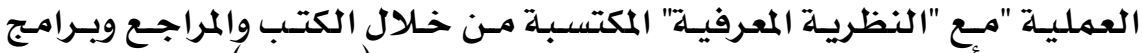

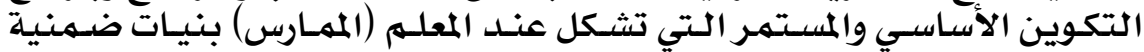

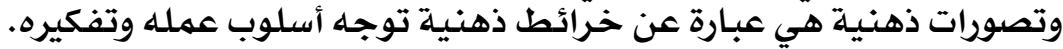

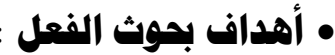

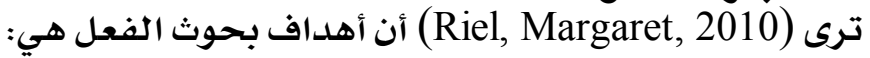

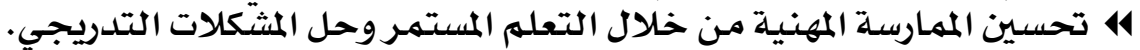

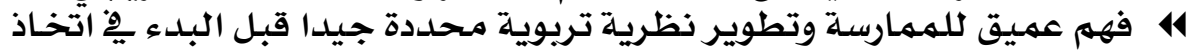

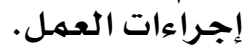

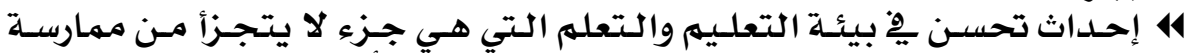

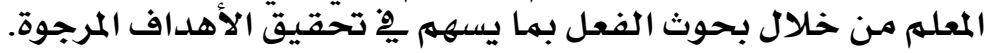

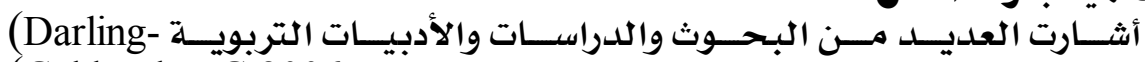
(Gebhard, J.G.2006, و والتربون Hammond, L. \& J. Baratz-Snowden., 2005, p.49) إلى (Lee, Young Ah \& Wange, Ye, 2012, p.p. 697- 709) p.17)

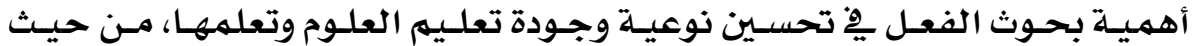
تحقيقها كلأهداف الناف التالية

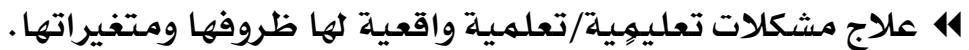

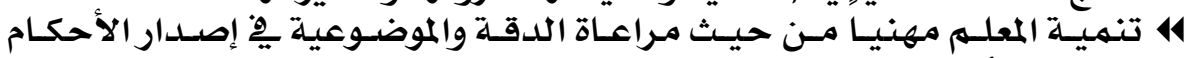

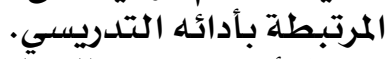

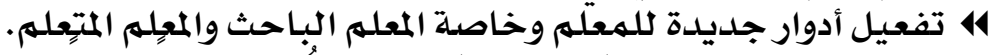

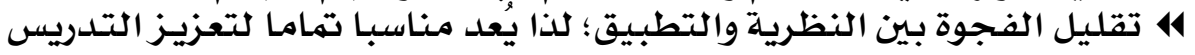

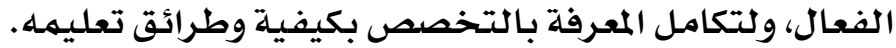

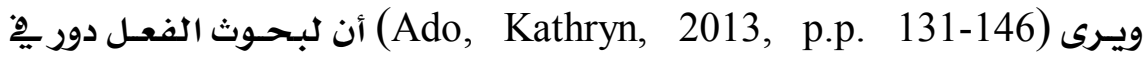

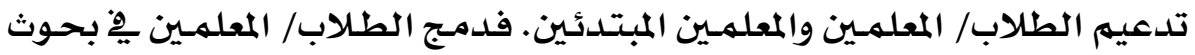

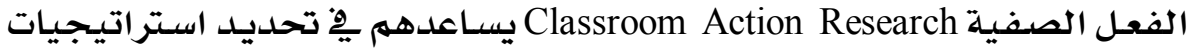

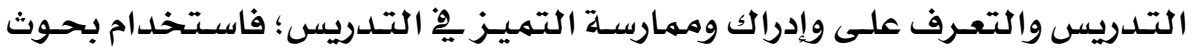

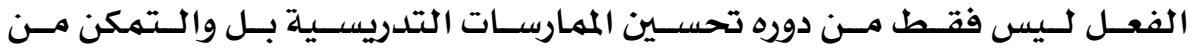

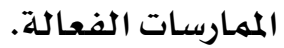

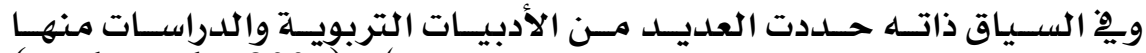

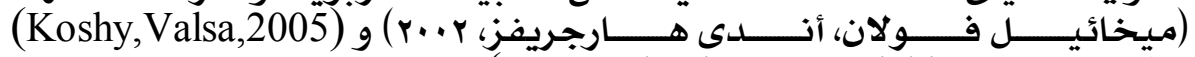

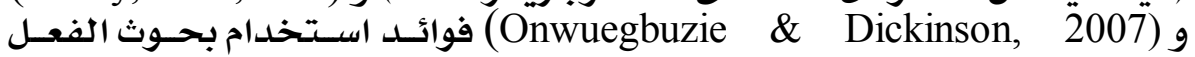
للطلاب/ المعلم-ين، ومنها:

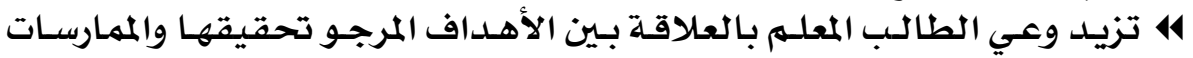
التدريسية. 


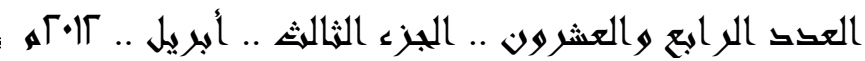

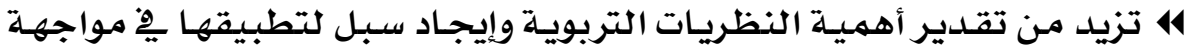

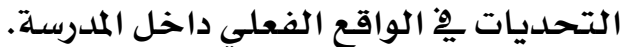

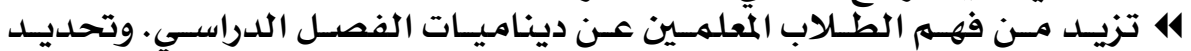

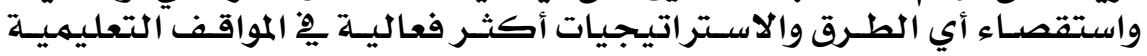
المتنوعة.

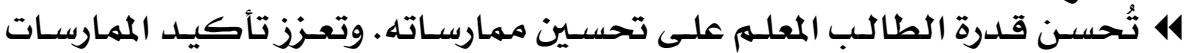
الفعالة.

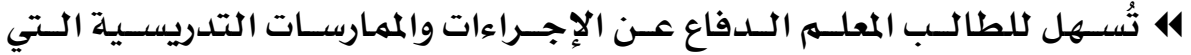

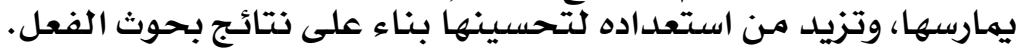

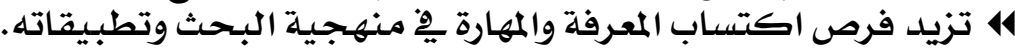

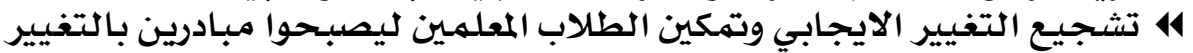

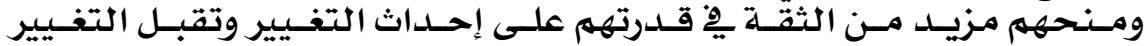

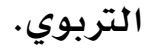

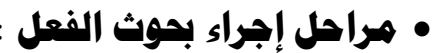

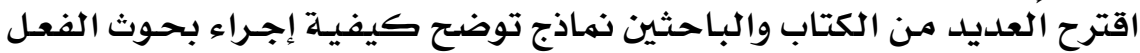

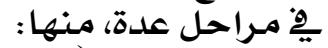

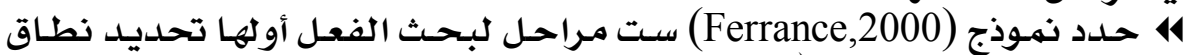

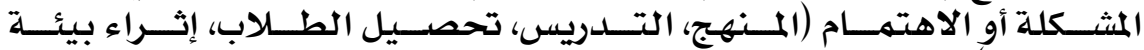

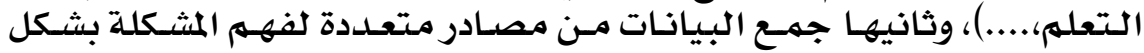

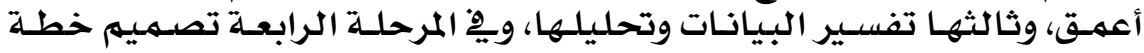

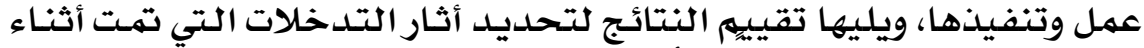

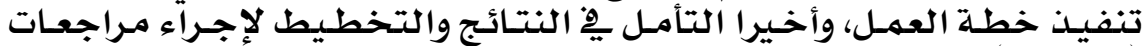
(تعديلات)، وتحديد العمليد الخطواتيرات المقبلة.

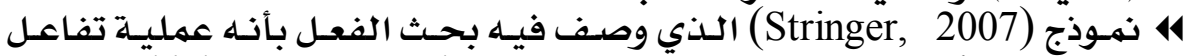

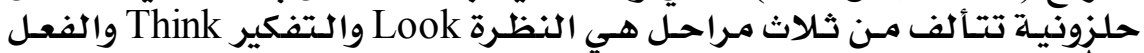

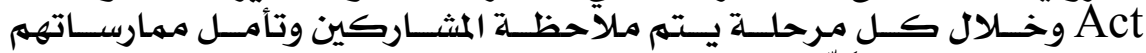

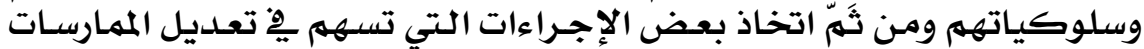

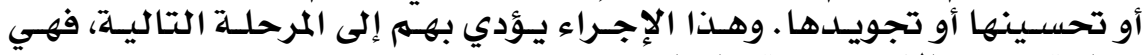

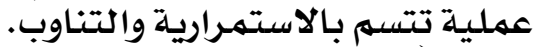

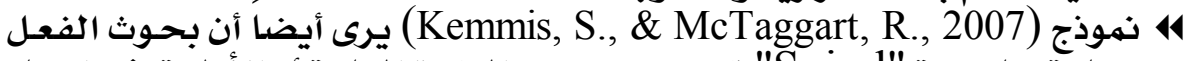

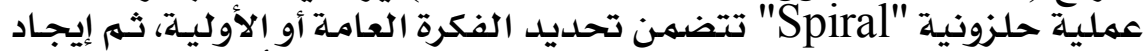

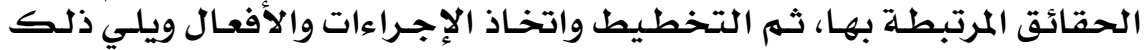

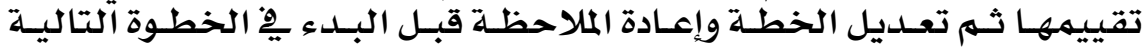
للعمل.

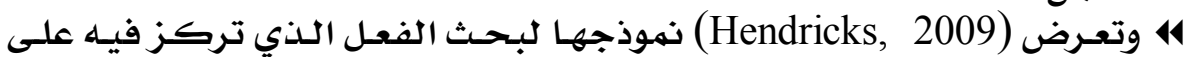

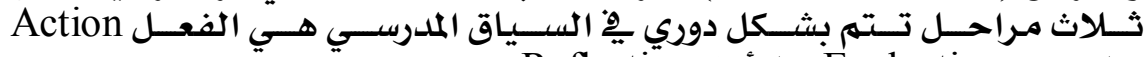

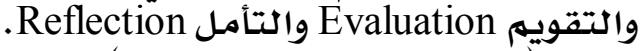

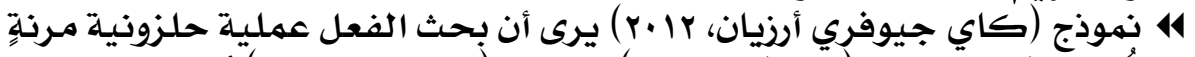

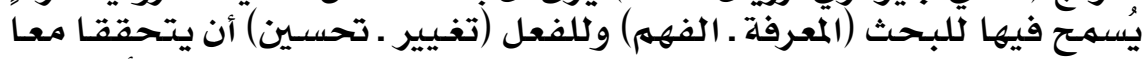

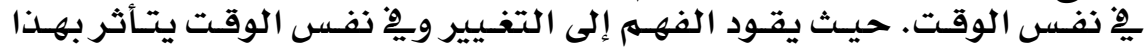




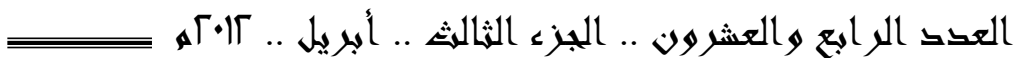

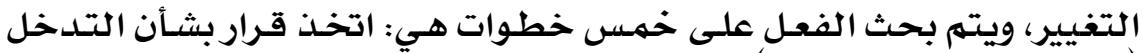

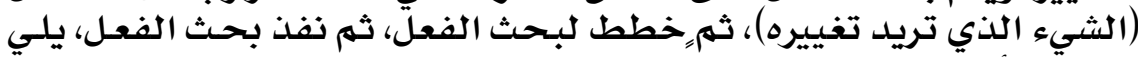

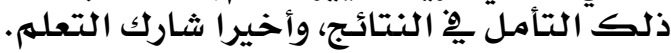

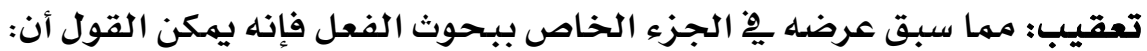

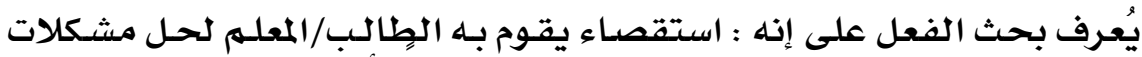

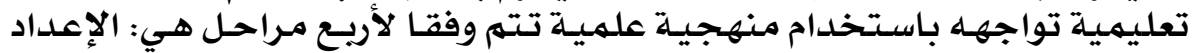

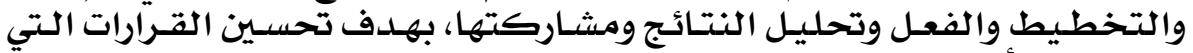

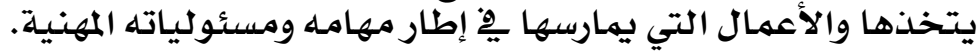

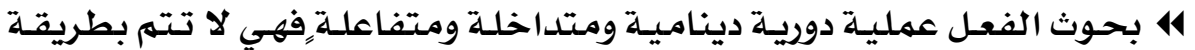

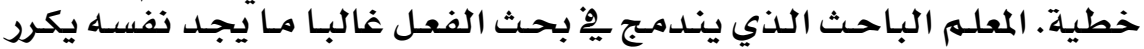

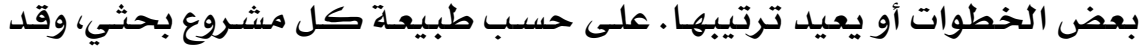

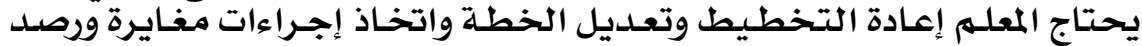

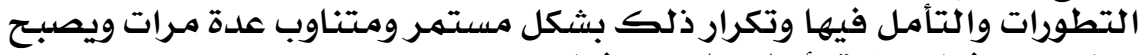

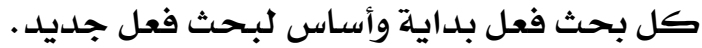

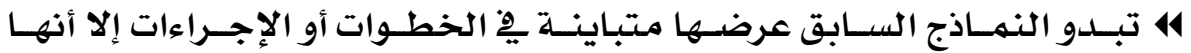

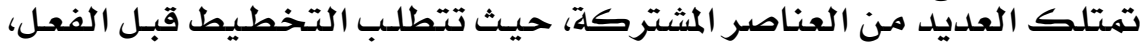

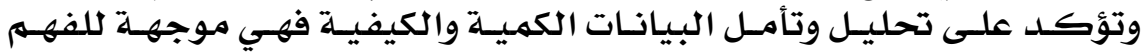
والتحسين.

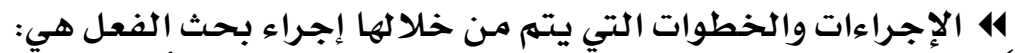

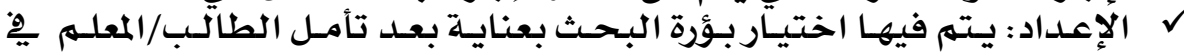

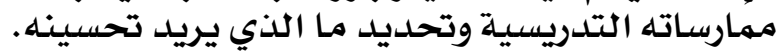

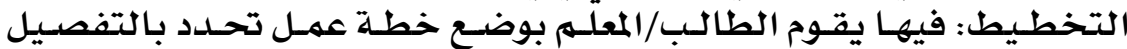

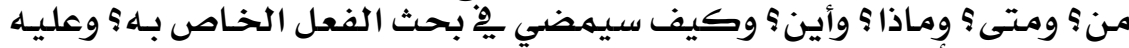

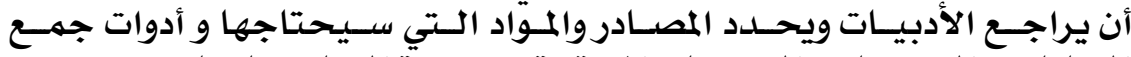

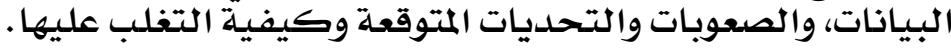

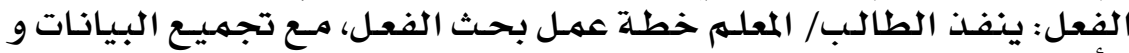

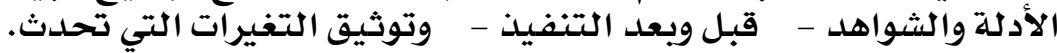

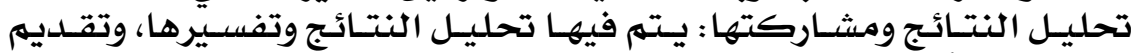

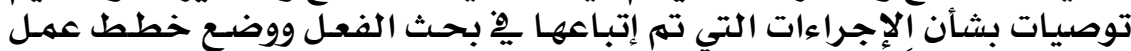

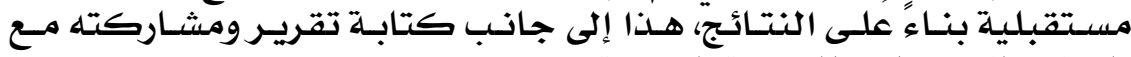

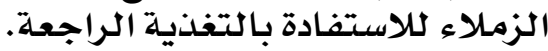

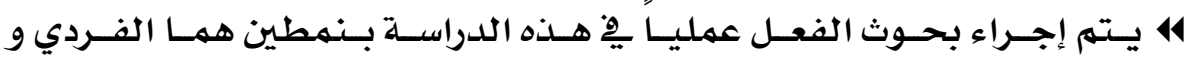

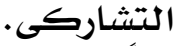

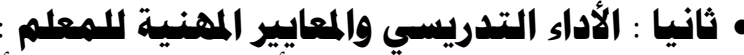

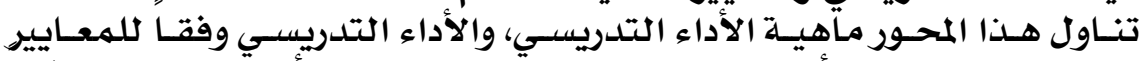

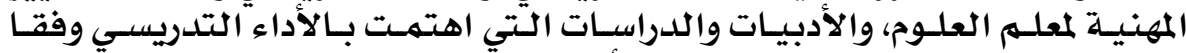

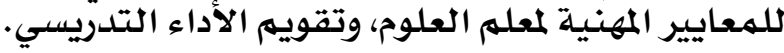




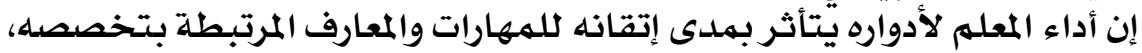

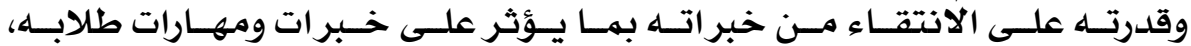

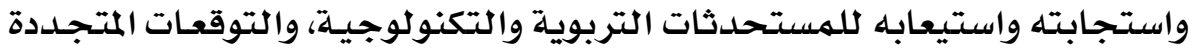

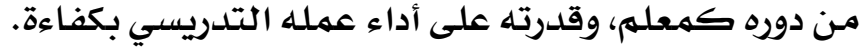

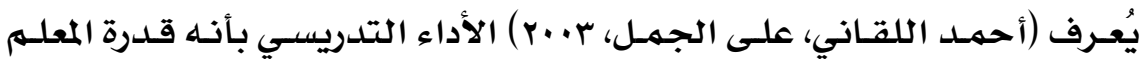

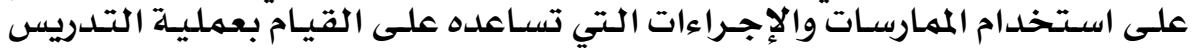

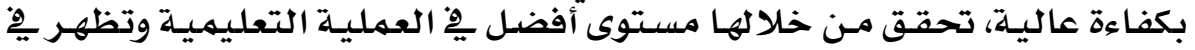

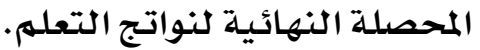

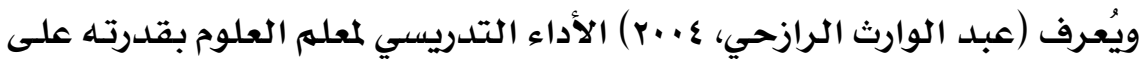

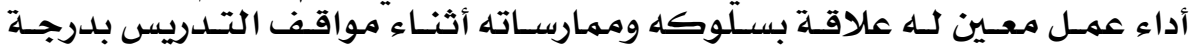

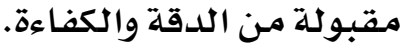

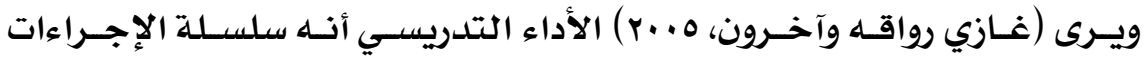

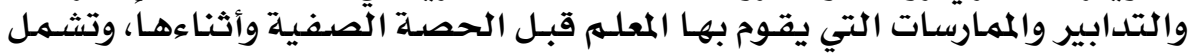

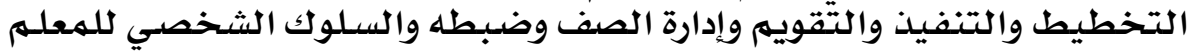

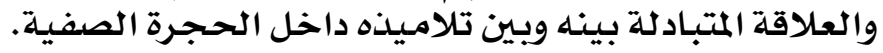

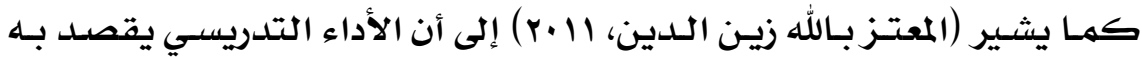

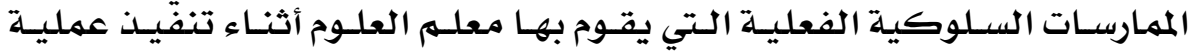

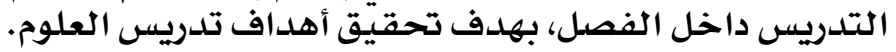

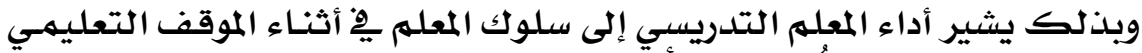

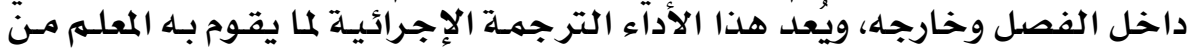

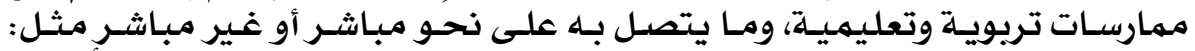

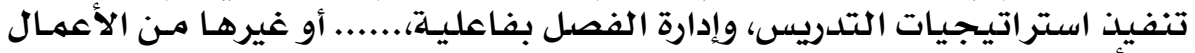

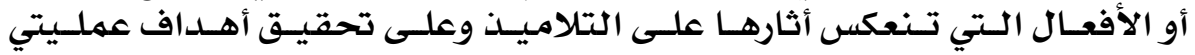
التعليه والتعلهم. الألتي.

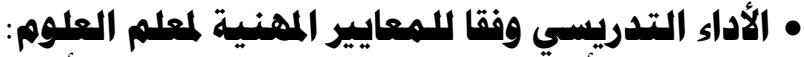

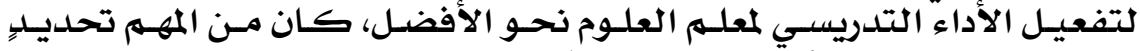

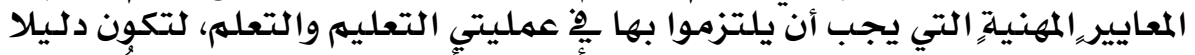

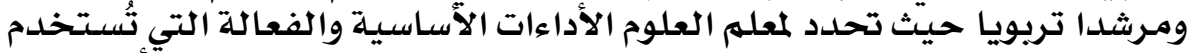

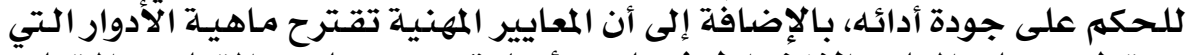

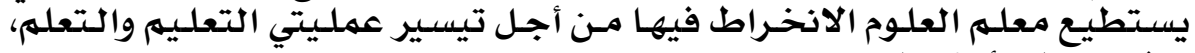
ورفع كفاءة أدائه التدريسي.

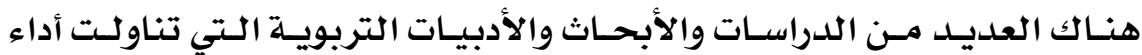

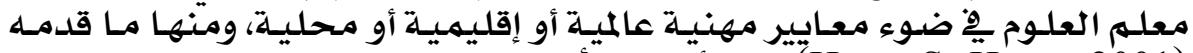
(Harry S. Hertz, 2001)

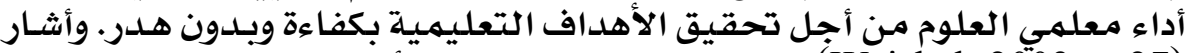
(Weichel, 2003, p.27)

\section{YYM}




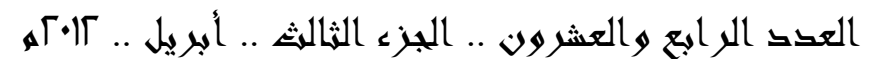

بهدف التأكد من امتلاكه للمعارف والمهارات المرتبطة بأدائه التدريسي ومن ثَمم

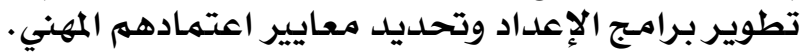

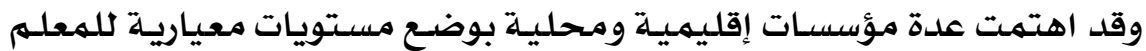

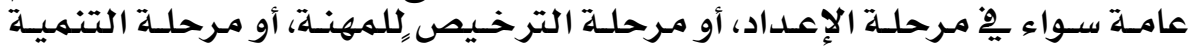

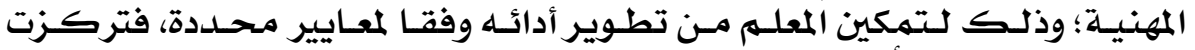

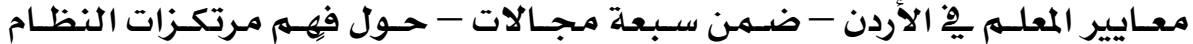

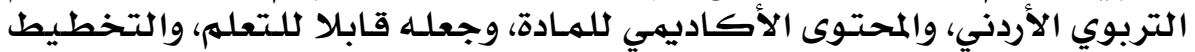

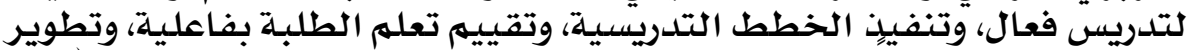

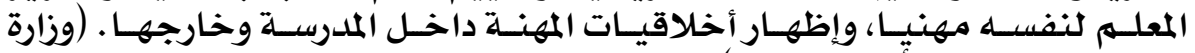

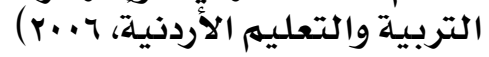

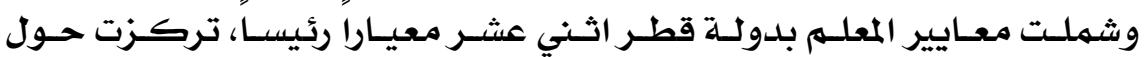

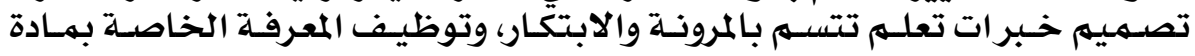

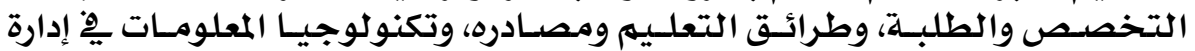

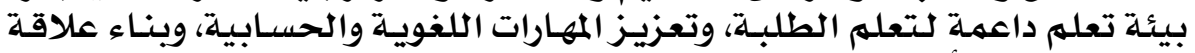

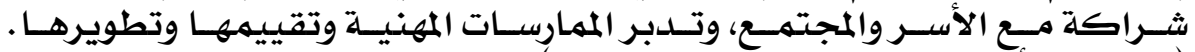

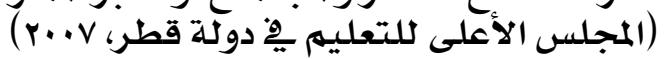

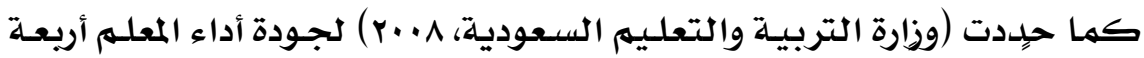

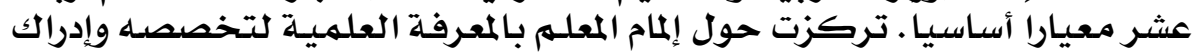

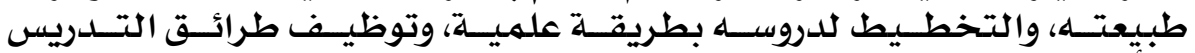

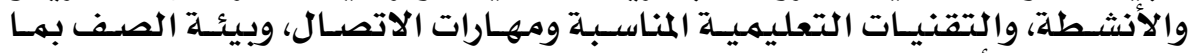

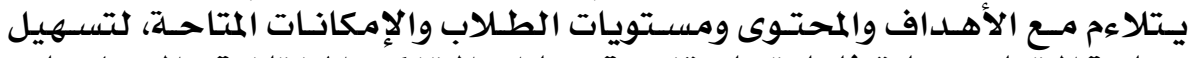

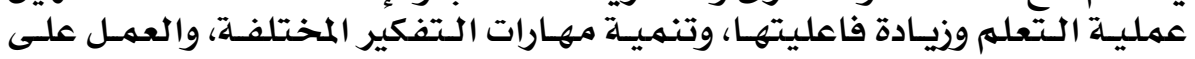

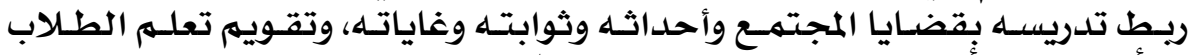

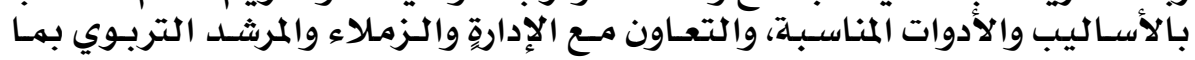

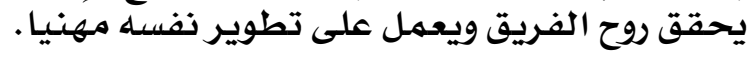

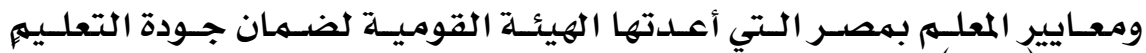

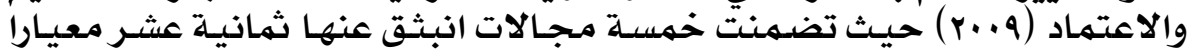

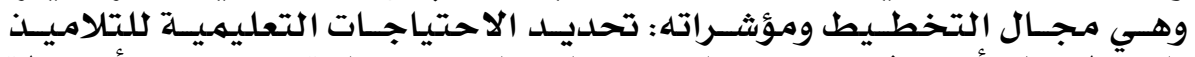

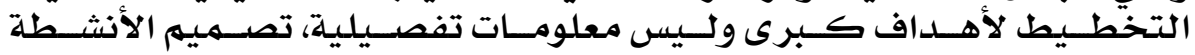

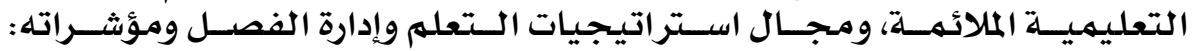

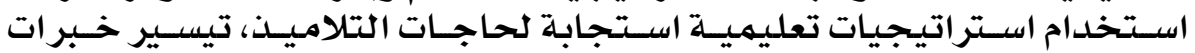

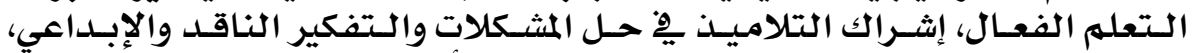

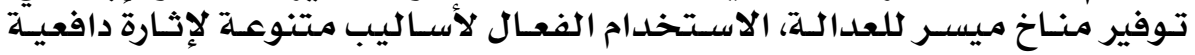

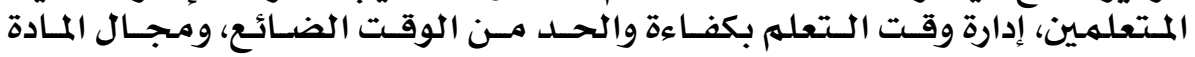

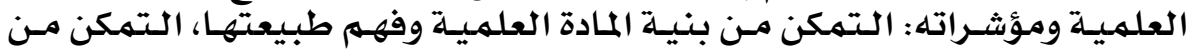

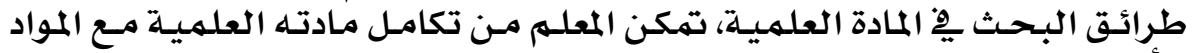

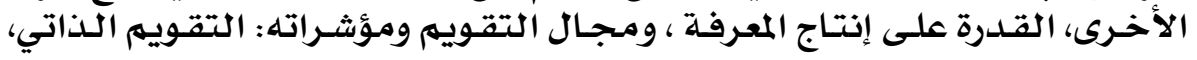




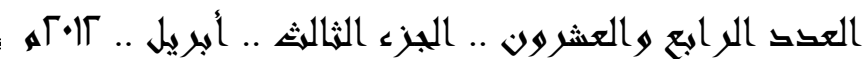

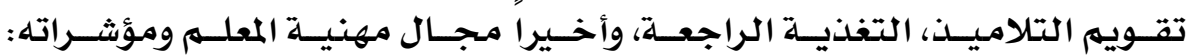
أخلاقيات المهنة والتنمية المهنية.

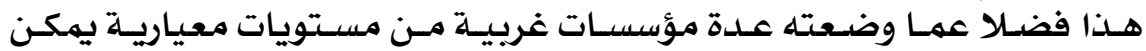

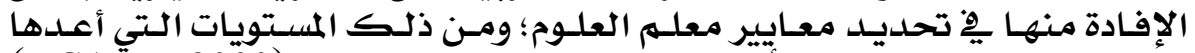

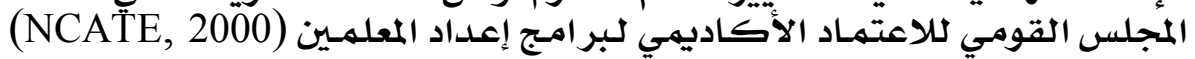

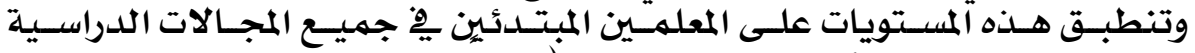

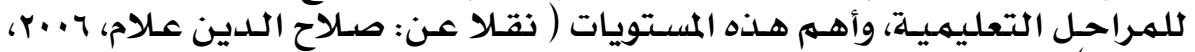

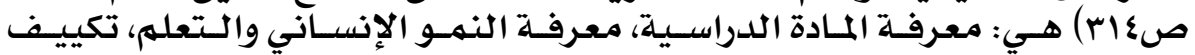

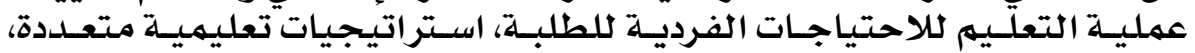

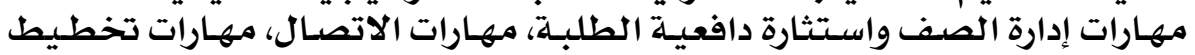

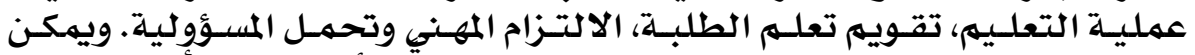

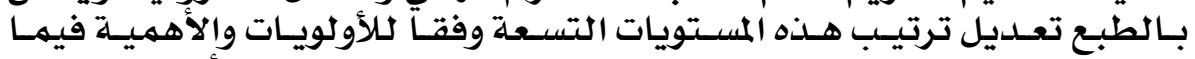

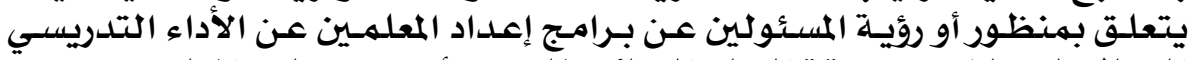

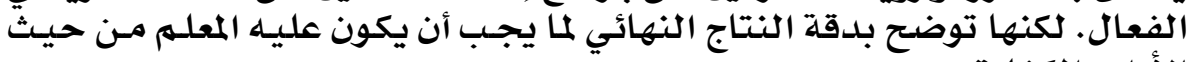
الأداء والكفاءة. آلكناء. توض.

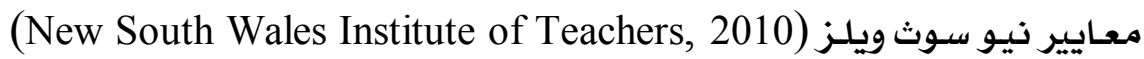

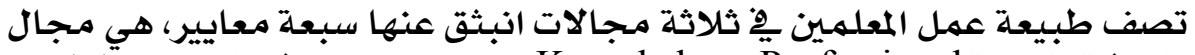

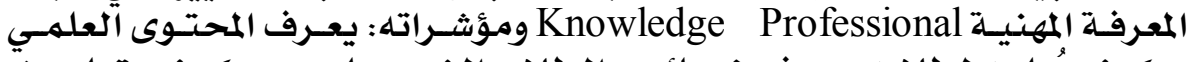

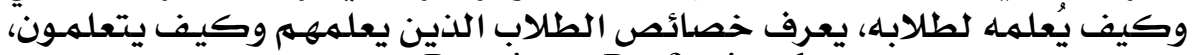

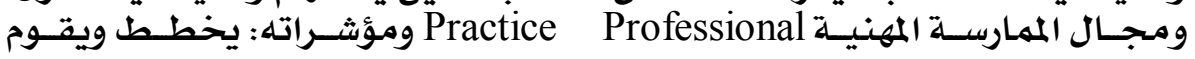

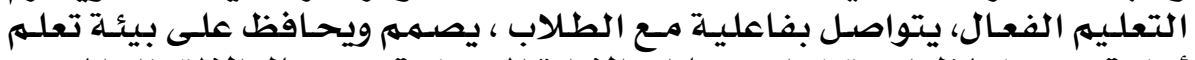

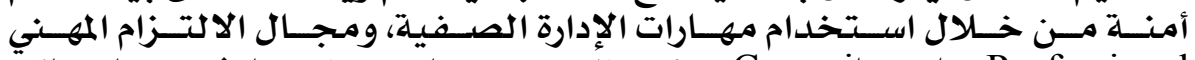

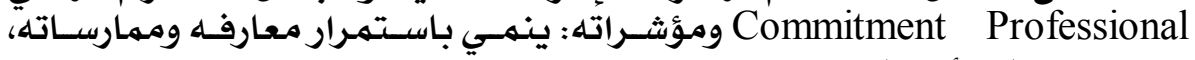
يشجع بحماس أعضاء مهنتـه ومجتمعحه.

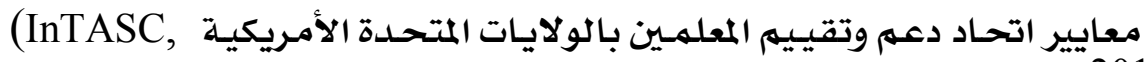

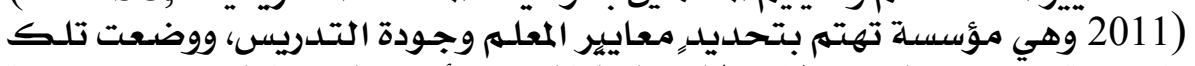

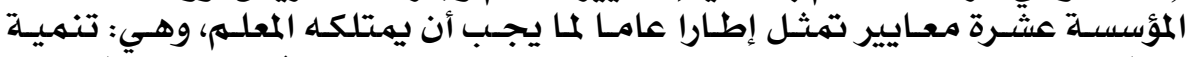

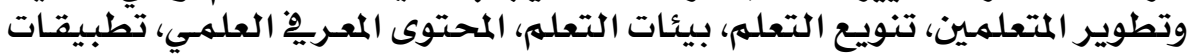

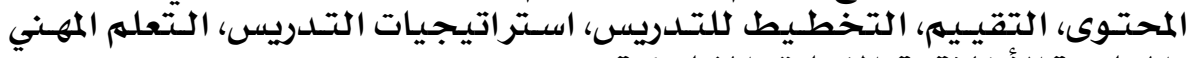

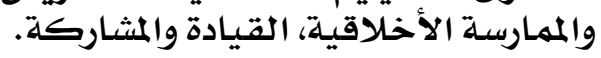

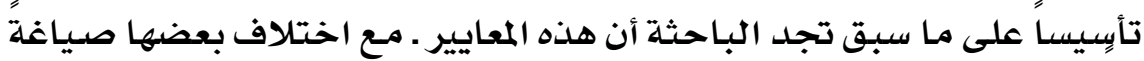

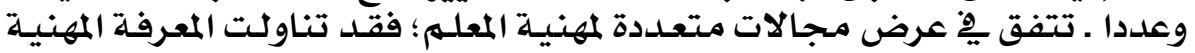

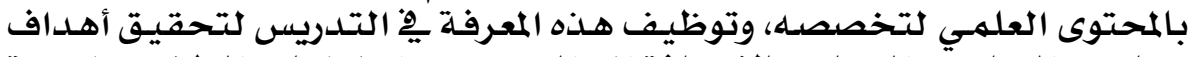

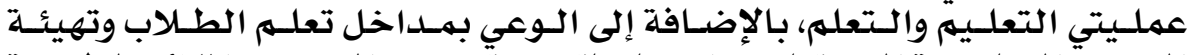

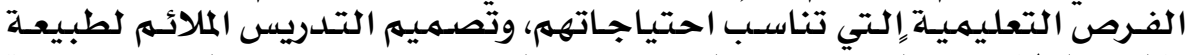

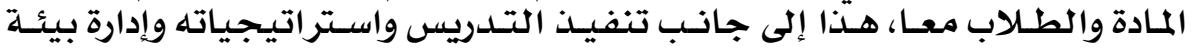

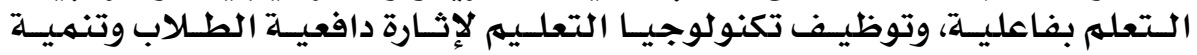

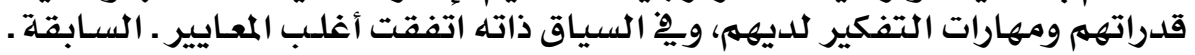

\section{YYO}




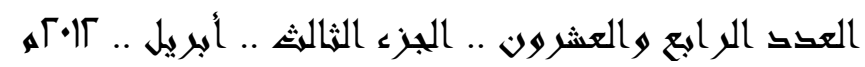

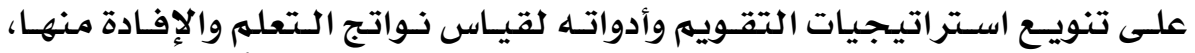

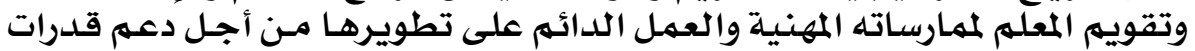
الطلاب وتحقيق أهداف التعلهم.

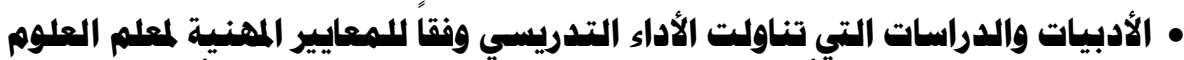

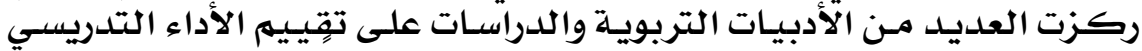

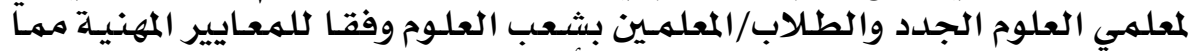

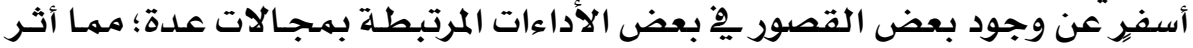
سلبا على تحقيق أهداف عمليتي التعليه والتعلهم المرجوة المرته

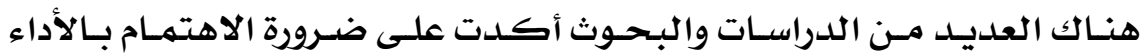

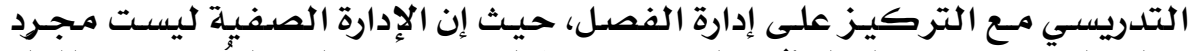

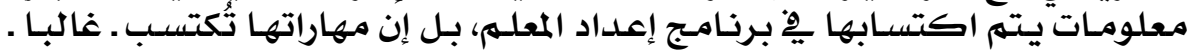

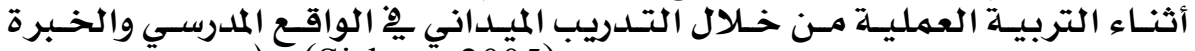

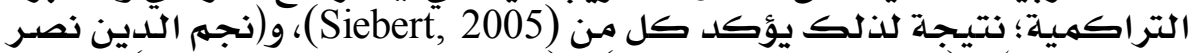

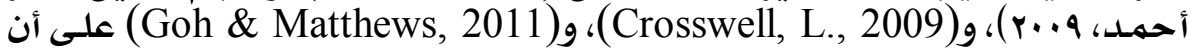

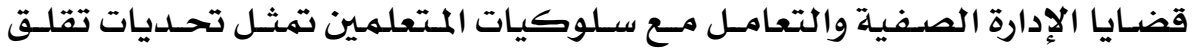

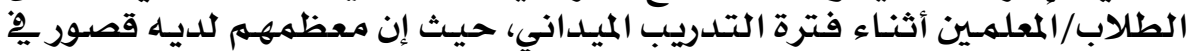

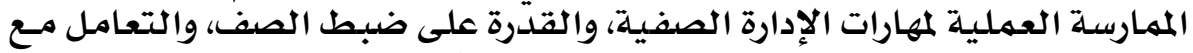

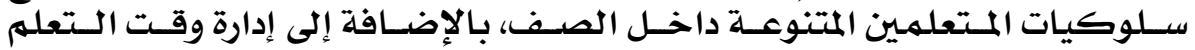

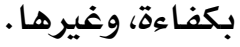

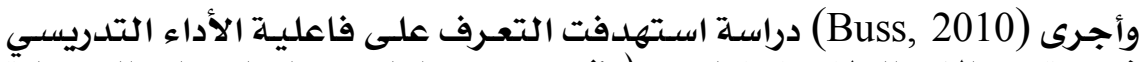

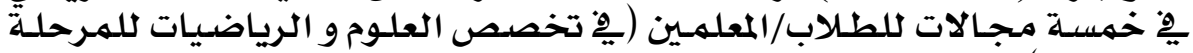

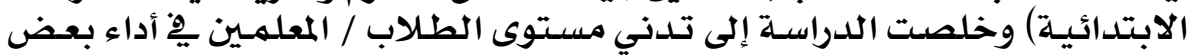

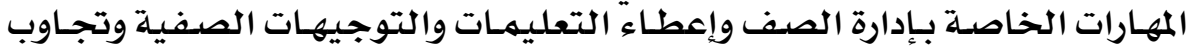
المتعلم-ين معهارا المخاه

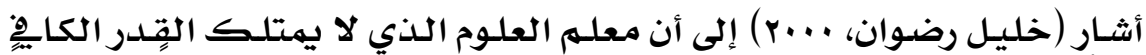

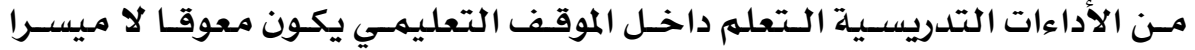

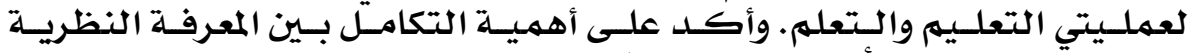

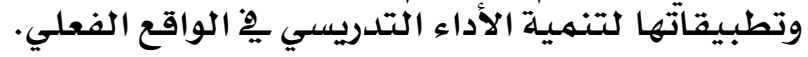

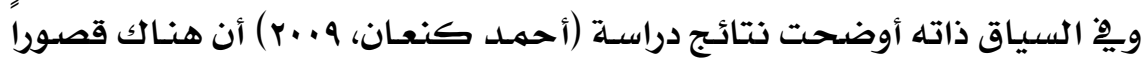

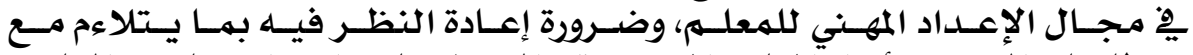

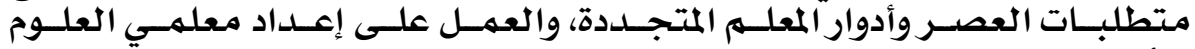

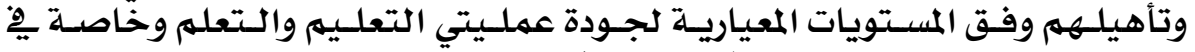

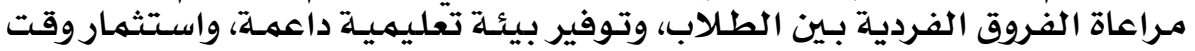

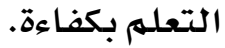

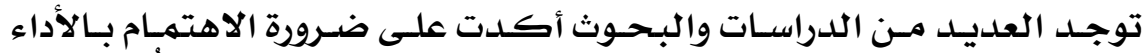

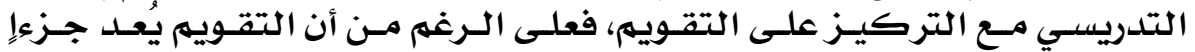

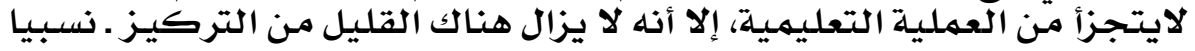

\section{YYT}




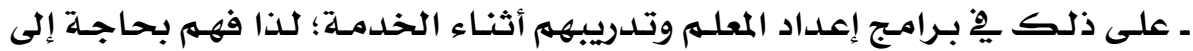

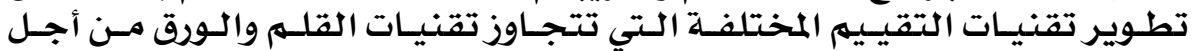

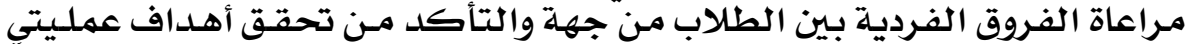

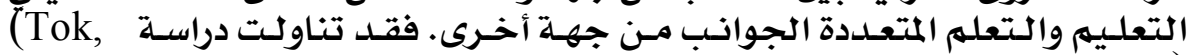

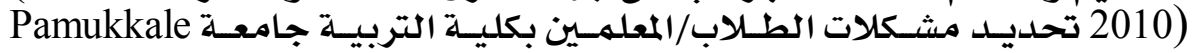

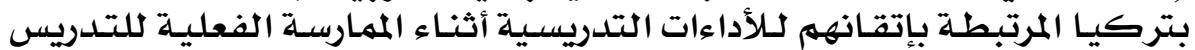

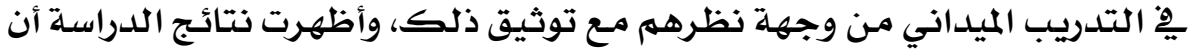

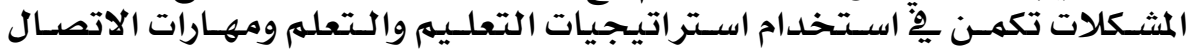

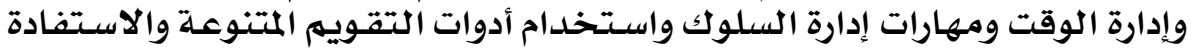

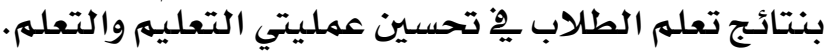

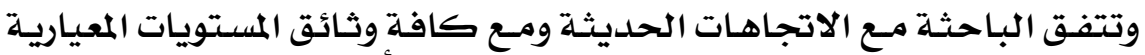

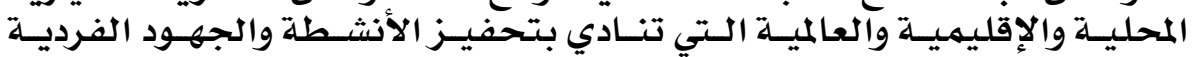

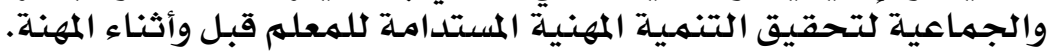

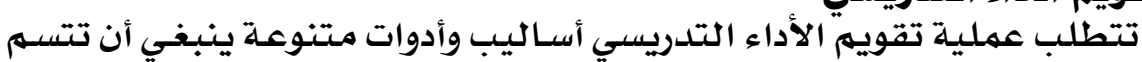

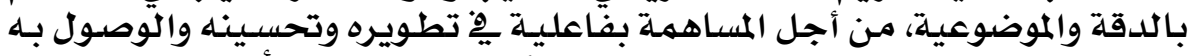

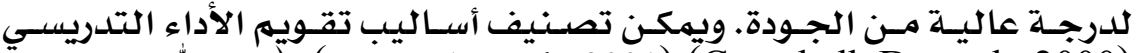
(Porter, A. et al., 2001) (Campbell, D. et al., 2000)

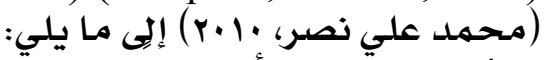

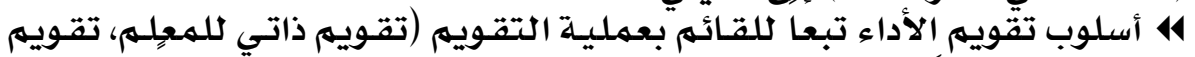

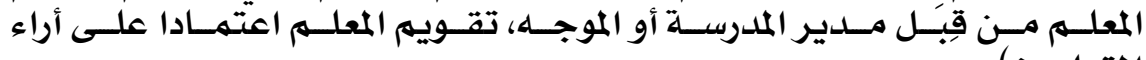

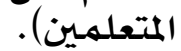

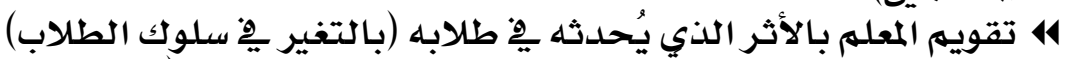

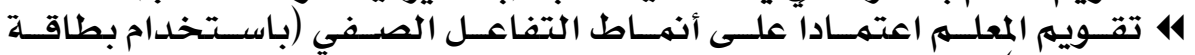
مـلاحظة).

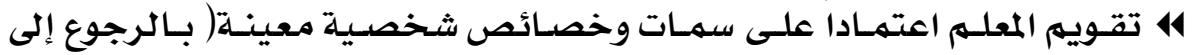

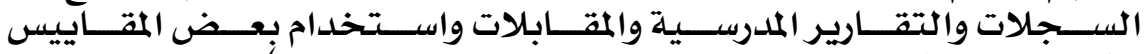

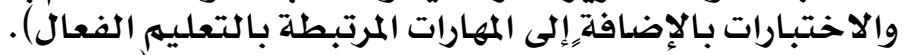

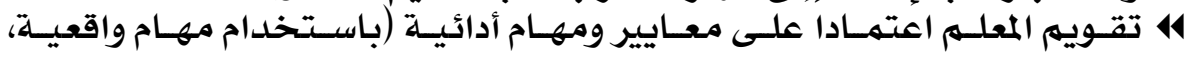

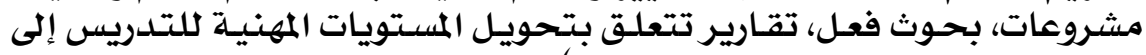

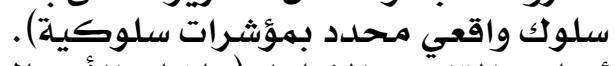

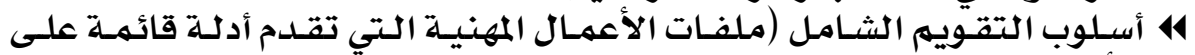

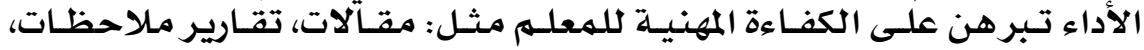

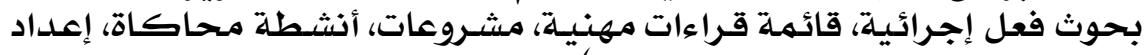

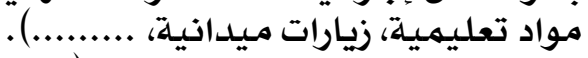

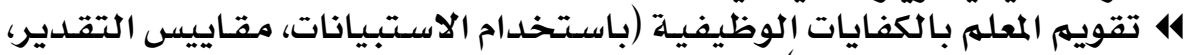
بطاقة الملاحظة، ........).

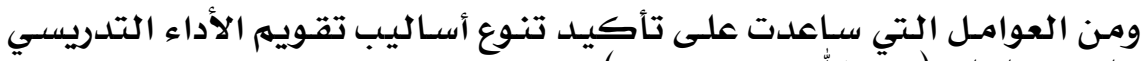

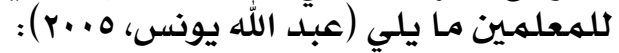

\section{YYV}




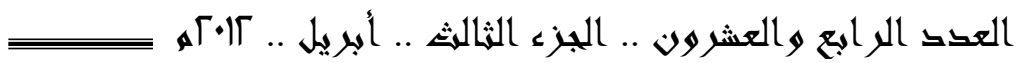

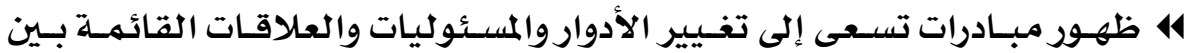

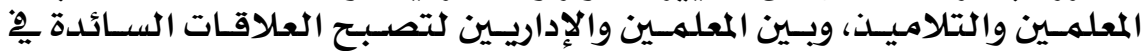

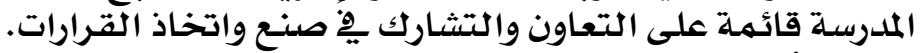

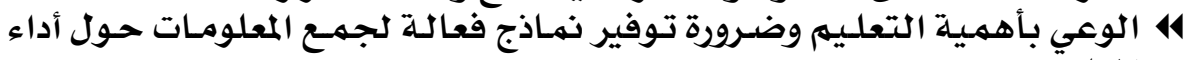
المعلهم.

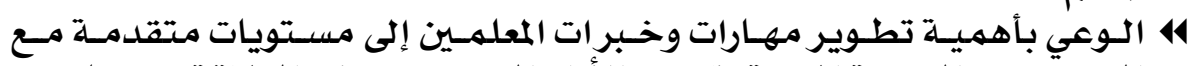

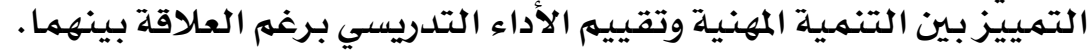

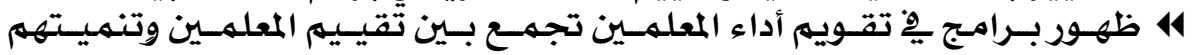

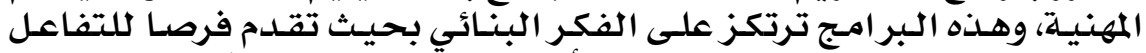

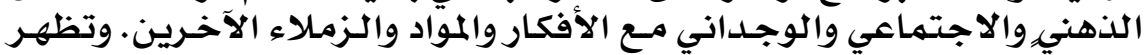

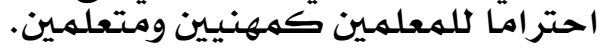

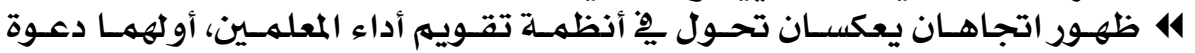

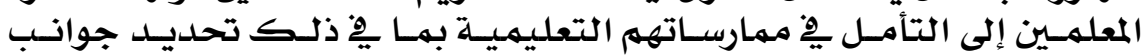

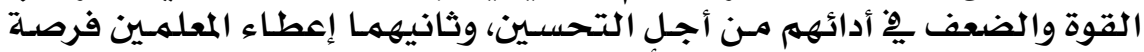

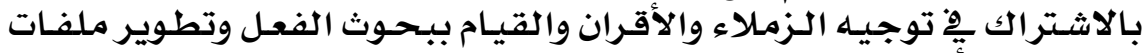

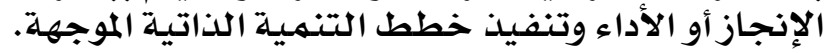

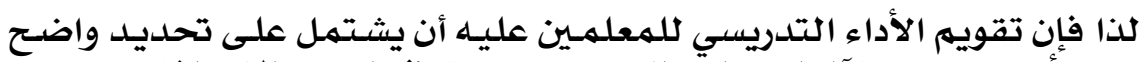

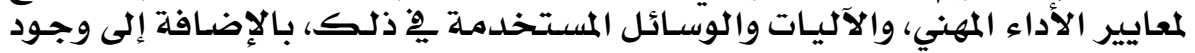

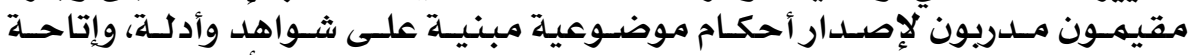

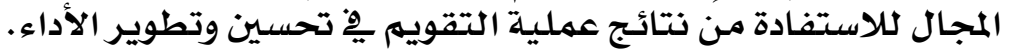

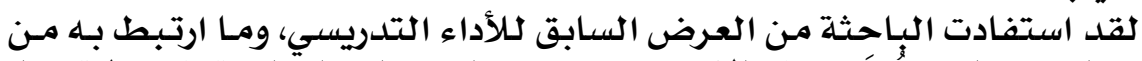

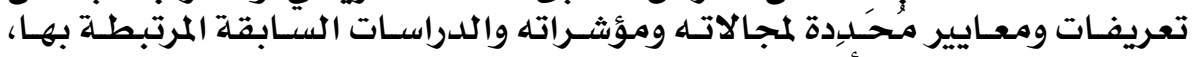

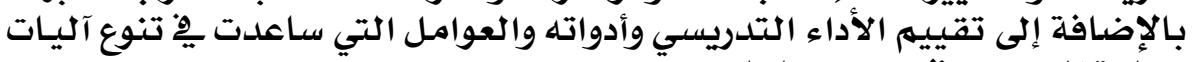

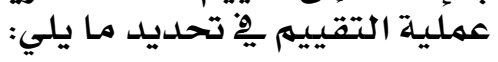

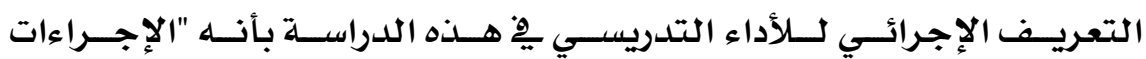

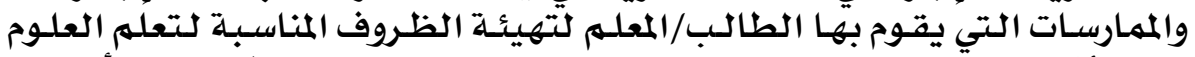

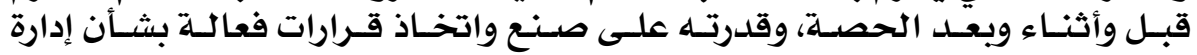

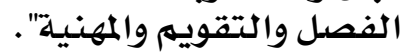

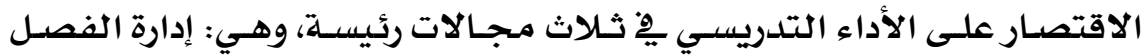

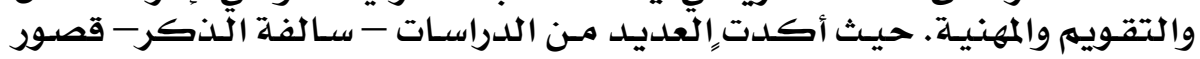

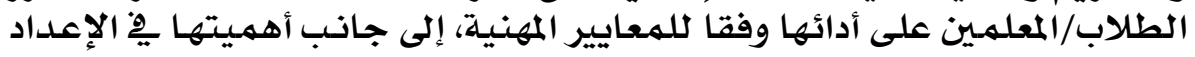
المهني للهمعلهمين. المعلهين.

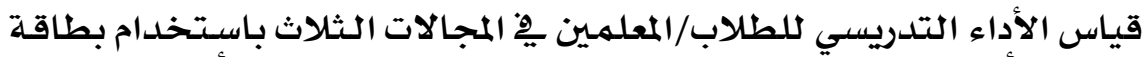

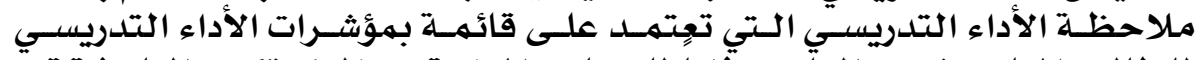

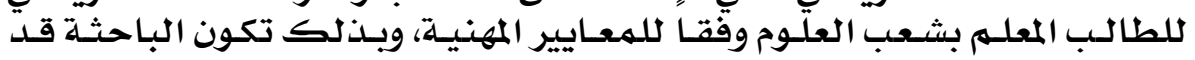

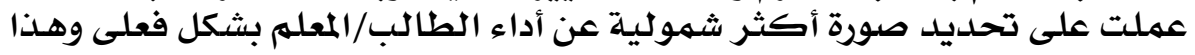

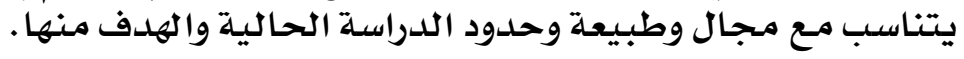




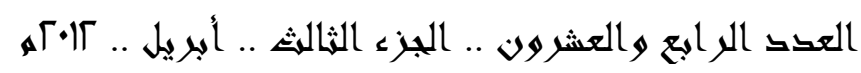

• ثالثاً: التفكير التأهلي ومستوبياته :

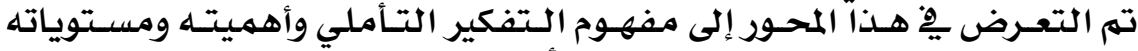

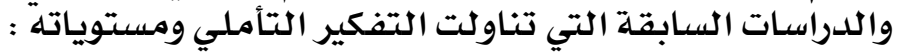

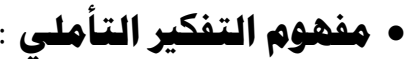

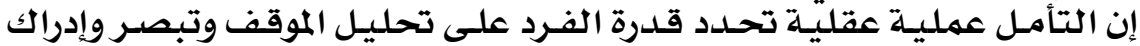

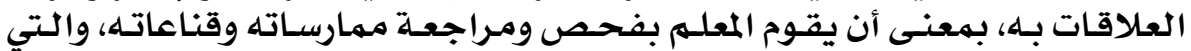

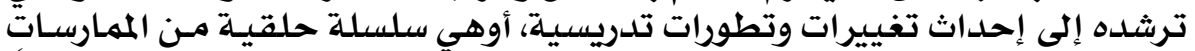

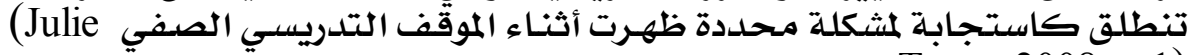
.Trace, 2008, p.1)

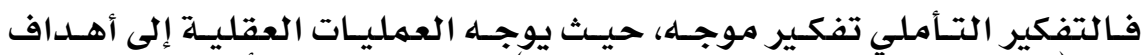

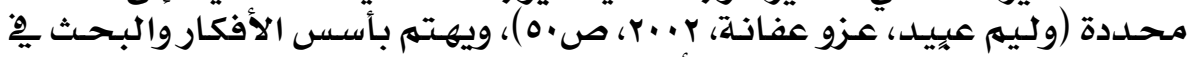

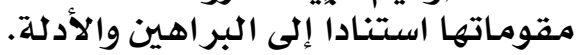

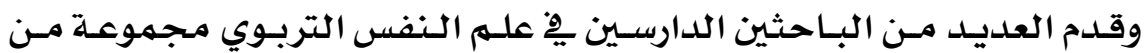

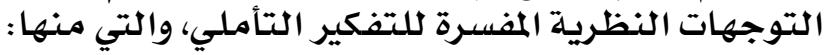

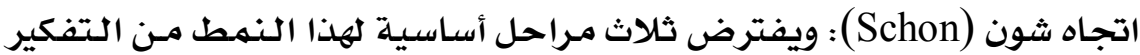

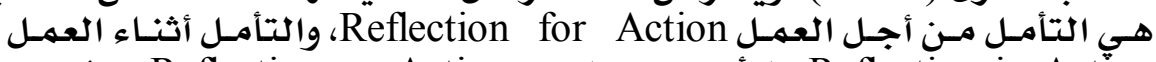
"Reflection in Action "المعلهم الفعال هو المعلهم المتأملـ".

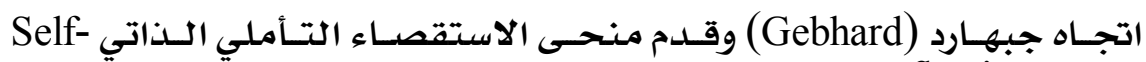
Reflective Inquiry

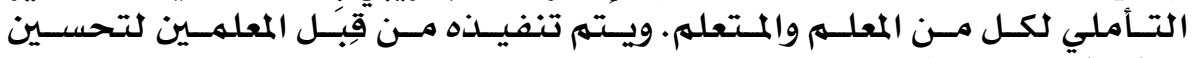

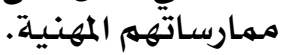

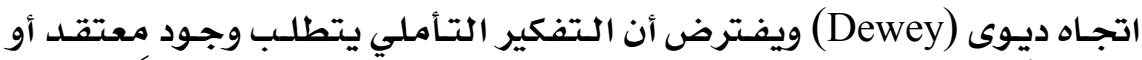

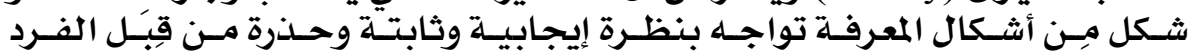

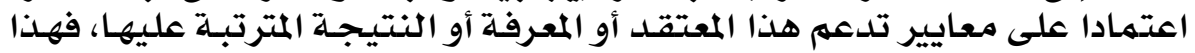

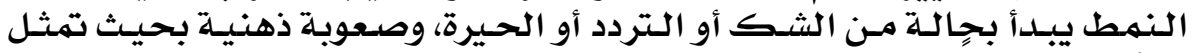

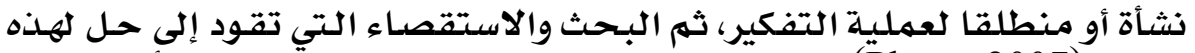

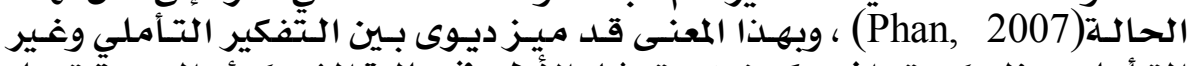

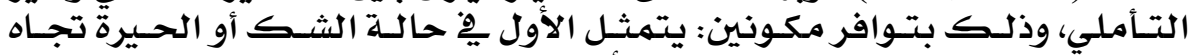

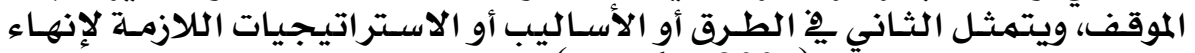

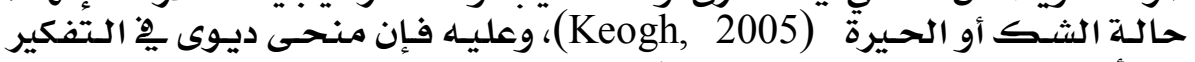

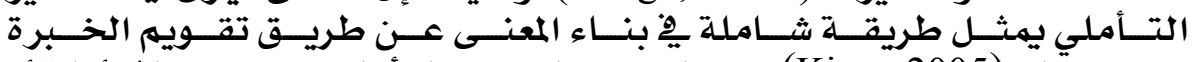

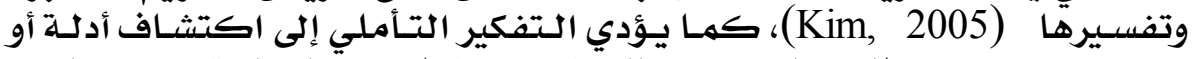

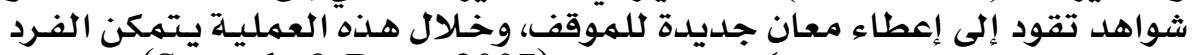

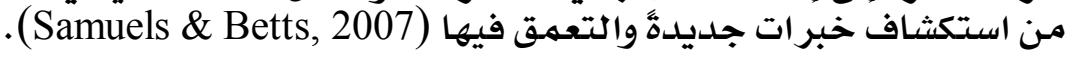

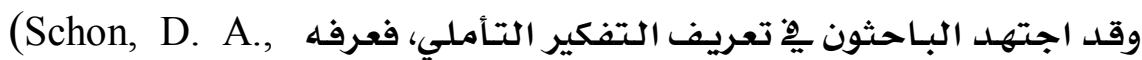

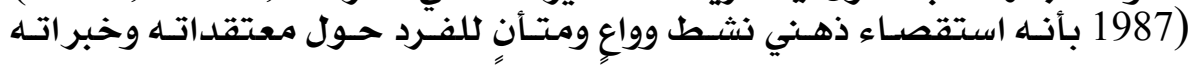




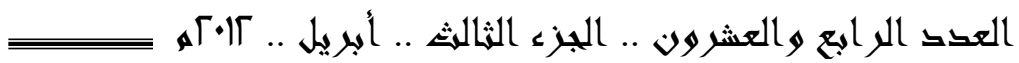

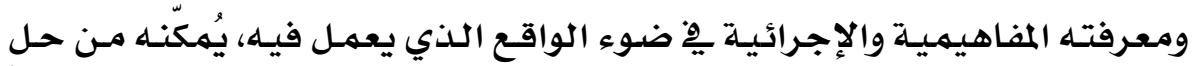

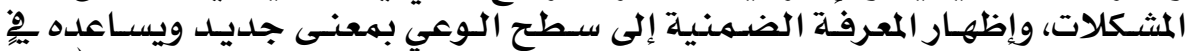

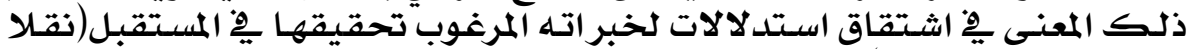
عن: (Phan, H.,2008).

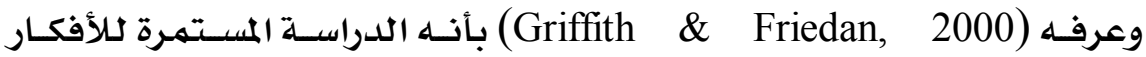

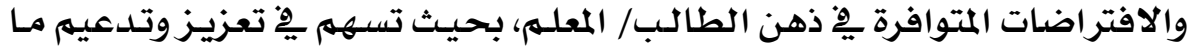
لديله من أراء وأفكار.

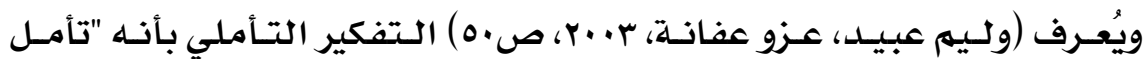

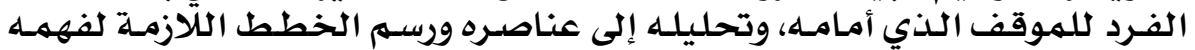

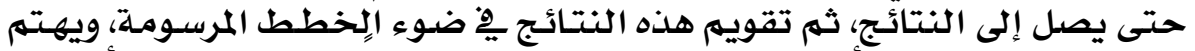

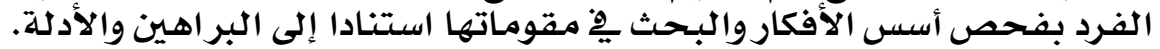

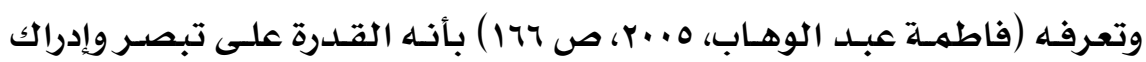

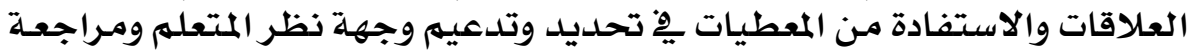

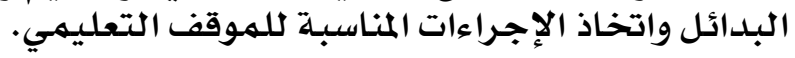

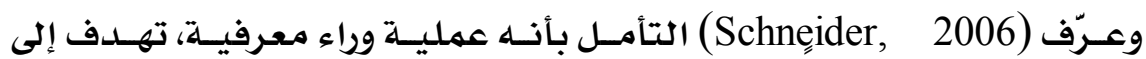

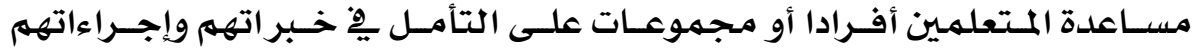

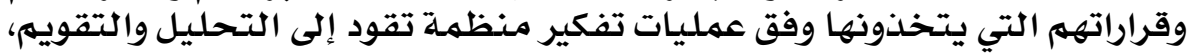

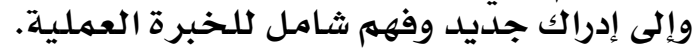

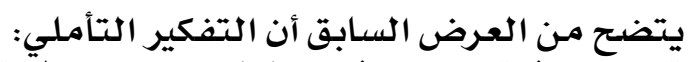

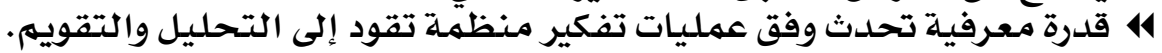

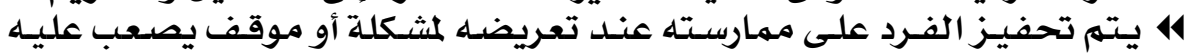

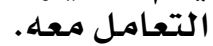

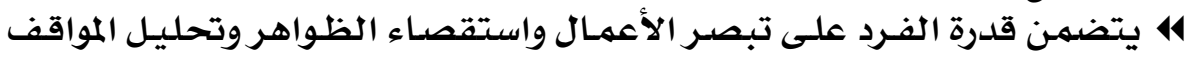

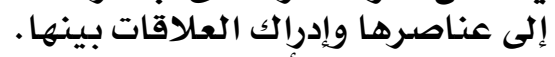

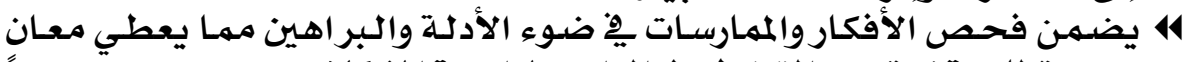

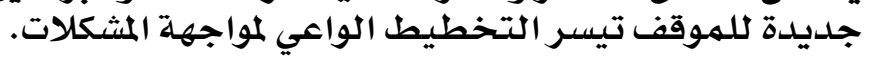

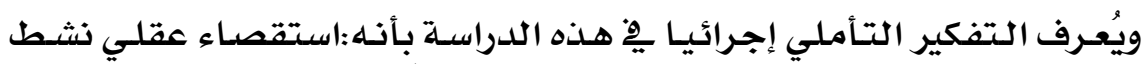

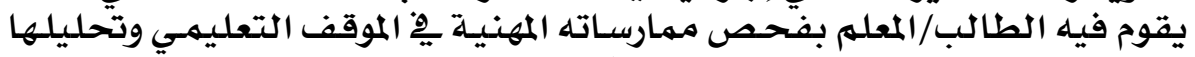

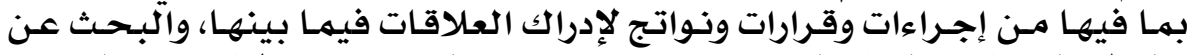

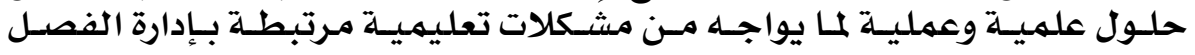

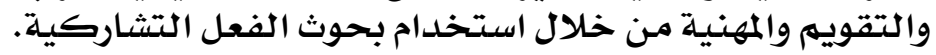

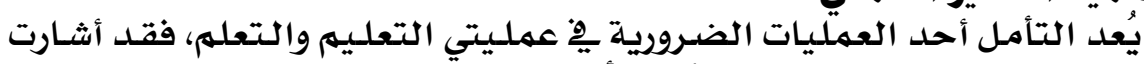

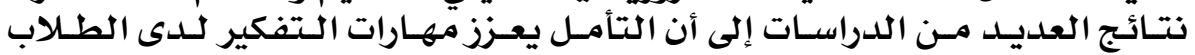

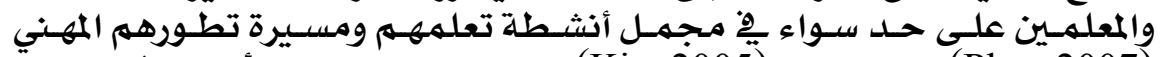

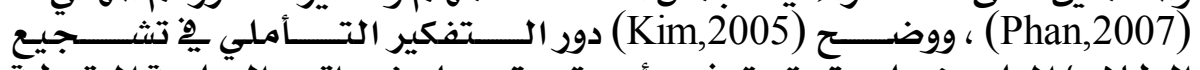

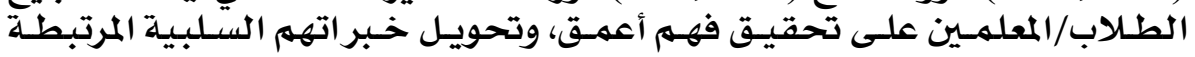

\section{rr.}




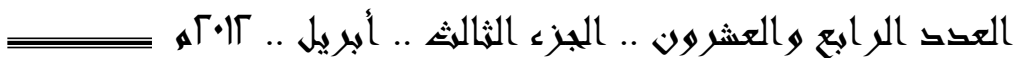

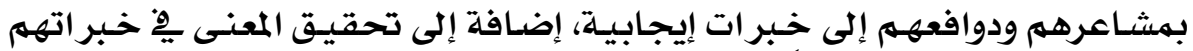

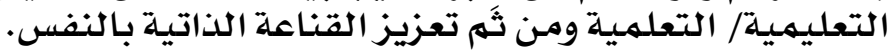

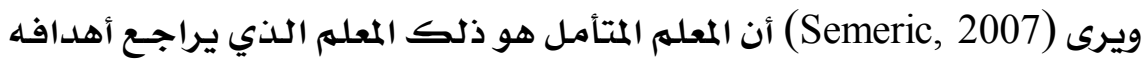

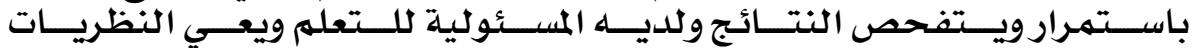
والاستراتيجيات التي تفسر أعماركاله.

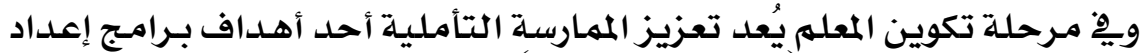

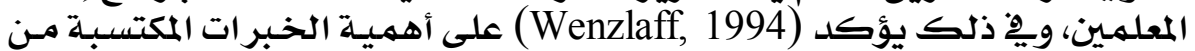

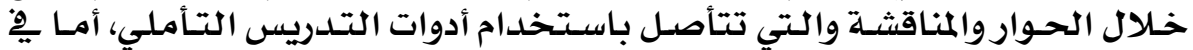

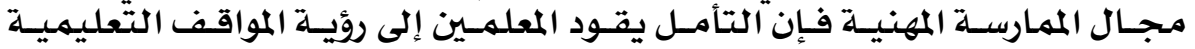

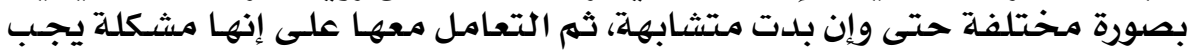

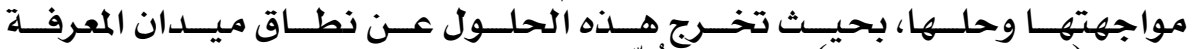

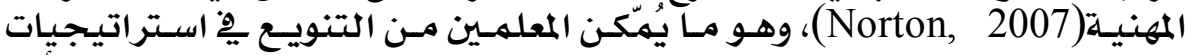

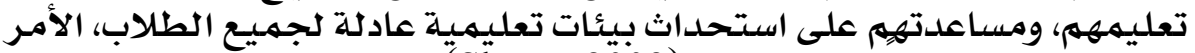

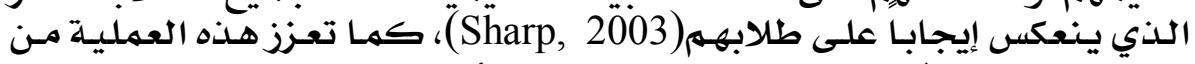

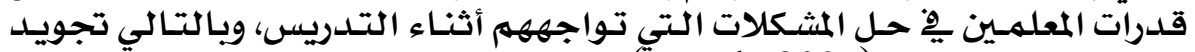
مهارساتهم التعليميـة (Keogh, 2005).

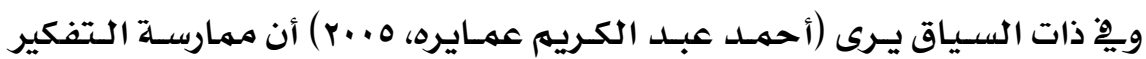

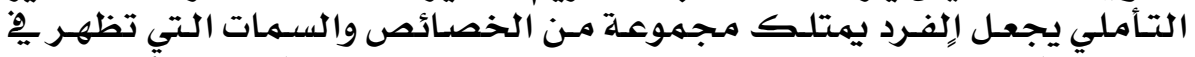

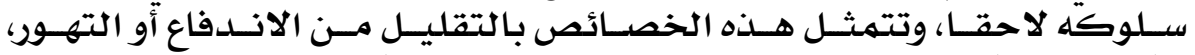

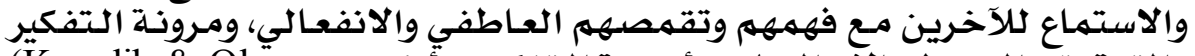

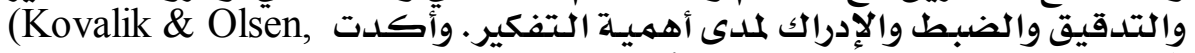
2010, p.4)

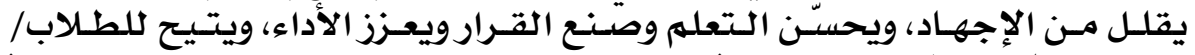

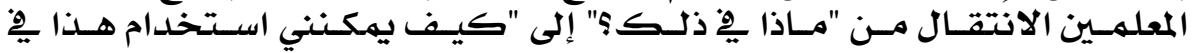

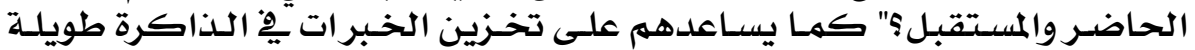

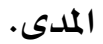

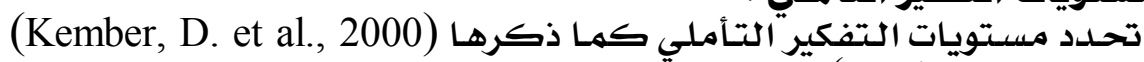

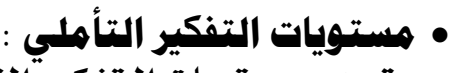

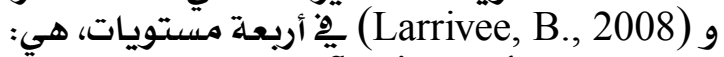

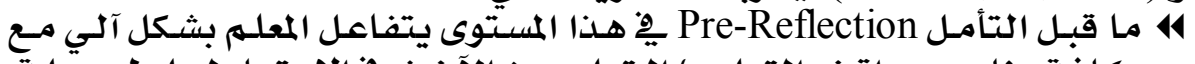

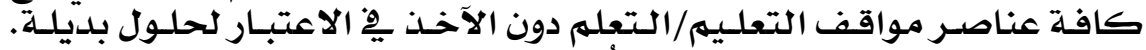

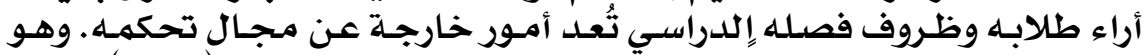

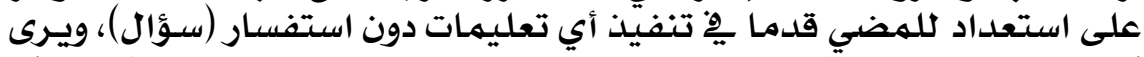

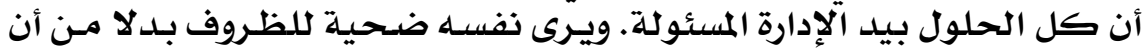

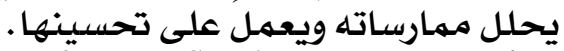

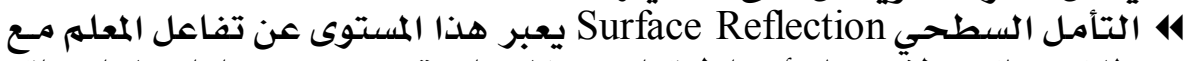

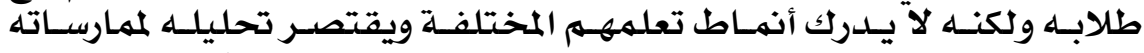

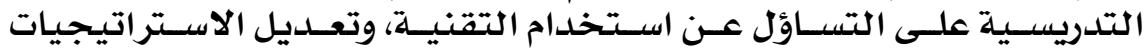


العقد المرابع والعشروه .. الجزء المثالمش .. أبريل .. Гا. أمه =

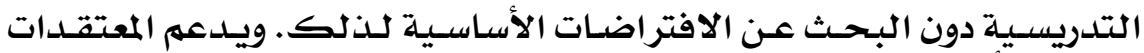

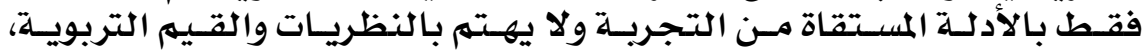

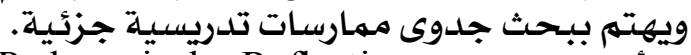

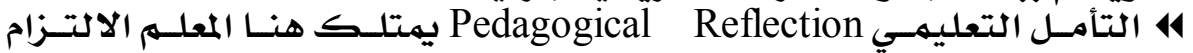

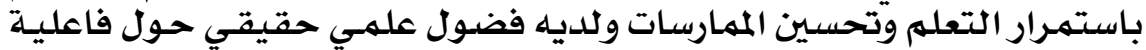

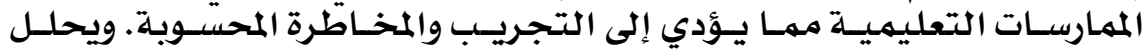

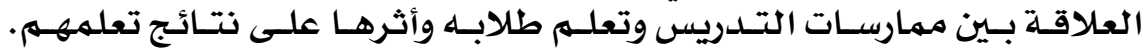

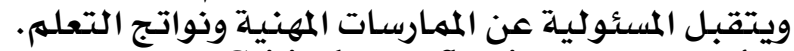

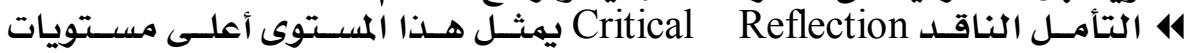

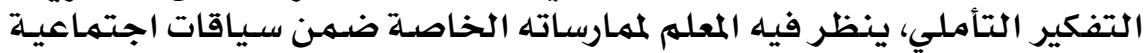

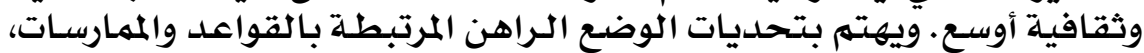

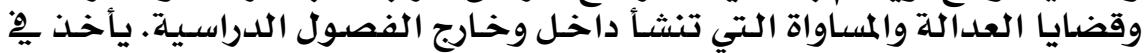

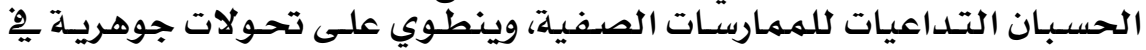

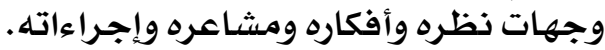

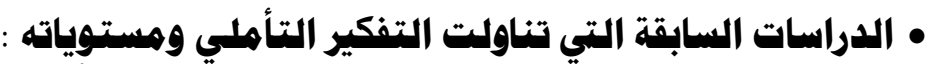

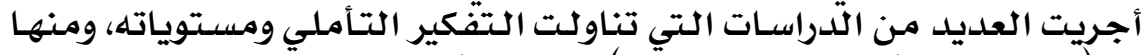

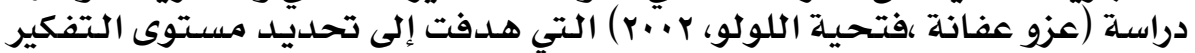

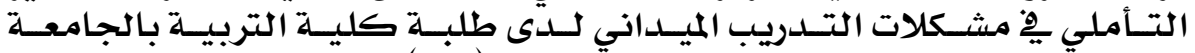

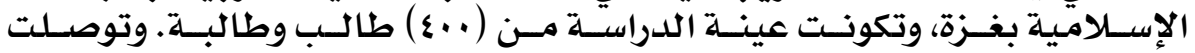

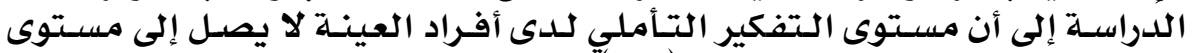

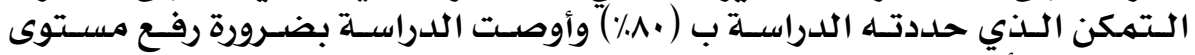

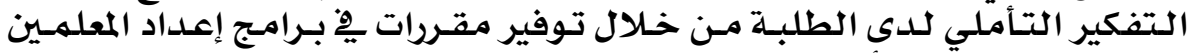

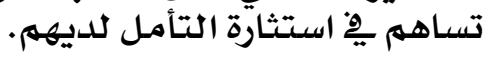

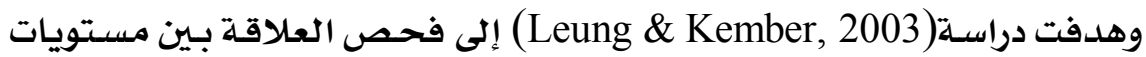

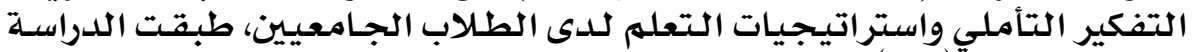

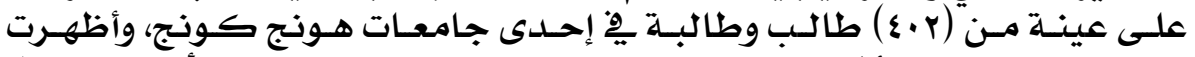

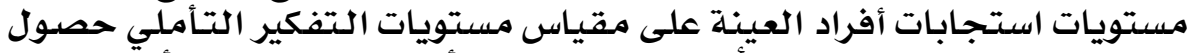

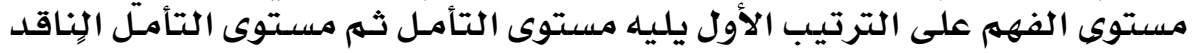

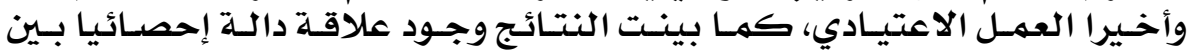

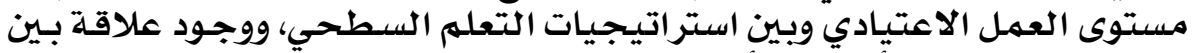

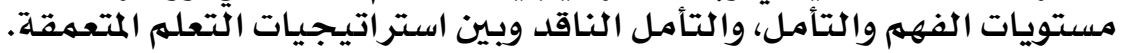

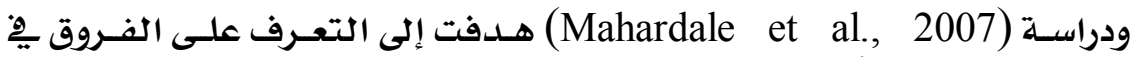

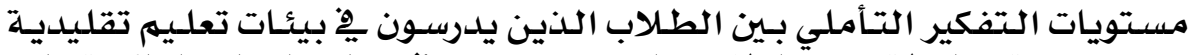

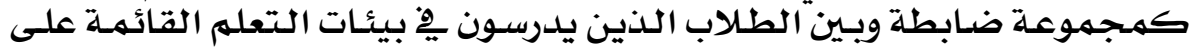

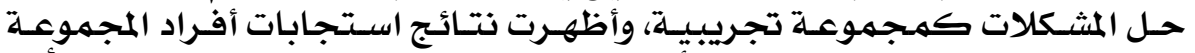

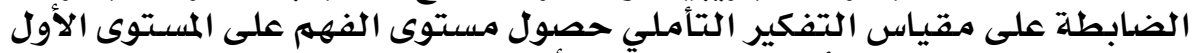

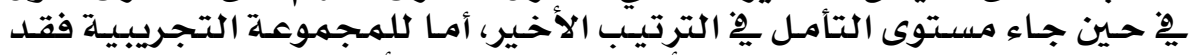

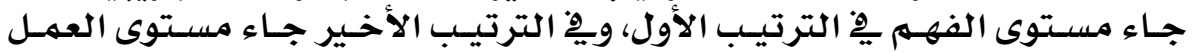

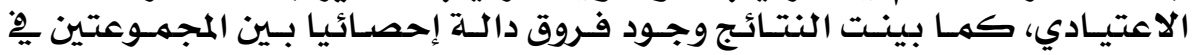

\section{YYY}




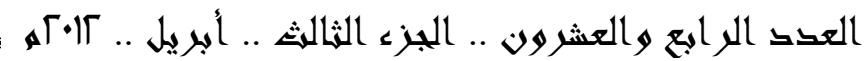

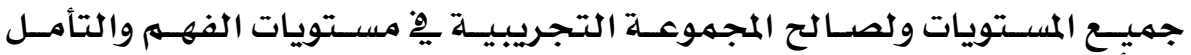

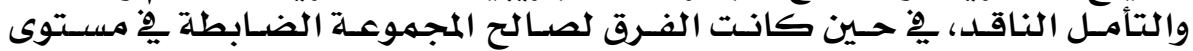

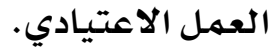

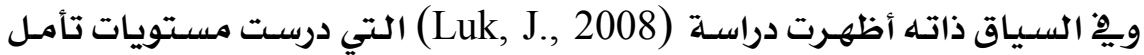

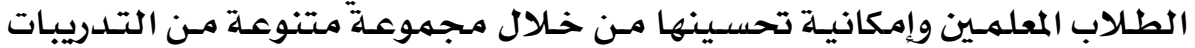

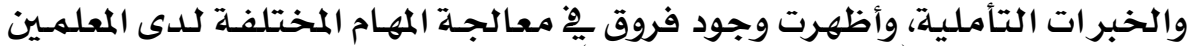

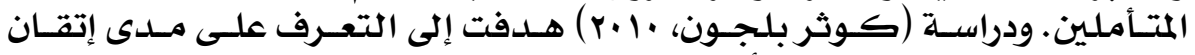

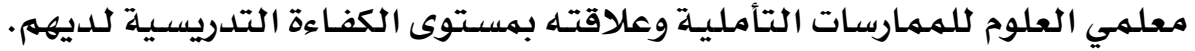

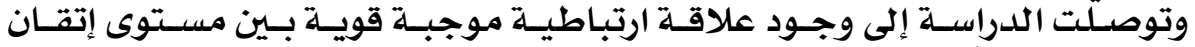

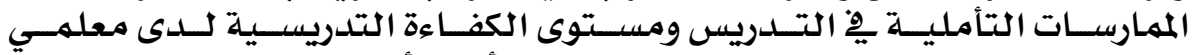

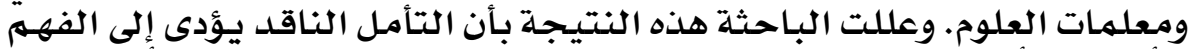

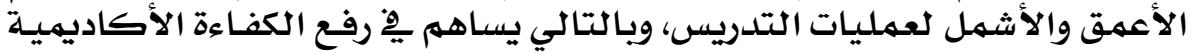

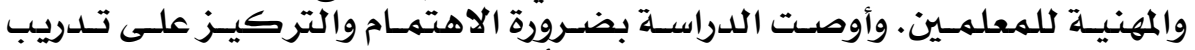

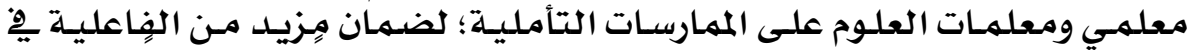

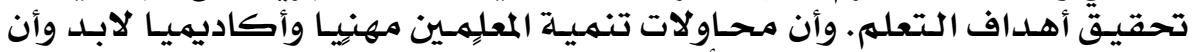

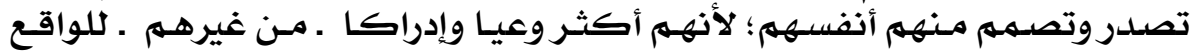

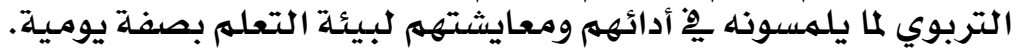

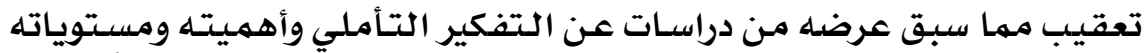

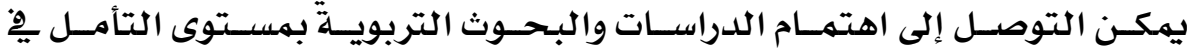

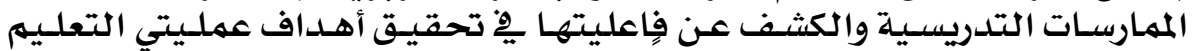

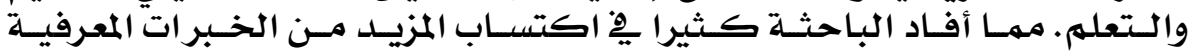

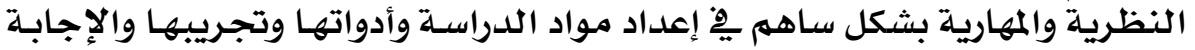

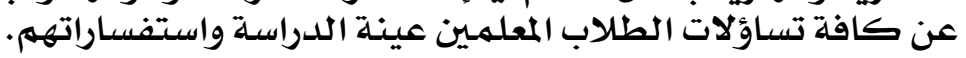

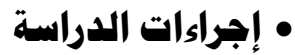

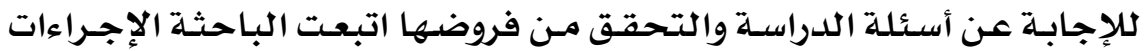

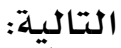

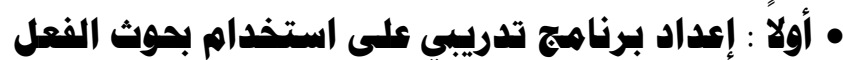

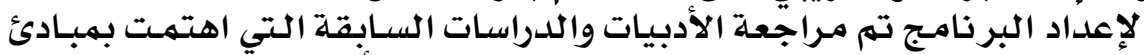

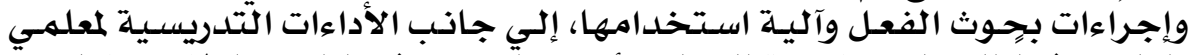

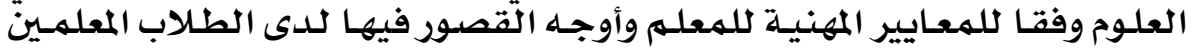

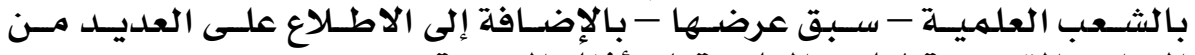

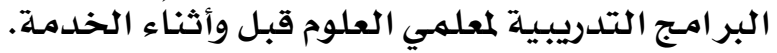

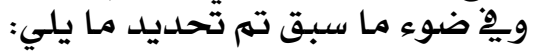

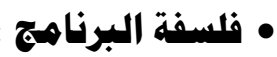

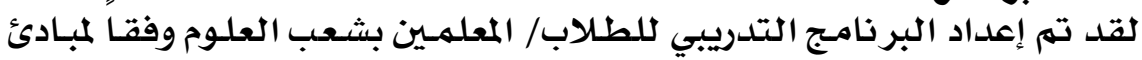

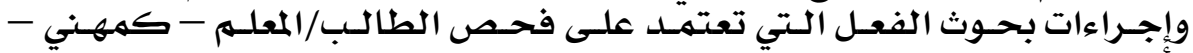

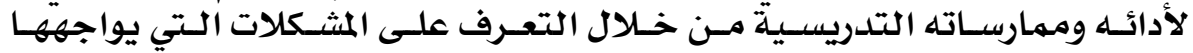

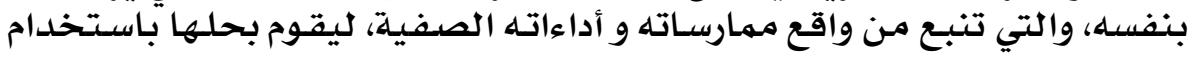

\section{rrr}




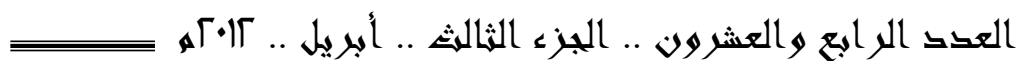

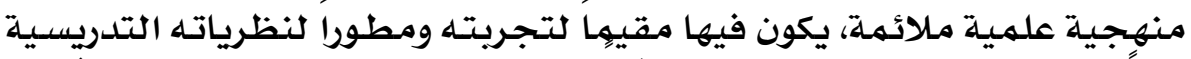

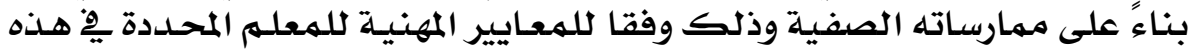
الدراسة.

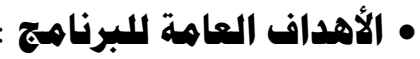

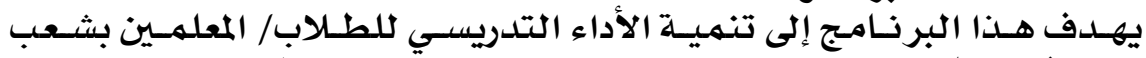

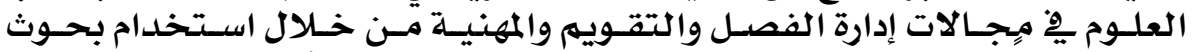

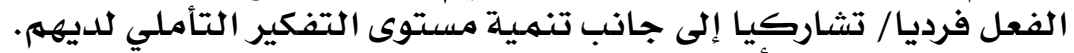

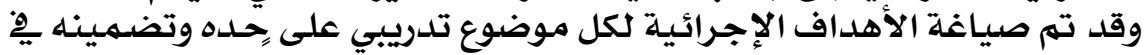

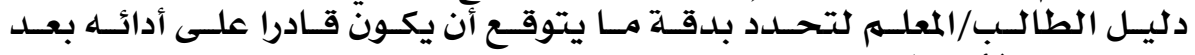

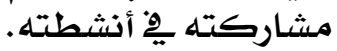

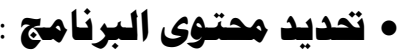

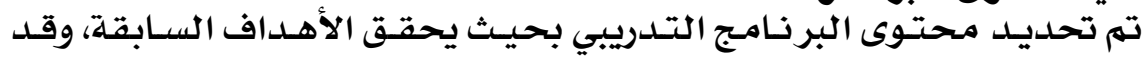

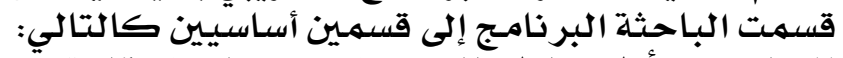

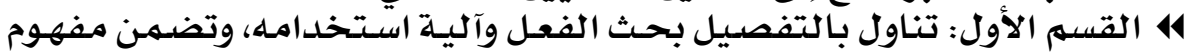

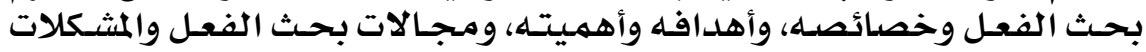

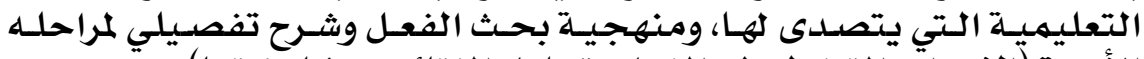

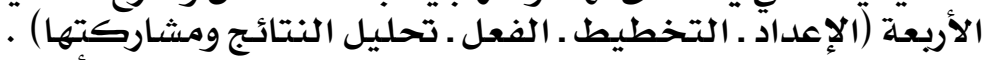

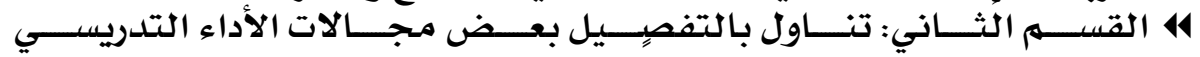

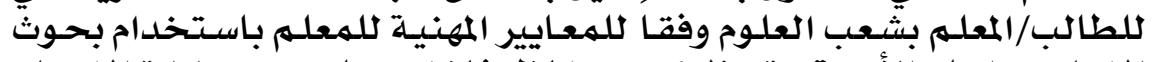

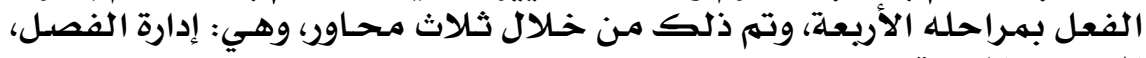
التقويهم، المهنية.

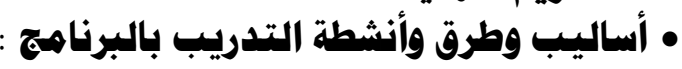

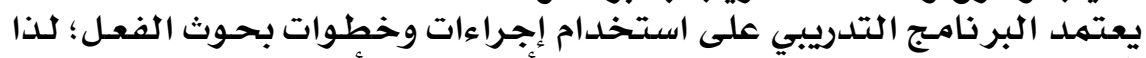

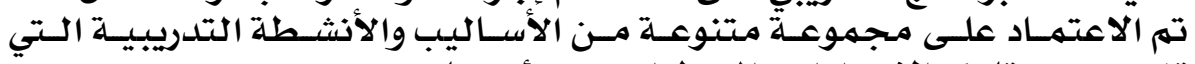

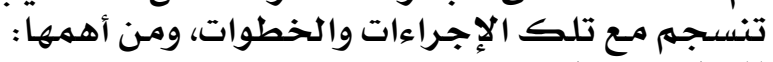
414 414 414 مناقشات فردية أعمل أو جماعية موجهه.

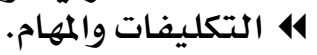
هاس الستة الحالية.

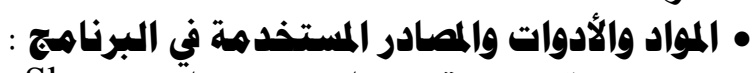

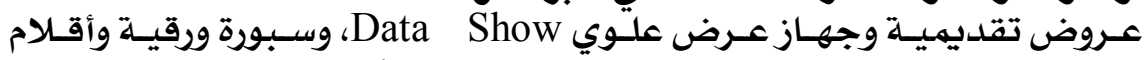

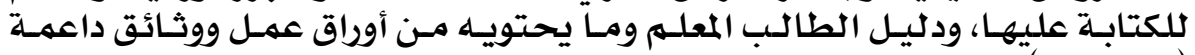

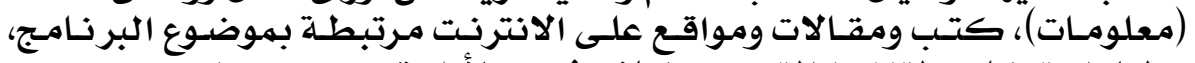

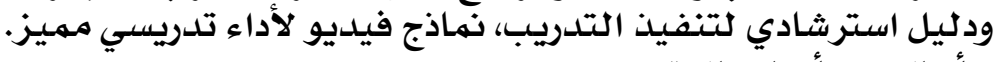

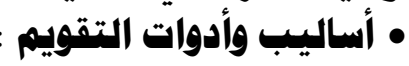

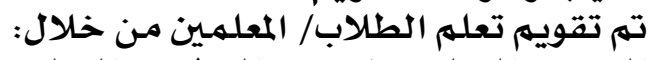

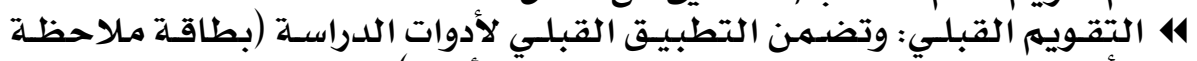

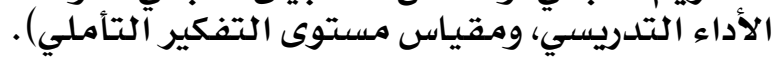

\section{Yr\&}




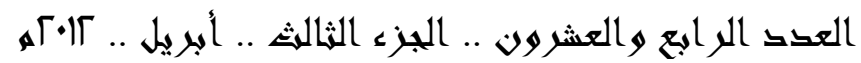

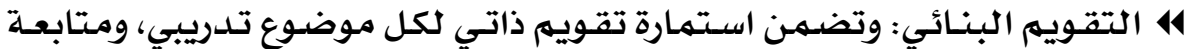

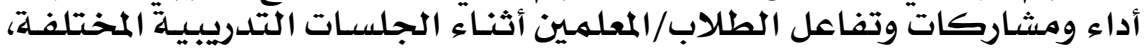

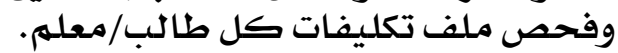

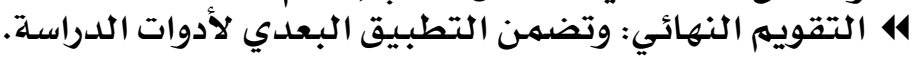

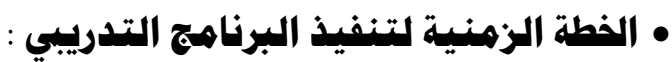

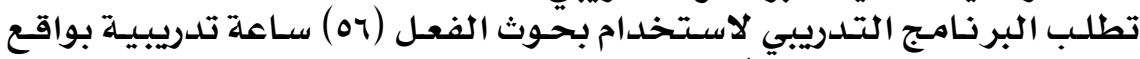

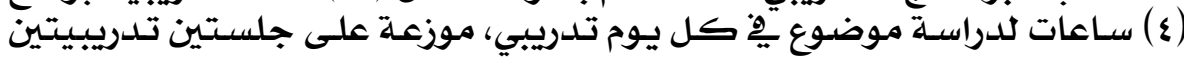

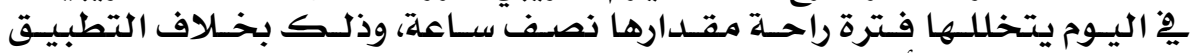

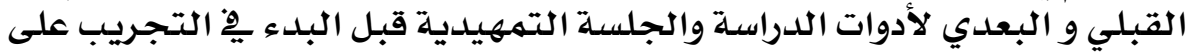

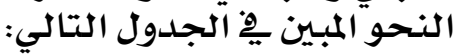

جدول ( 1 ) : خطة تنفيذ البرنامج التدريبي لاستخدام بحوث الفعل

\begin{tabular}{|c|c|c|c|c|}
\hline آلمكان & التصاعيب & \multicolumn{2}{|c|}{ محتويات البرنامـج } & الفترة الزمنية \\
\hline \multirow{5}{*}{ قالكاعة } & & \multirow{2}{*}{\multicolumn{2}{|c|}{ ألقسم الاول: }} & \multirow{5}{*}{ "اريّيع آيامة } \\
\hline & | أساعات & & & \\
\hline & | ل كساعات & \multicolumn{2}{|c|}{ ـ يتضدات بها. الفعل والمشكلات التربوية التي } & \\
\hline & | ل كساعات & \multicolumn{2}{|c|}{ 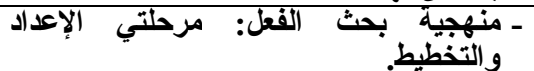 } & \\
\hline & كاعسات & \multirow{2}{*}{\multicolumn{2}{|c|}{ 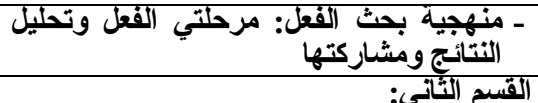 }} & \\
\hline \multirow{11}{*}{ 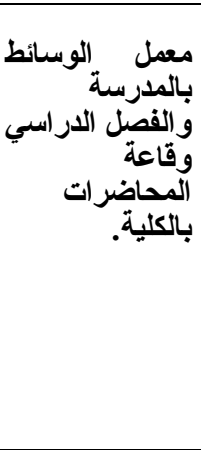 } & & & & \multirow{11}{*}{ لقلمداء اسبوعي } \\
\hline & | عاعسات & تخطيط وتنظيم التفاعلات الصفية & \multirow{4}{*}{ الفصإرة } & \\
\hline & | كاعات & إثُارة دافعية الطلاب لتعلم الطلاب & & \\
\hline & | ل كساعات & تهيئهة البيئة الفيزيقِية & & \\
\hline & 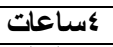 & إدارة وقتت التُعليم و ألتّعل & & \\
\hline & | & المبادئ النظريـة لتقييم تعلم العلوم & \multirow[t]{3}{*}{ ـالتقويم } & \\
\hline & | كاساعات & الدو ات تقييم تعلم العلوم & & \\
\hline & | ل كساعات & وتحسين التثرئج التقييم في تخطيط & & \\
\hline & | & الالتز ام بالتميز & \multirow[t]{3}{*}{ ـالمهنية } & \\
\hline & 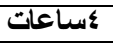 & التشثارك مع الزملاء & & \\
\hline & | ل كاعاعات & إتباع المعايير الاخلاقية & & \\
\hline
\end{tabular}

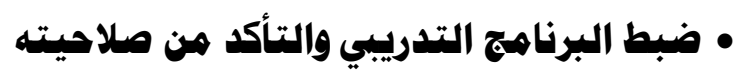

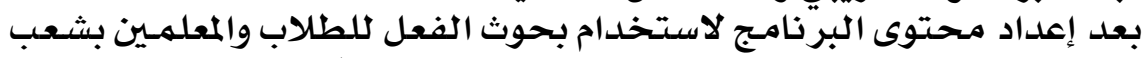

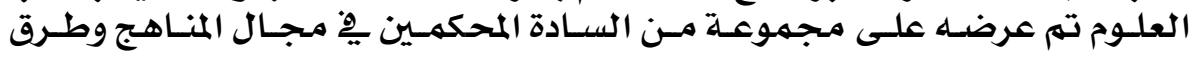

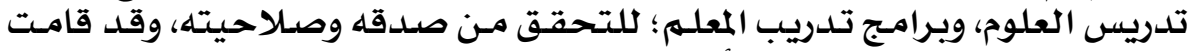

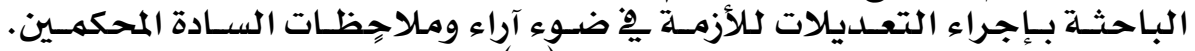

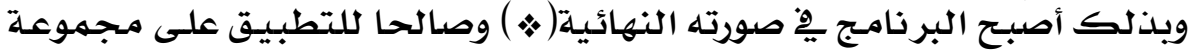
الدراسـة.

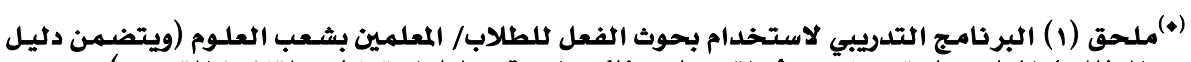

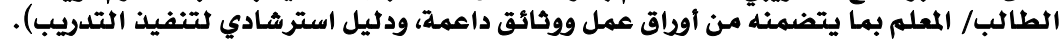

\section{Yro}




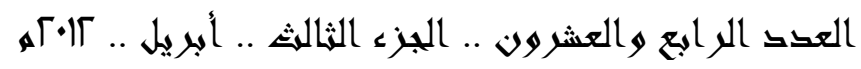

• ثانيا : إعداد أداتا الدراسة

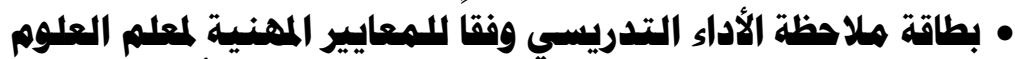

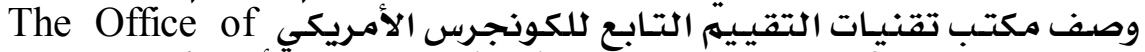
الفي Technology Assessment of U.S.A. Congress

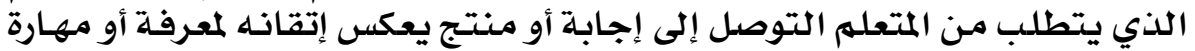

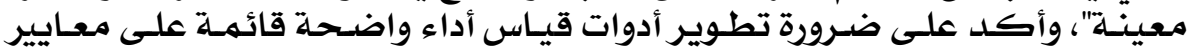

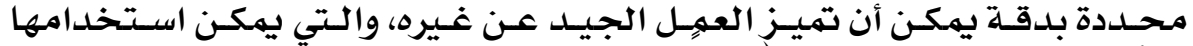

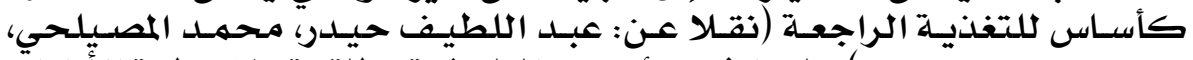

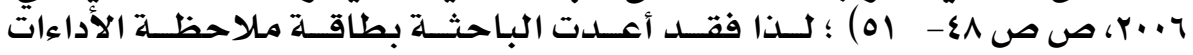

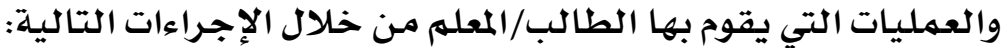

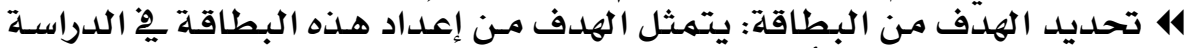

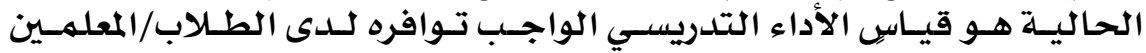

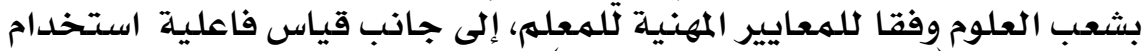

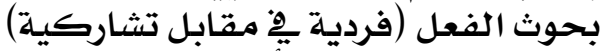

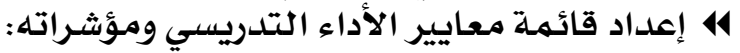

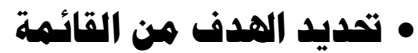

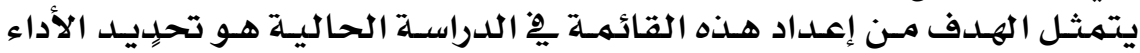

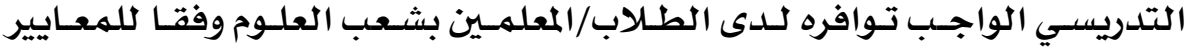
المهنية للهمعلهم.

• تهديد هصادر اشتقاق قائمة همايير الأداء التدريسي وهؤشئراته :

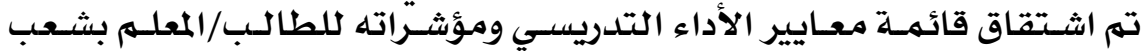

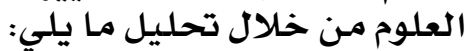

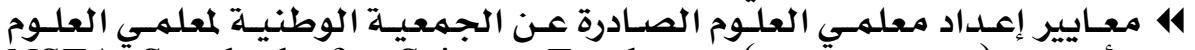
الأمريكيـة NSTA Standards for Science Teacher (NSSTP, 2012) Preparation

4 Interstate معايير اتحـاد دعم وتقيـيه المعلمـين بالولايـات المتحسدة الأمريكيـة Teacher Assessment and Support Consortium (InTASC,2011)

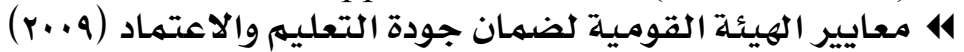

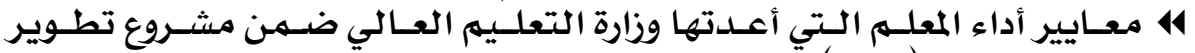

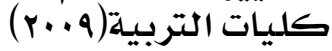

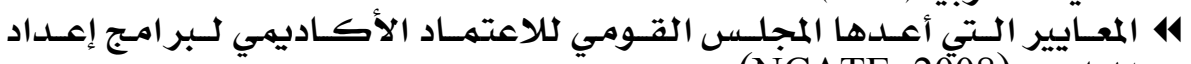
المعلم-ين (NCATE, 2008)

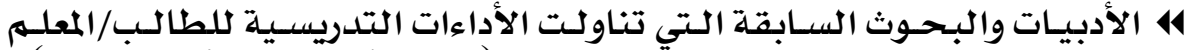

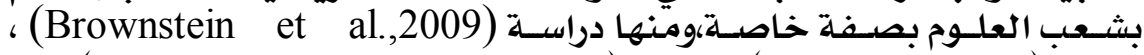

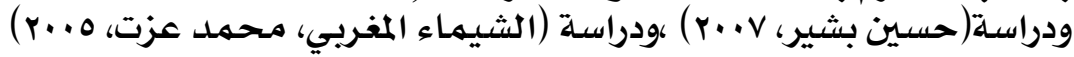

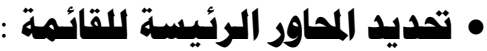

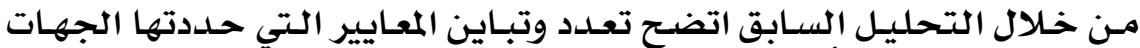

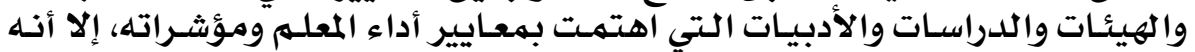

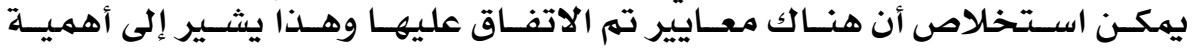

\section{Yry}




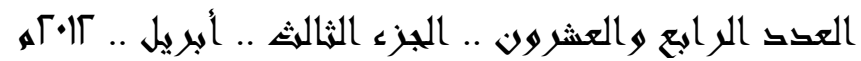

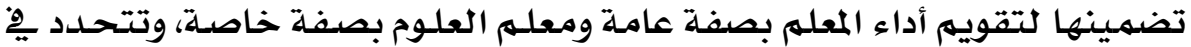

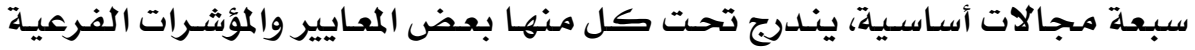

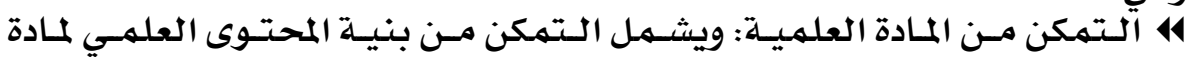

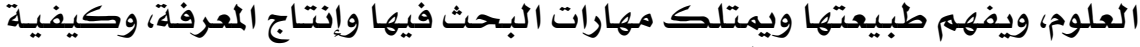

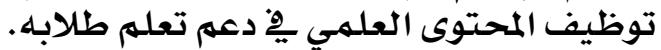

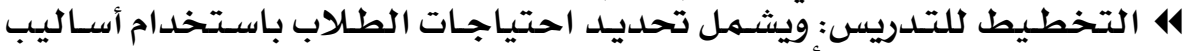

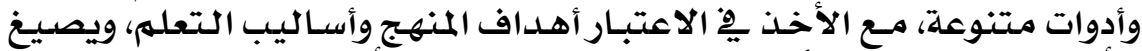

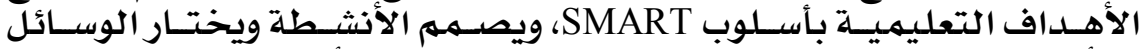

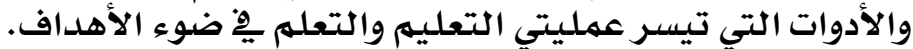

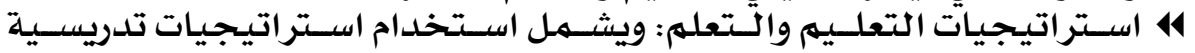

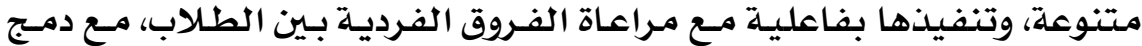

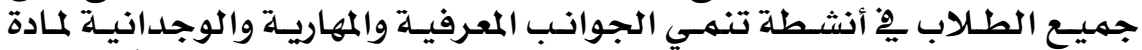

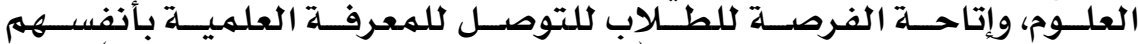

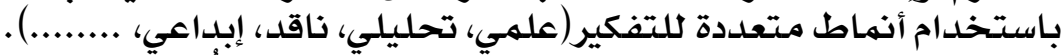

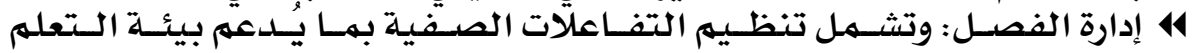

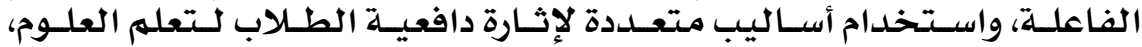

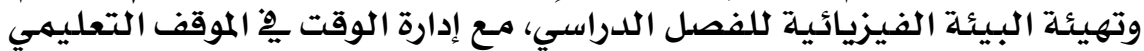

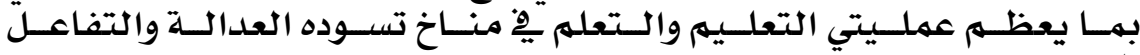

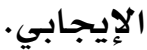

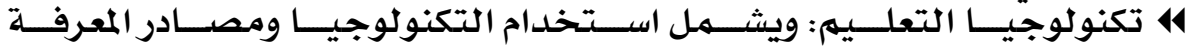

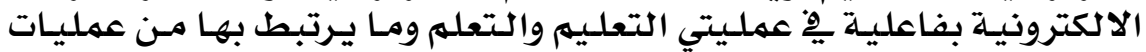

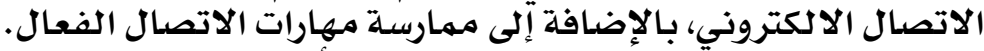

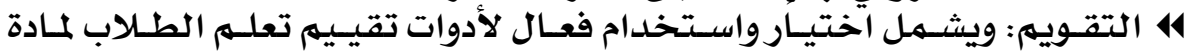

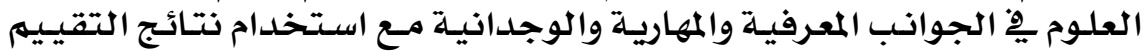

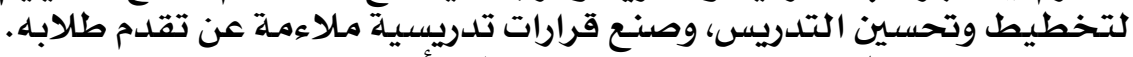

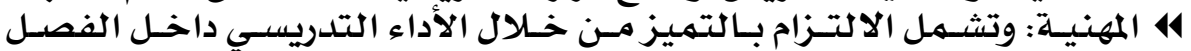

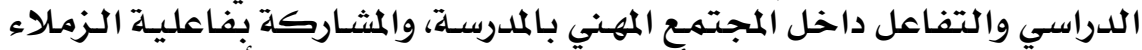

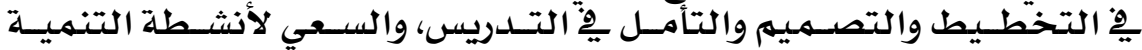

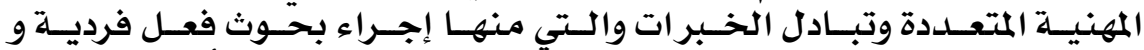

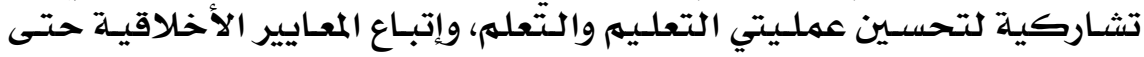

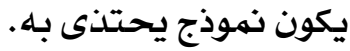

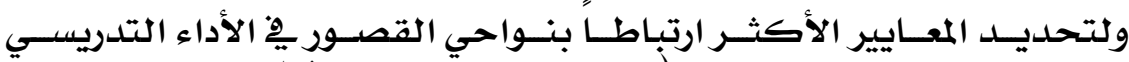

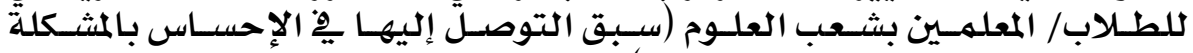

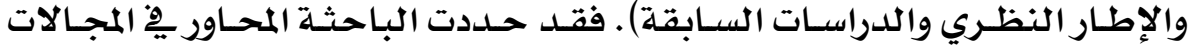

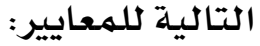

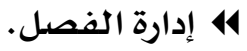
4 414

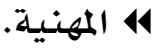

\section{YrV}




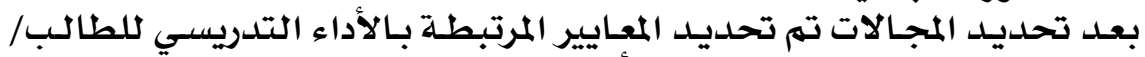

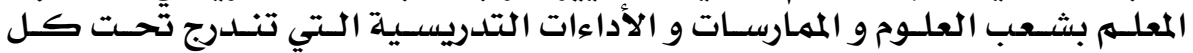

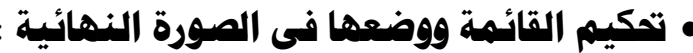

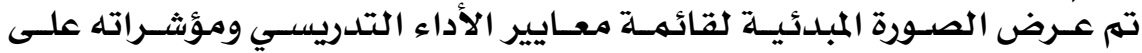

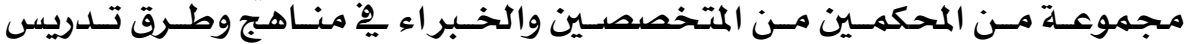

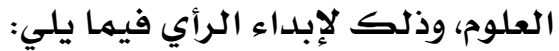

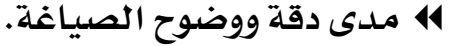

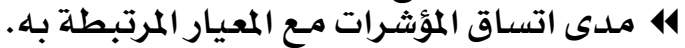

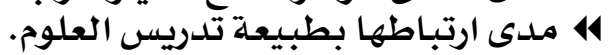
414

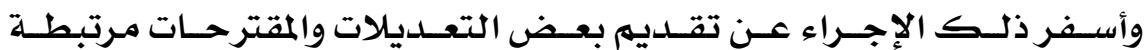

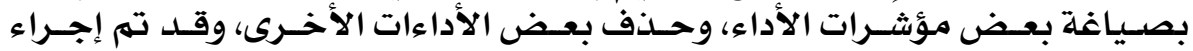

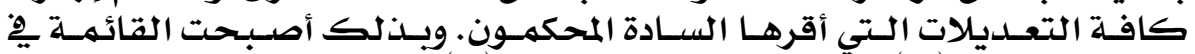

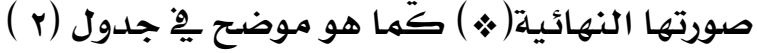

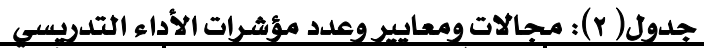

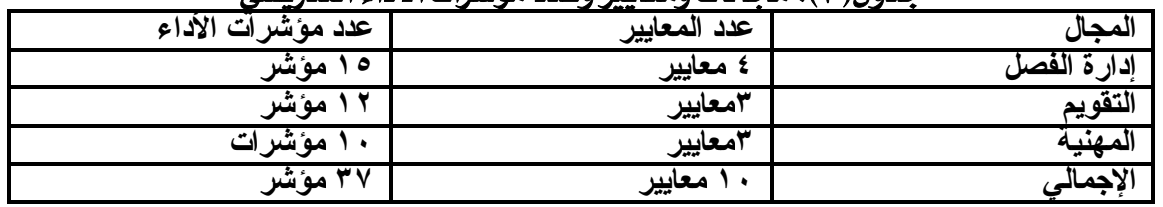

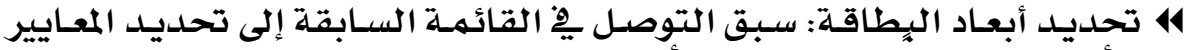

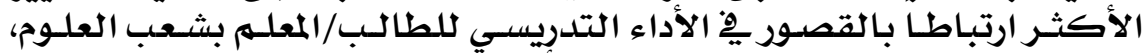

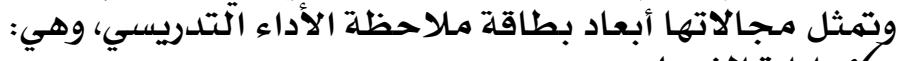

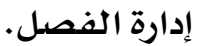

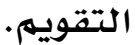
المهنية.

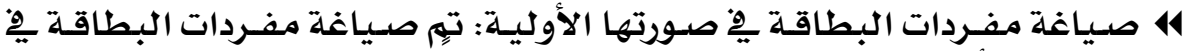

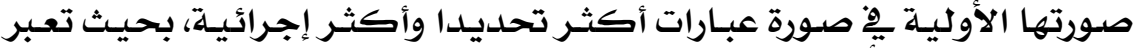

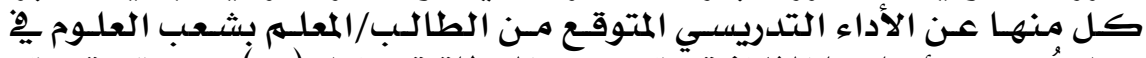

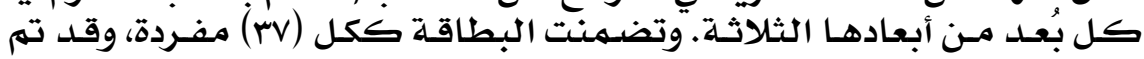

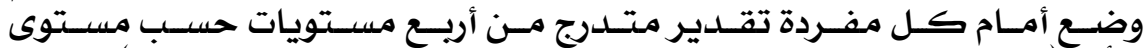

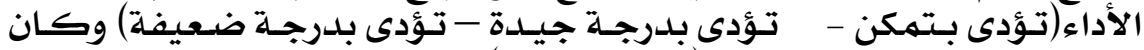

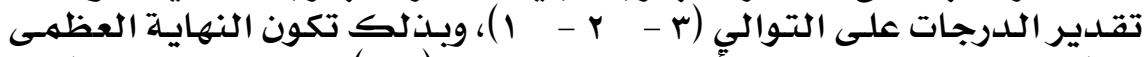

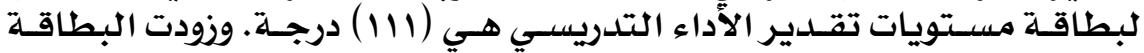

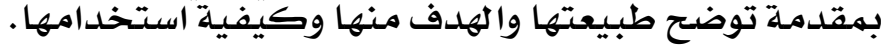




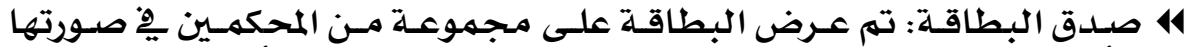

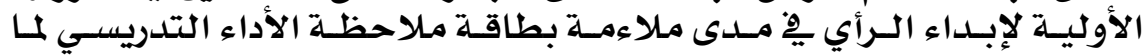

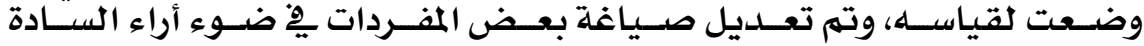

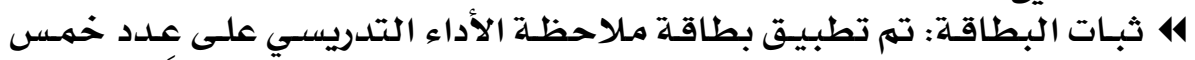

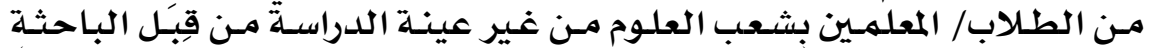

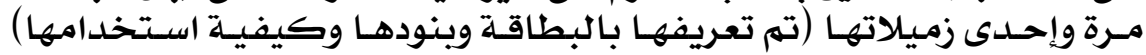

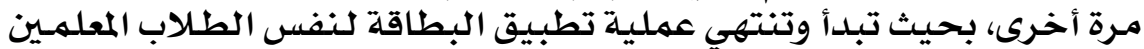

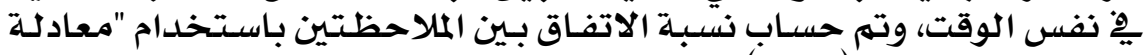

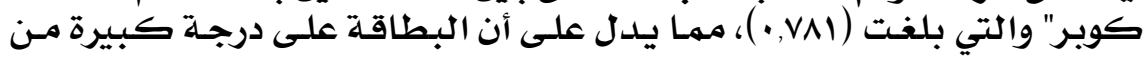

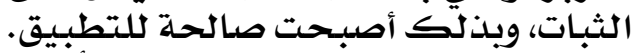

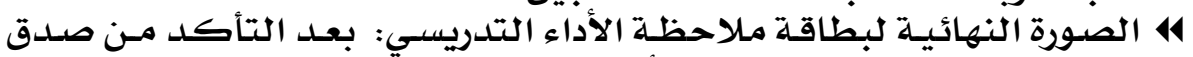

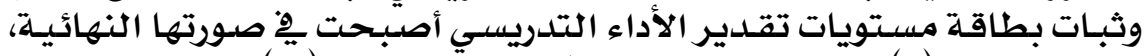

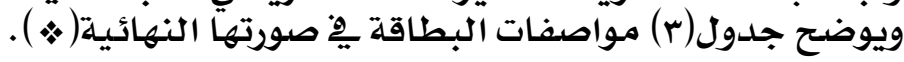

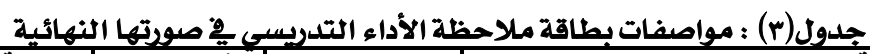

\begin{tabular}{|c|c|c|c|}
\hline الارجة الكلية & رقم المفردة & عدد المفردات & أبعاد البطاقة" \\
\hline$\leqslant 0$ & $10-1$ & 10 & إدارة الفصل \\
\hline 4 & $r V_{-} 19$ & ir & التقويم \\
\hline r. & $r V_{-} r \Lambda$ & 1. & المهنية \\
\hline 111 & & $r v$ & المجموع \\
\hline
\end{tabular}

هقياس هستوى التفكير التأهلي :

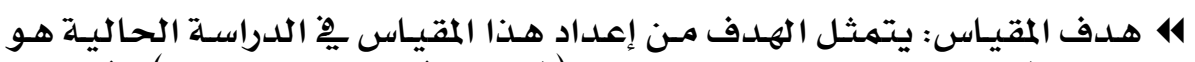

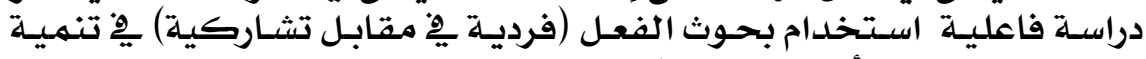

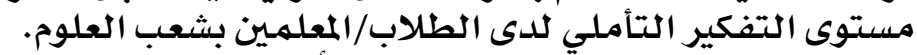

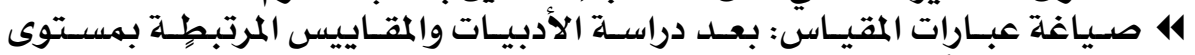

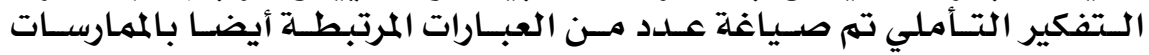

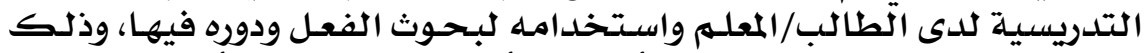

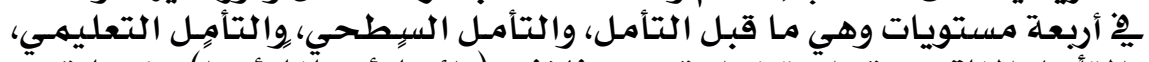

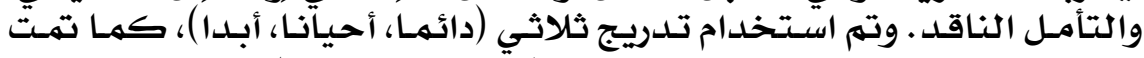

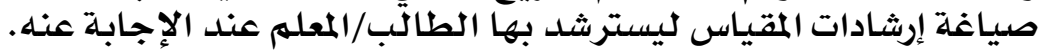

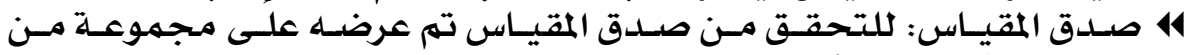

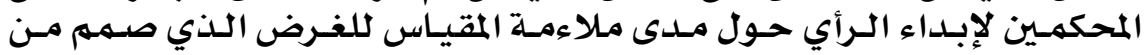

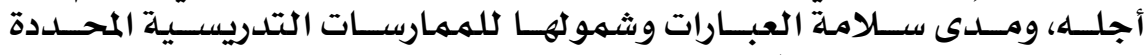

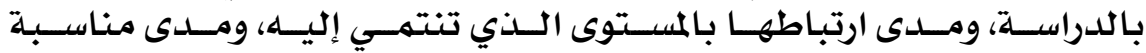

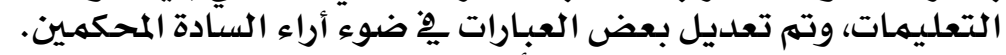

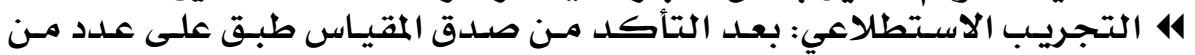

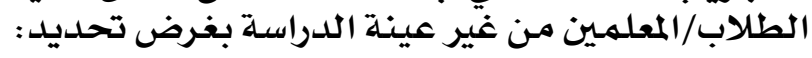




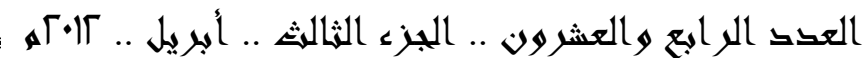

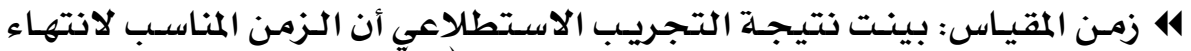

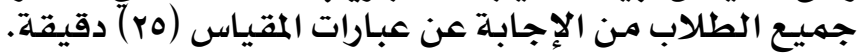

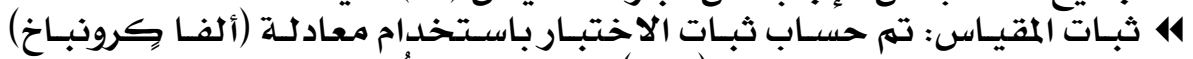

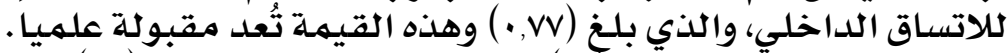

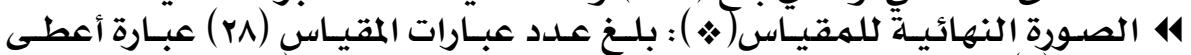

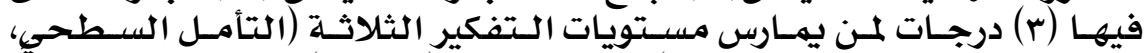

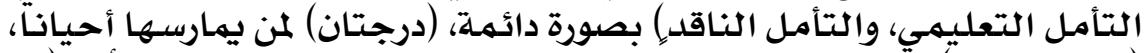

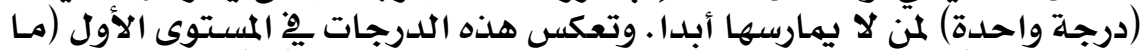

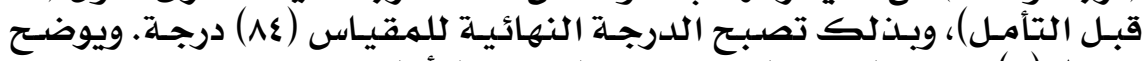

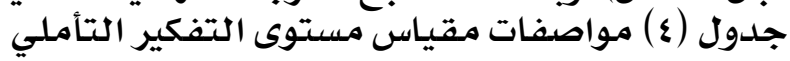
جدول(๕): مواصفات مقياس مستوى التفكير التاملي معاتي التفيري

\begin{tabular}{|c|c|c|}
\hline عدد العبارات & آرقام العبار ات & أبعاد المقياس \\
\hline $\bar{v}$ & 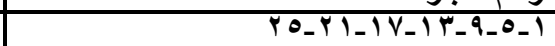 & مَا قبل التَامل \\
\hline$\overline{\mathrm{V}}$ & 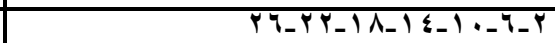 & التامل السطحي \\
\hline $\bar{v}$ & 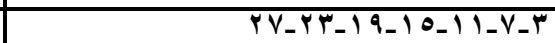 & آلتامل التعليمي \\
\hline $\bar{v}$ & Y & التامل الناقات \\
\hline TA & & المجموع الكلي \\
\hline
\end{tabular}

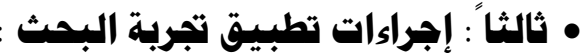

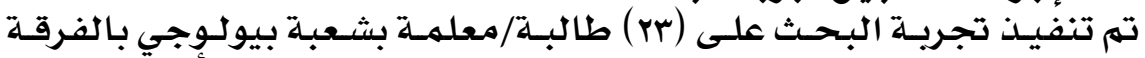

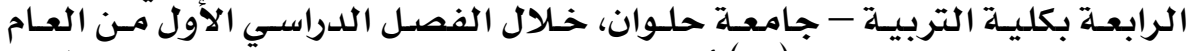

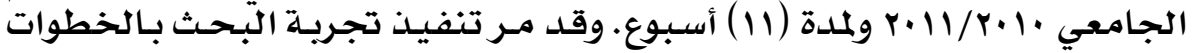
التتالية: الجاهي:

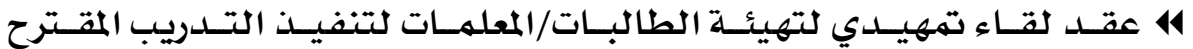

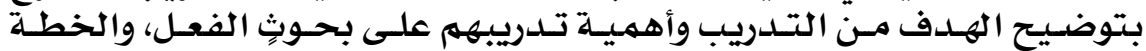

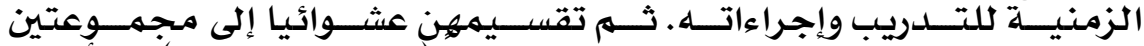

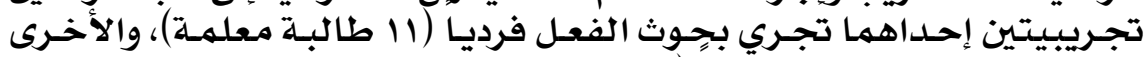

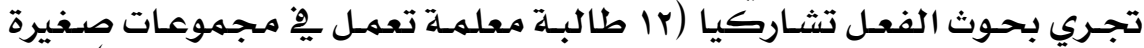

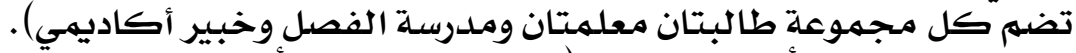

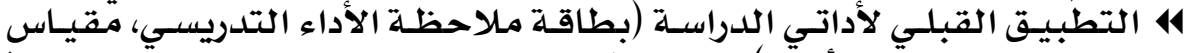

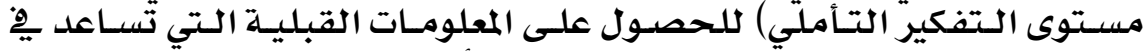

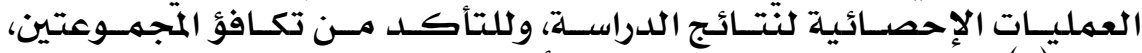

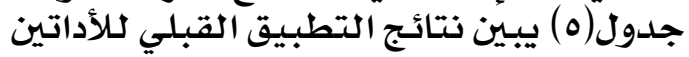

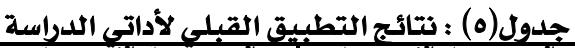

\begin{tabular}{|c|c|c|c|}
\hline وفيمستوى الدلاية المسوبه & 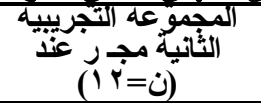 & الأجليو مجه التجريبية & أداتا الدر اسة \\
\hline " غير داله & $1 \cdots, 0$ & 1199,0 & ألتشريسهي ملاحظه الاداء \\
\hline غير داله V V & TRY & 91 & التقكيَاسل التأملي مستوى \\
\hline
\end{tabular}

(ه)ملحق (ع) مقياس مستوى التفكير التاملي 


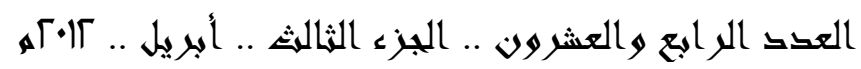

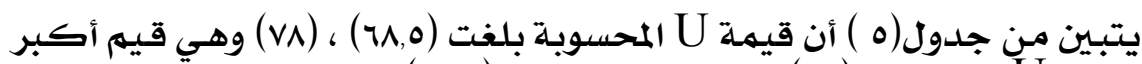

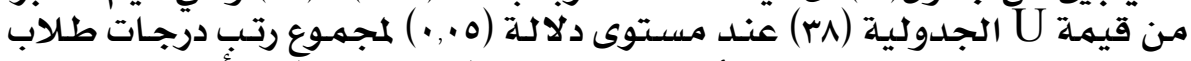

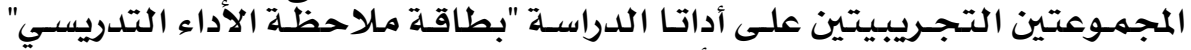

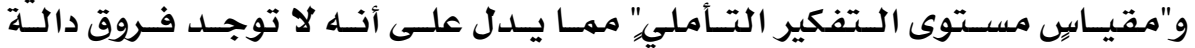

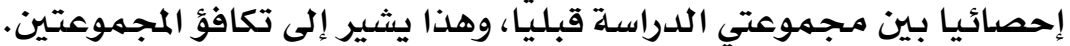

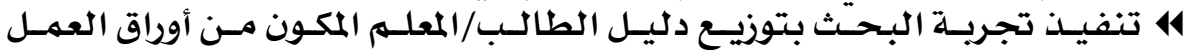

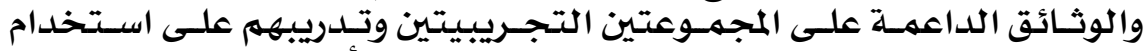

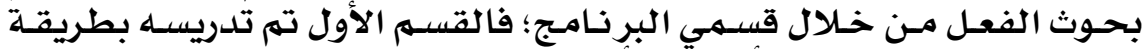

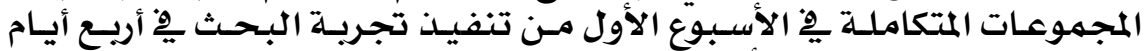

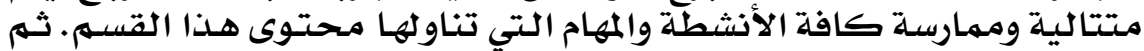

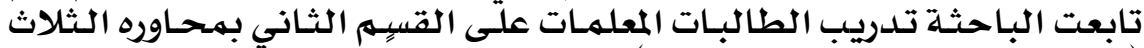

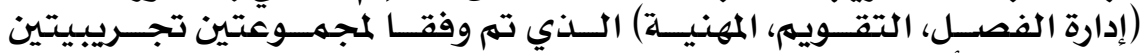

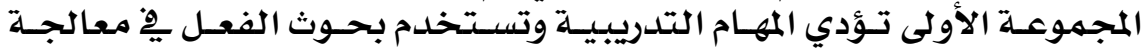

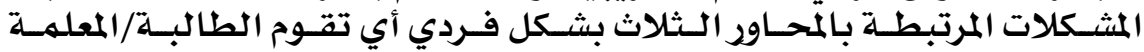

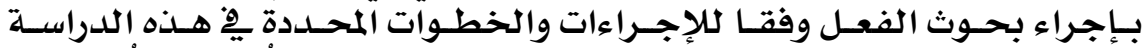

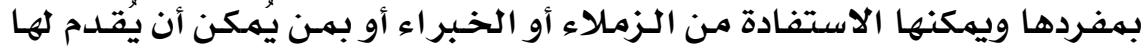

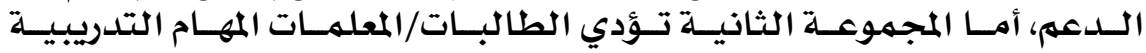

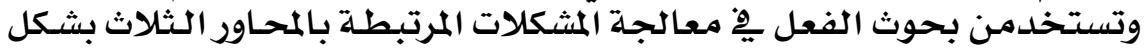

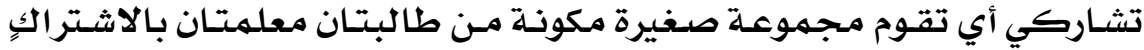

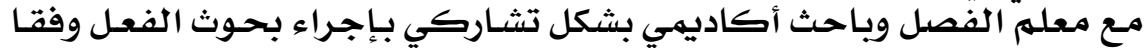

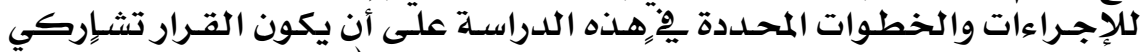

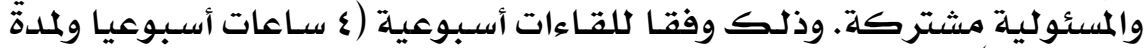

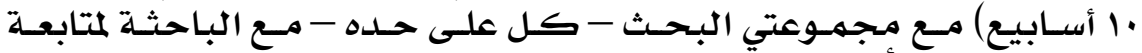

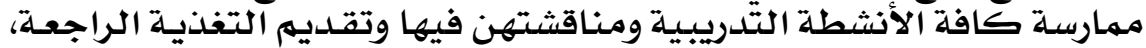

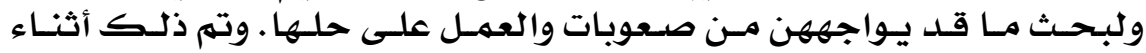

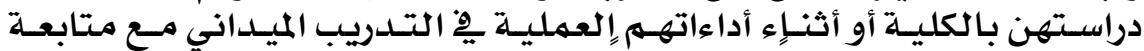

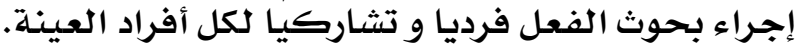

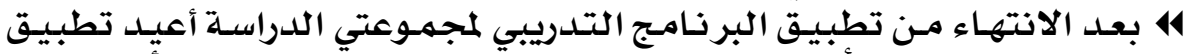

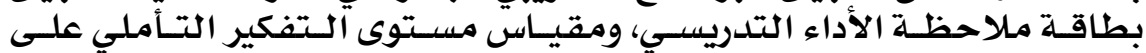

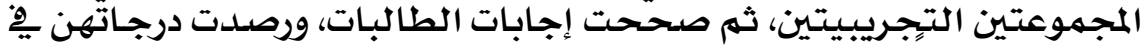

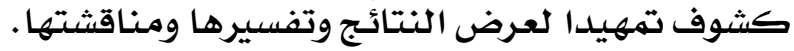

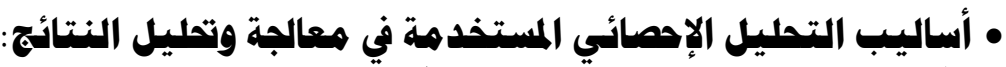

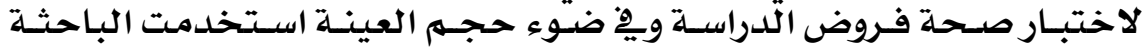
أساليب التحليل الإحسائي التحوفي التالية:

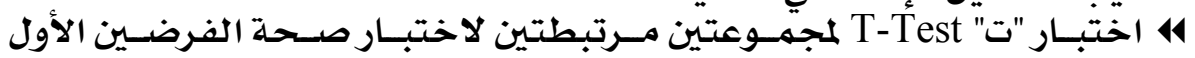

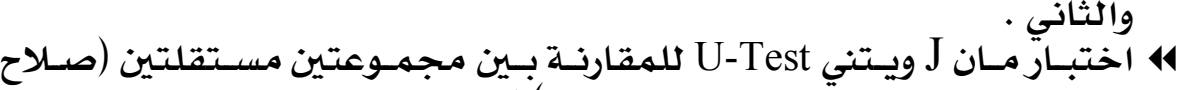

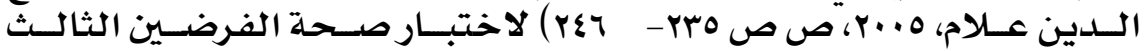

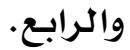
14 معامل ارتباط بيرسون لاختبار صحة الفرض الخامس. 


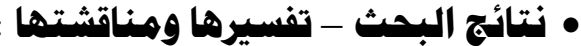

يتم عرض نتائج هذه الدراسـة ومناقشتها وفقاً لتساؤلاتها، وذلك على على النحو

\section{• النتائج المتعملقة بالسؤال الأول}

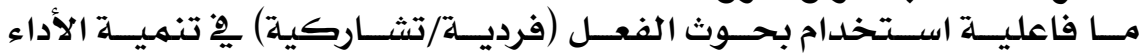

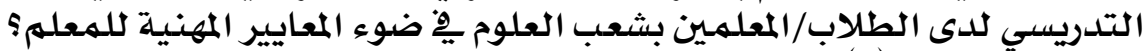

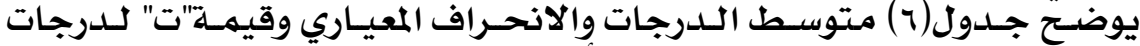

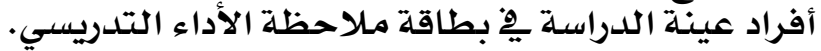

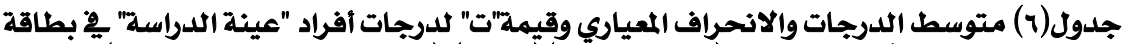

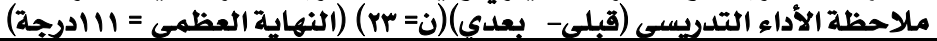

\begin{tabular}{|c|c|c|c|c|c|c|}
\hline مستوى & "الجدولية & "المحسوبة "ت" & الالمعيار افي & المتوسط & العدد & التطبيق \\
\hline \multirow[t]{2}{*}{$\cdot, \cdot 0$} & \multirow[t]{2}{*}{$r, \cdot V \varepsilon$} & \multirow[t]{2}{*}{$10, r_{0}$} & 11,01 & $0 \leq, \wedge V$ & $r r$ & القبلي \\
\hline & & & $\Lambda, \leqslant \mu$ & $1 \cdot r, r r$ & $r r$ & البعدي \\
\hline
\end{tabular}

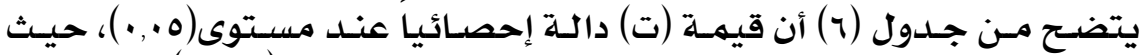

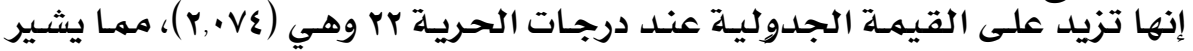

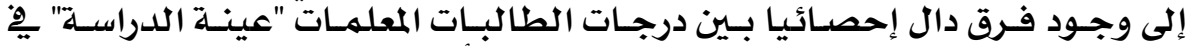

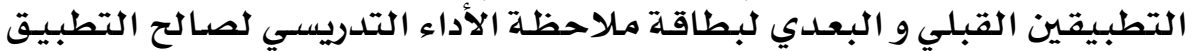

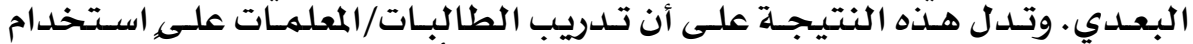

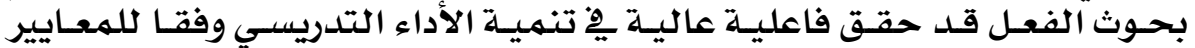

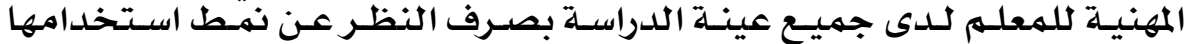

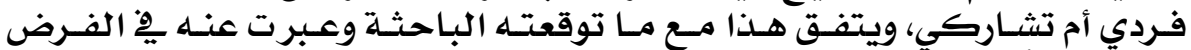

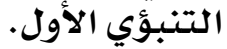

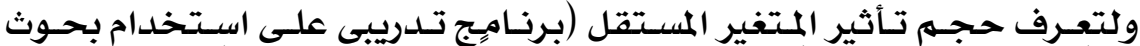

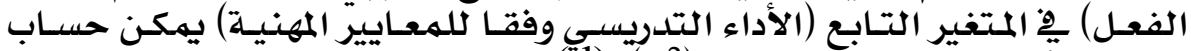

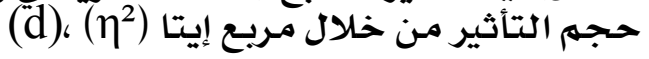

\begin{tabular}{|c|c|c|c|c|}
\hline حجم التأثيّري & قيمة "d" & $\eta^{2}$ & المتغير التابع & المتغير المستقل \\
\hline كبيز & \&, & $\cdot, 91$ & الأداء التدريسي & الفعل المدام بحوث \\
\hline
\end{tabular}

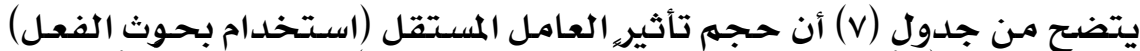

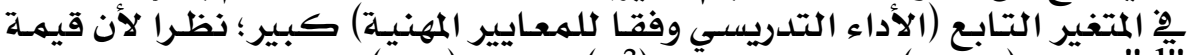

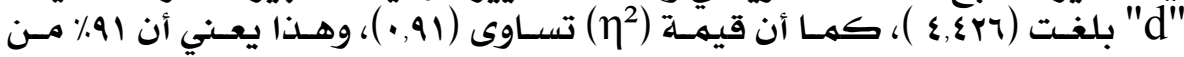

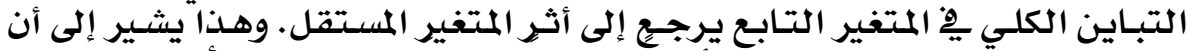

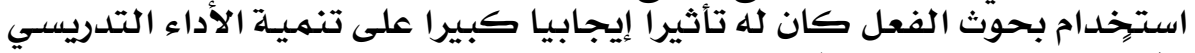

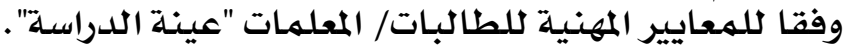




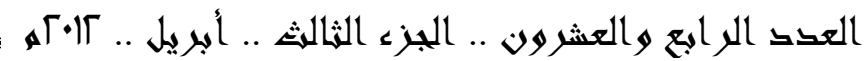

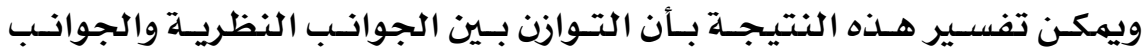

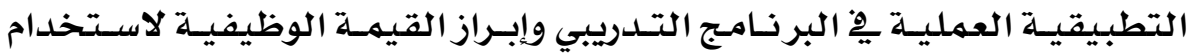

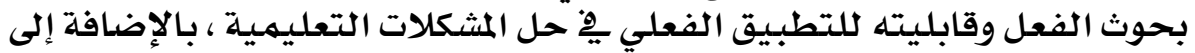

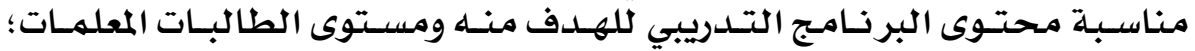

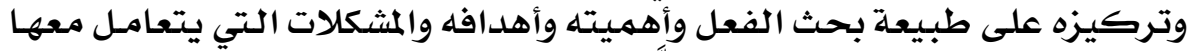

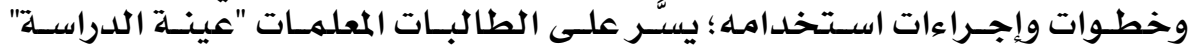

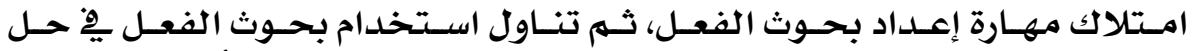

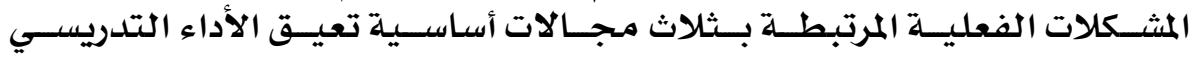

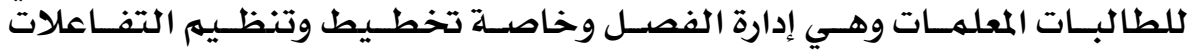

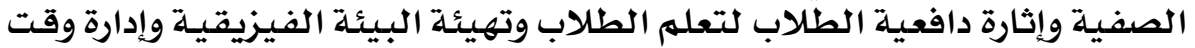

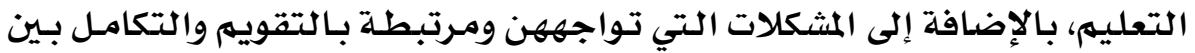

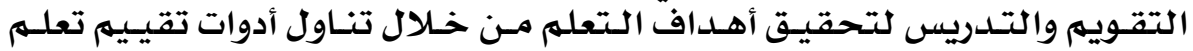

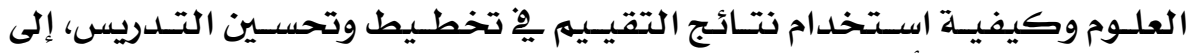

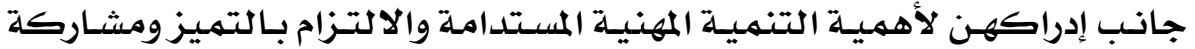

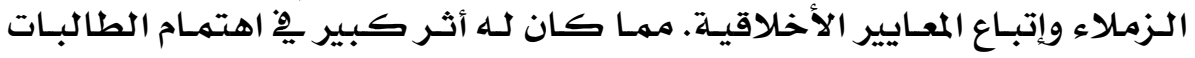

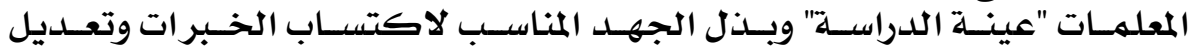

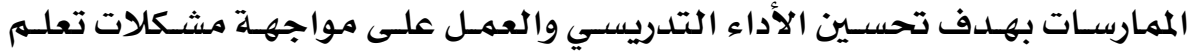
طلابهم.

ومـن التفسـيرات الممكنـة لهـذه النتيـجـة أن مشـكلة بحثث الفعل كانت مشـكلة

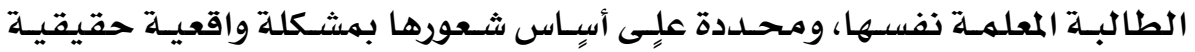

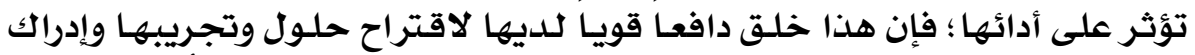

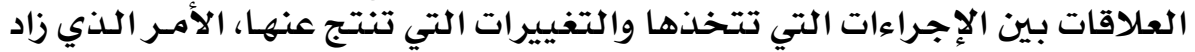

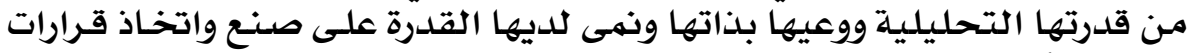

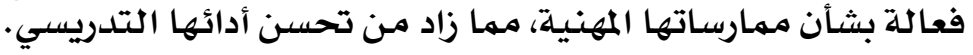

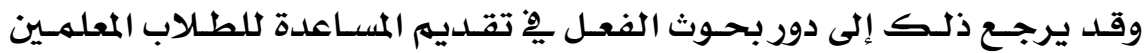

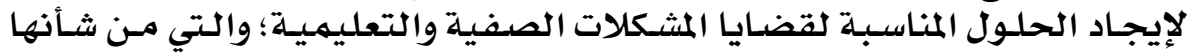

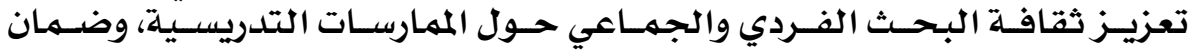

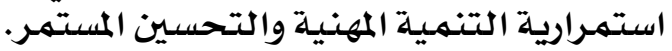

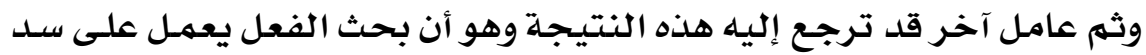

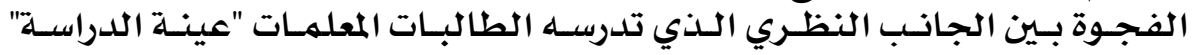

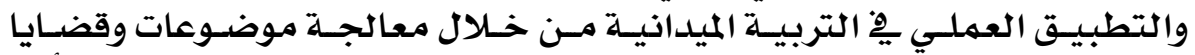

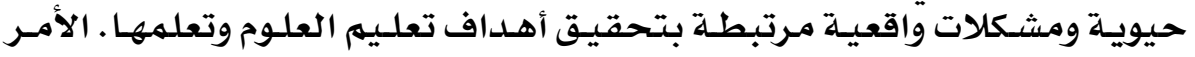

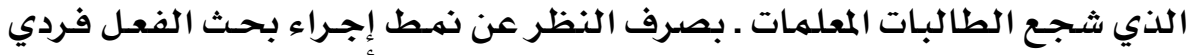

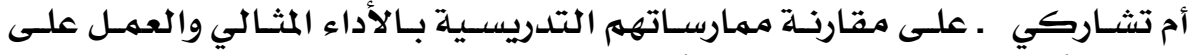

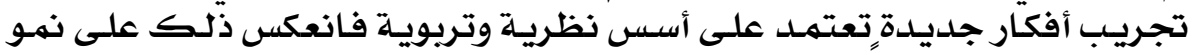

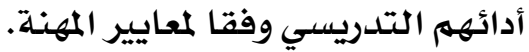




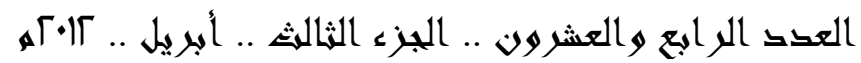

وتتفق هـذه النتيجــة مـع دراسـة (Kirkwood, M. \& Christie, D.,2006)

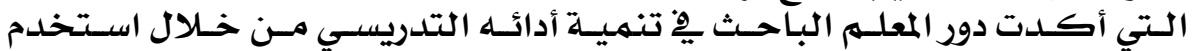

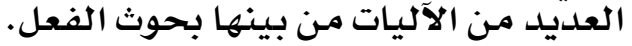

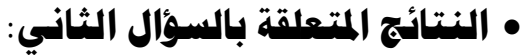

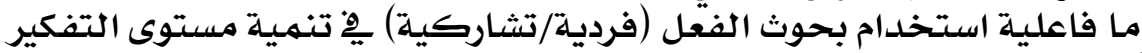

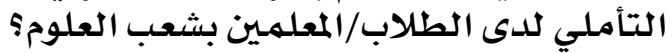

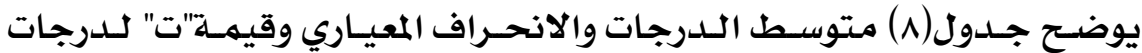

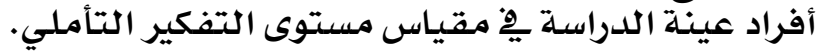

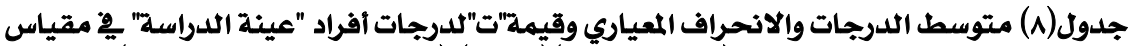

\begin{tabular}{|c|c|c|c|c|c|c|}
\hline مستوى & "ت & "ت" & الأحر اف & المتو سط & العدد & $x_{n}$ \\
\hline الدالة & الجدولية & التحسوبة & المعياري & & & \\
\hline دالة & $r, \cdot V \varepsilon$ & $T \leqslant, \leqslant r$ & $\mathrm{~V}, \wedge 1$ & $\leqslant r, \leqslant v$ & $r r$ & القبلي \\
\hline إحصائياً & & & 7,199 & $V \leqslant, 7 r$ & $r r$ & البعدي \\
\hline
\end{tabular}

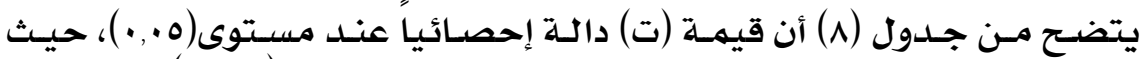

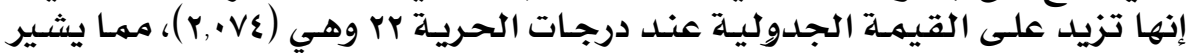

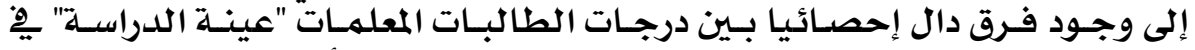

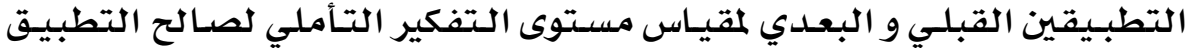

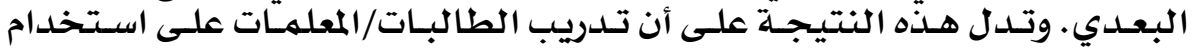

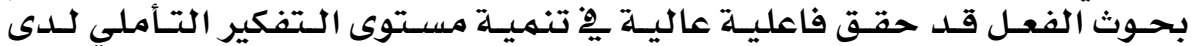

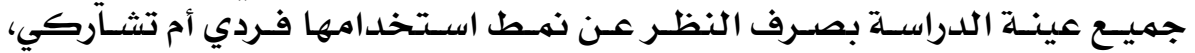

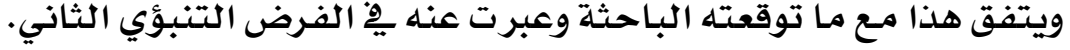

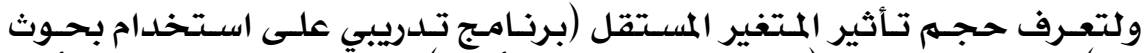

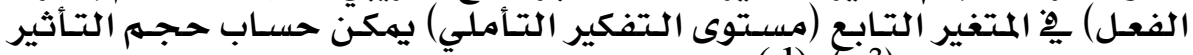

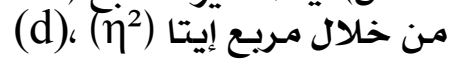

\begin{tabular}{|c|c|c|c|c|}
\hline حجم التأثيّر & قيمة "d" & $\eta^{2}$ & المتغير التّابع & المتغير المستقل \\
\hline كبيز & $r, 977$ & $\cdot, 9 \cdot \varepsilon$ & التأملتئى $\quad$ التفكير & الفعل امت \\
\hline
\end{tabular}

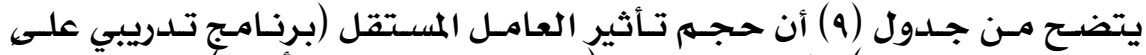

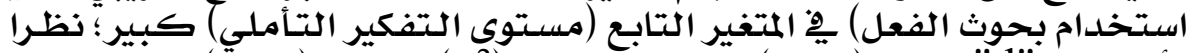

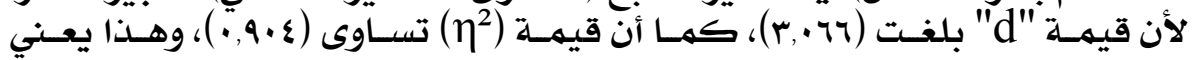

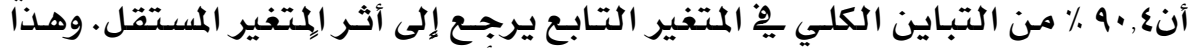

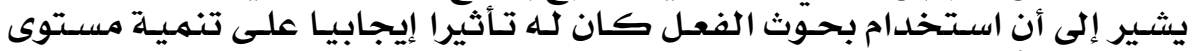

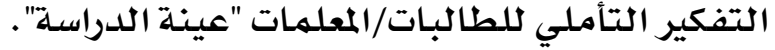

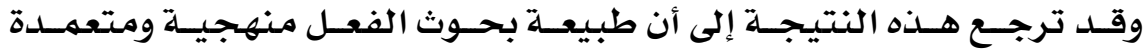

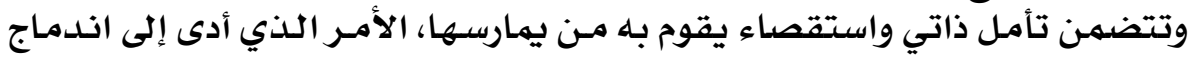

\section{$Y \varepsilon \varepsilon$}




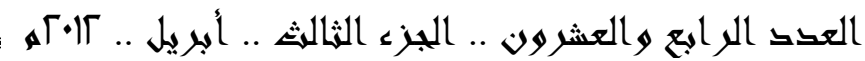

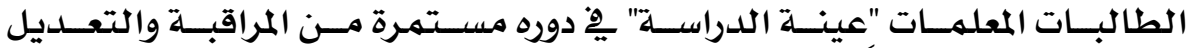

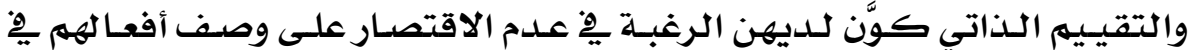

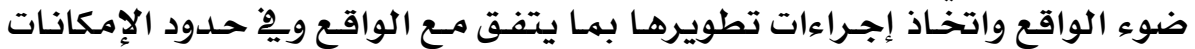

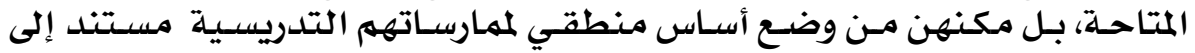

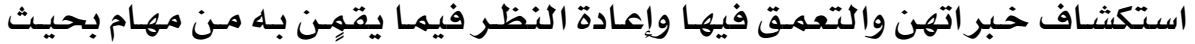

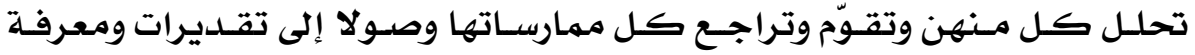

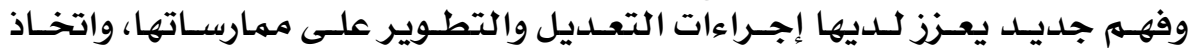

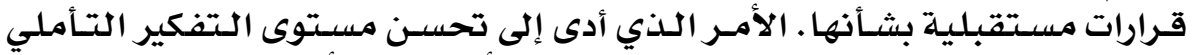

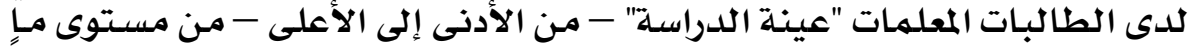

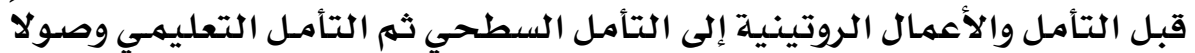

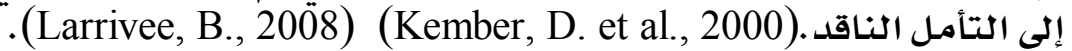

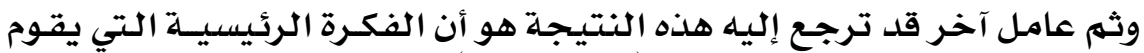

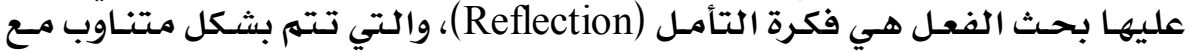

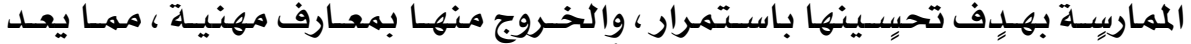

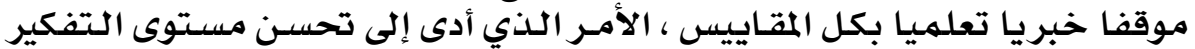

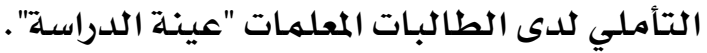

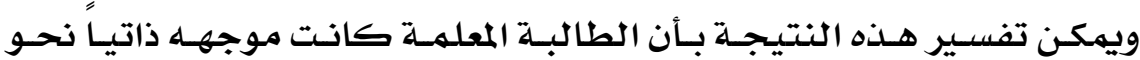

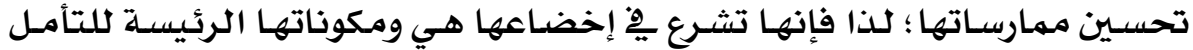

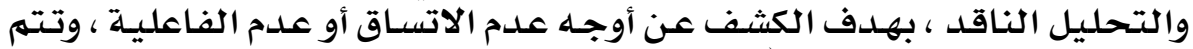

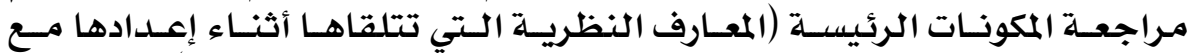

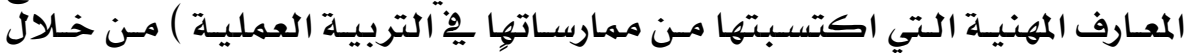

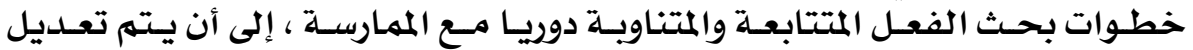

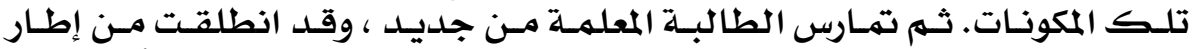

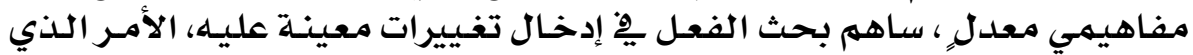

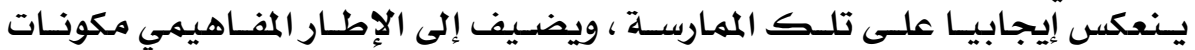

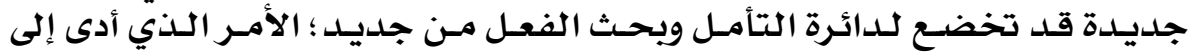

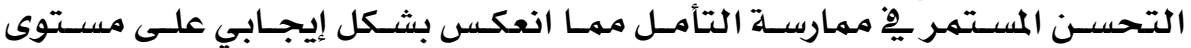

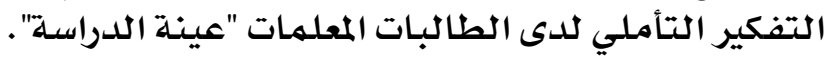

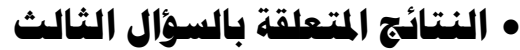

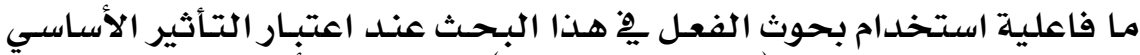

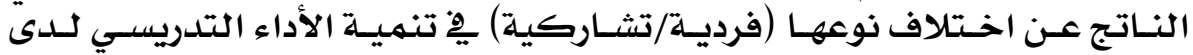

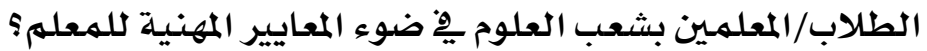

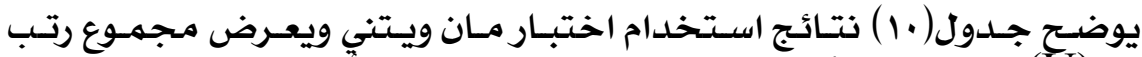

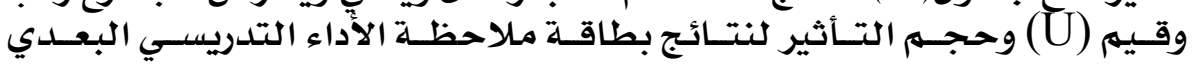
لطالبات مجموعتي الدراسة النير. 


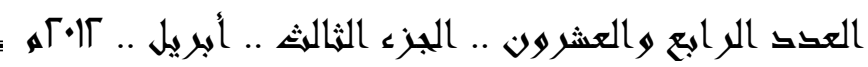

جدول( . ) مجموع رتب وقيم (U) وحجم التأثير لنتائج بطاقة ملاحظة الأداء التدريسي البعدي

\begin{tabular}{|c|c|c|c|c|c|c|}
\hline & & & & & & \\
\hline التأتيُم & $\begin{array}{l}\text { فيمة } \\
\text { (r) }\end{array}$ & ألجدوليةّة & الثيمسوبة (Uي) & (تثجريبية & (فرذدي) & الأداة \\
\hline كبيز & $\cdot, \wedge \vee q$ & $r \wedge$ & Tr & $i v \wedge$ & $O r$ & الأباء التذريسئي ملاحظة \\
\hline
\end{tabular}

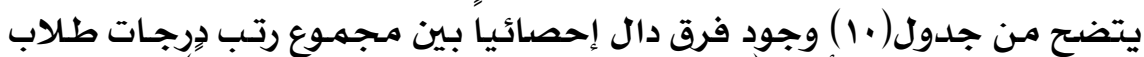

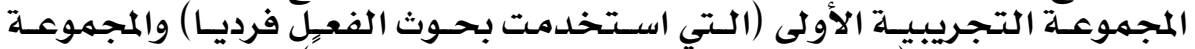

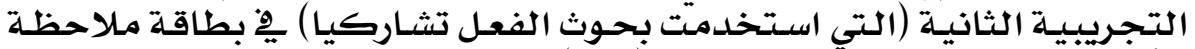

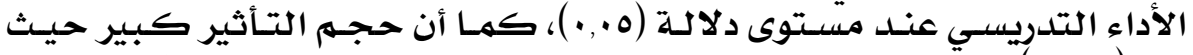

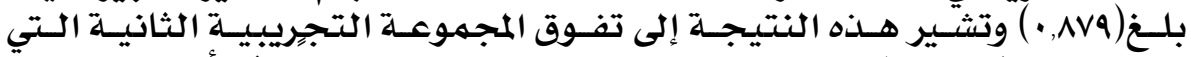

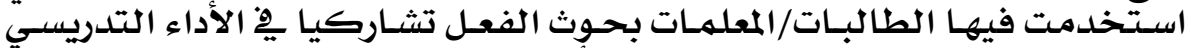

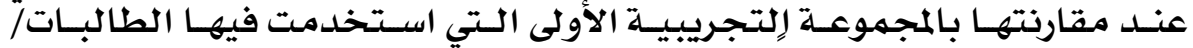

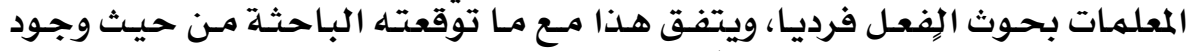

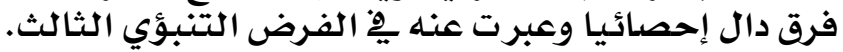

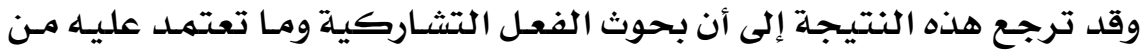

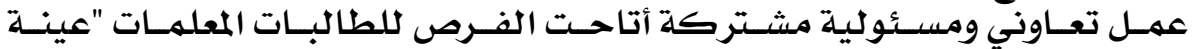

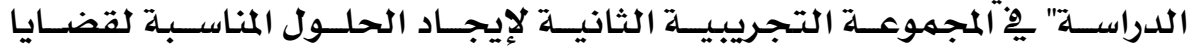

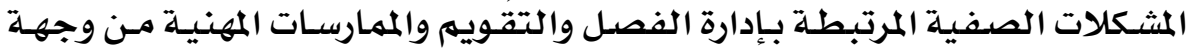

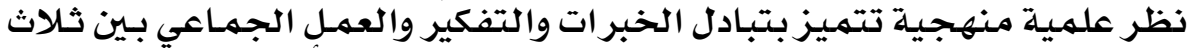

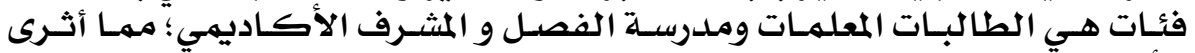

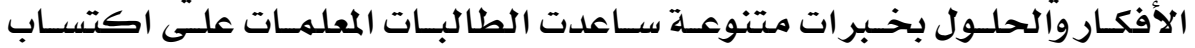

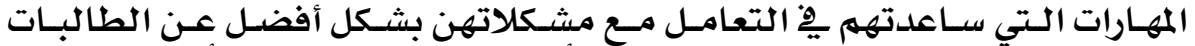

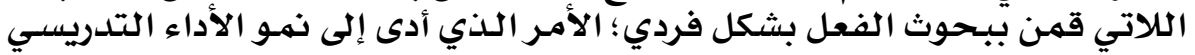

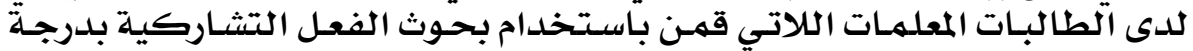

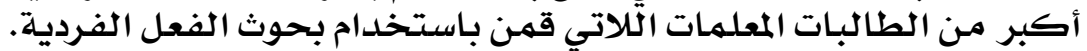

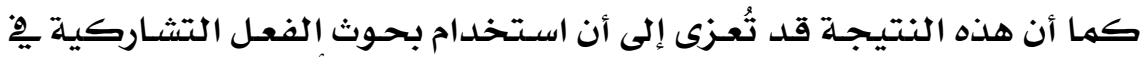

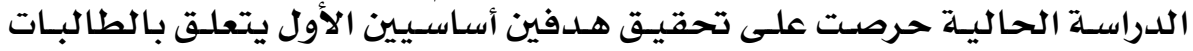

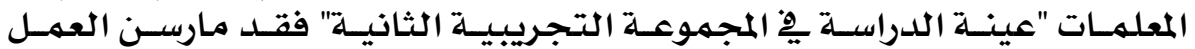

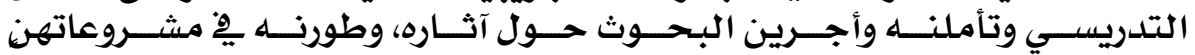

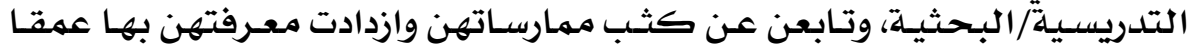

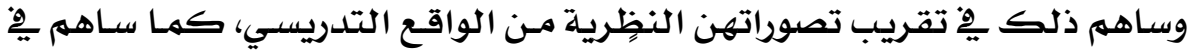

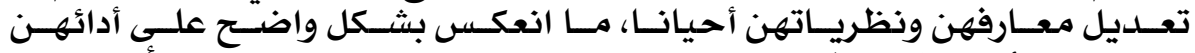

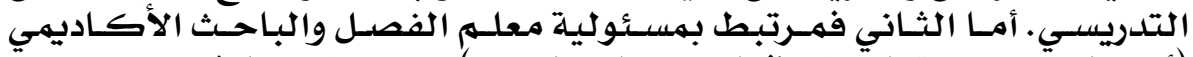

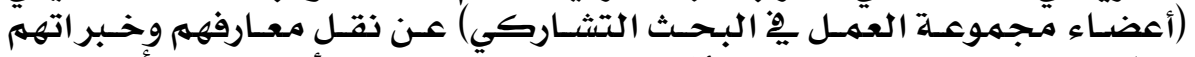

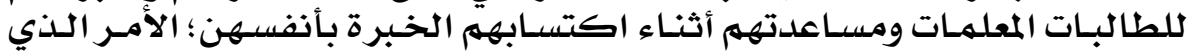

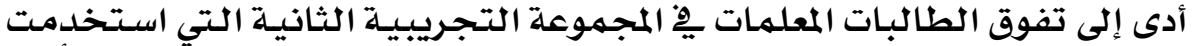

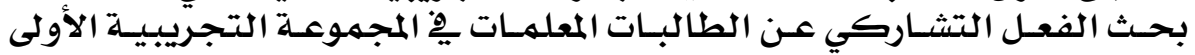
التي استخدمت بحث التهارسي الفُعل الفردي.

\section{$Y \varepsilon 7$}




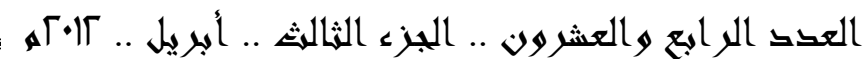

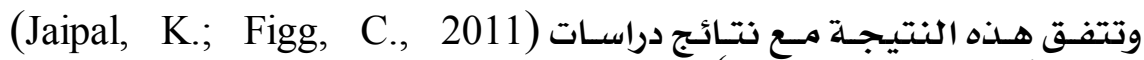

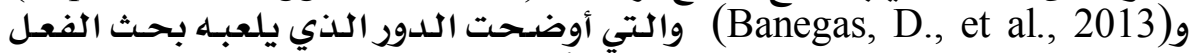

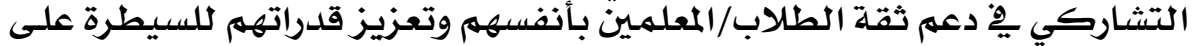

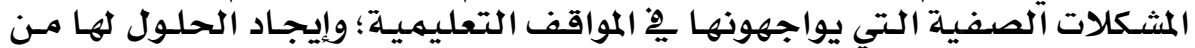

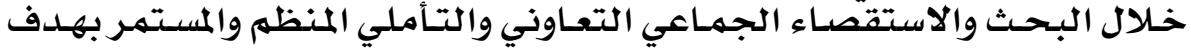

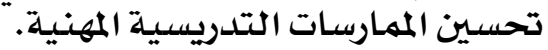

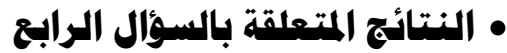

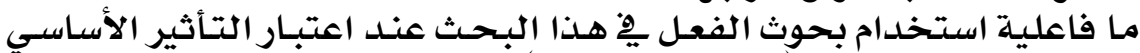

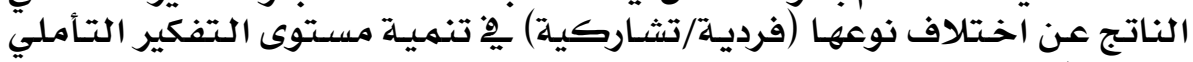

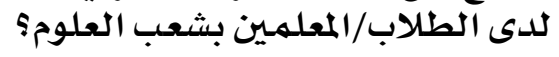

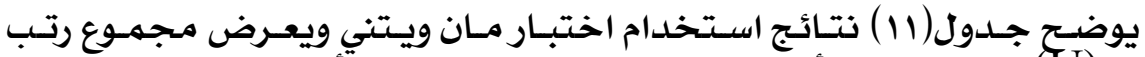

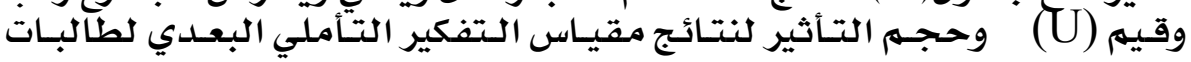
مجمهوعتي الدراسـة. جدول(11) مجموع رتب وقيم (U) وحجم التأثير لنتائج مقياس التفكير التاملي البعدي لطالبات

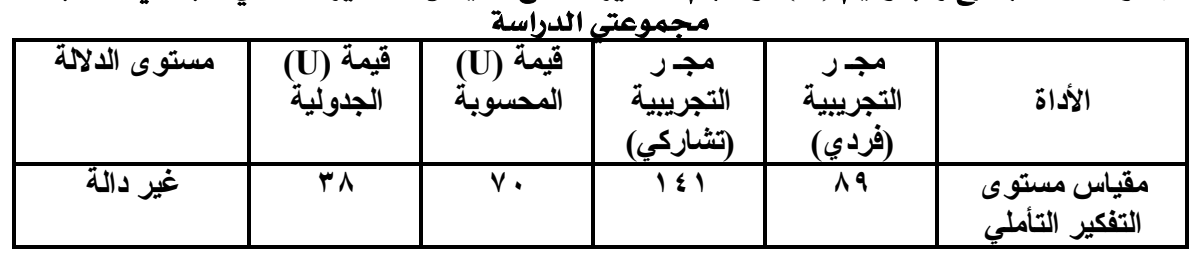

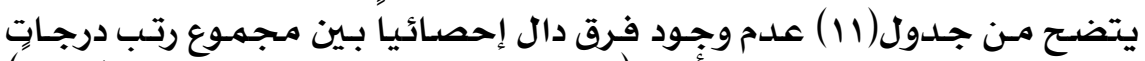

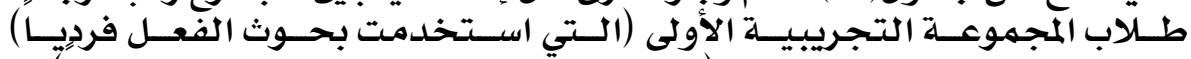

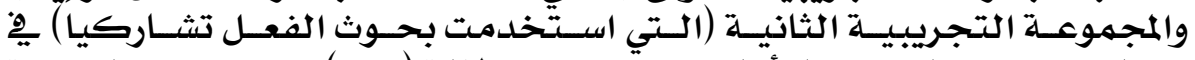

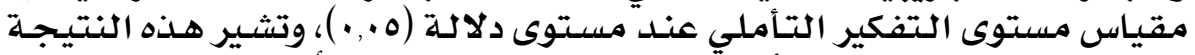

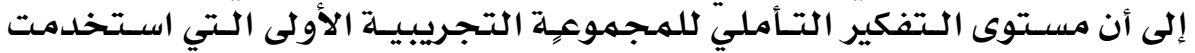

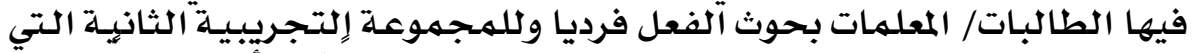

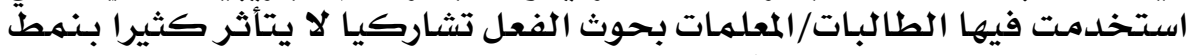

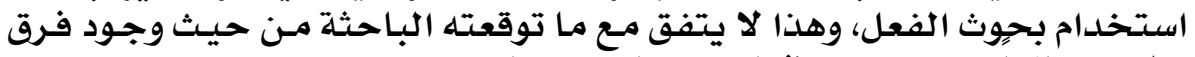

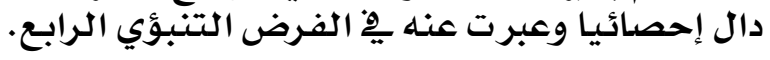

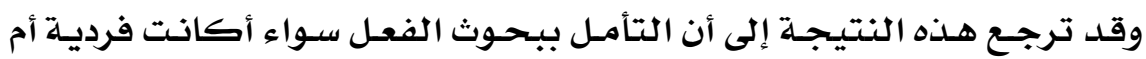

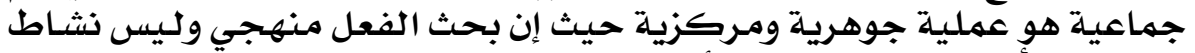

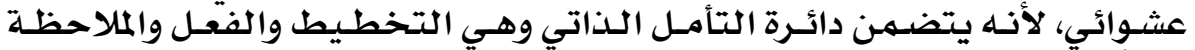

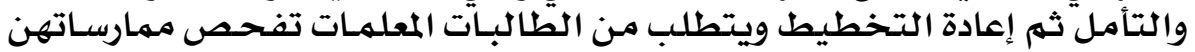

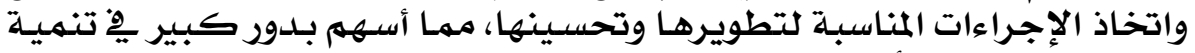

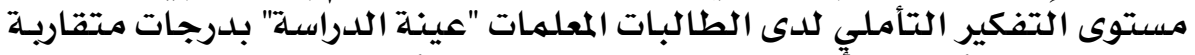

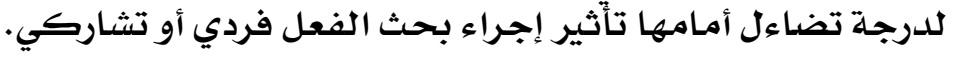

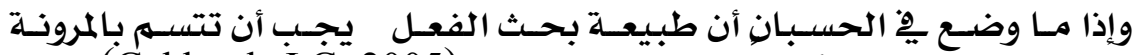

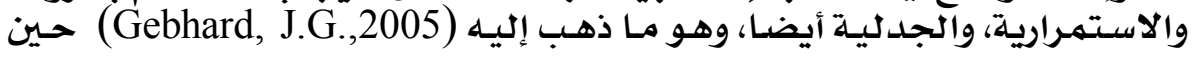

\section{$r \varepsilon V$}




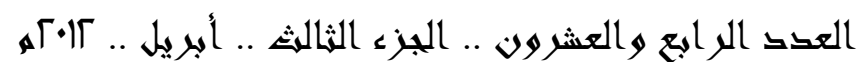

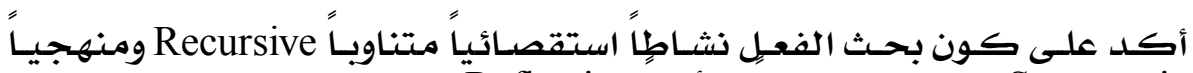

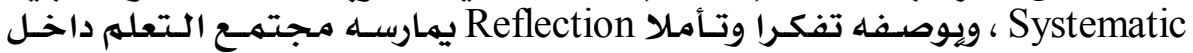

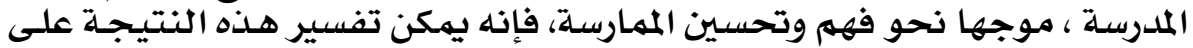

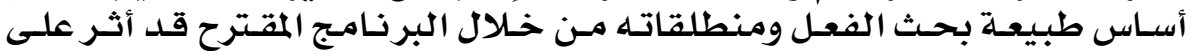

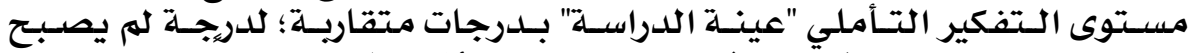

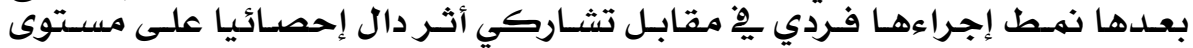
التفكير التأملي لديهن.

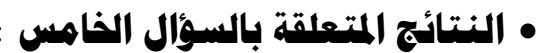

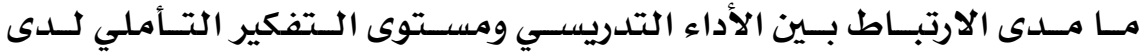

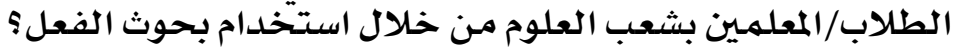

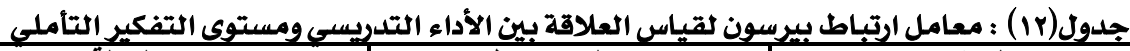

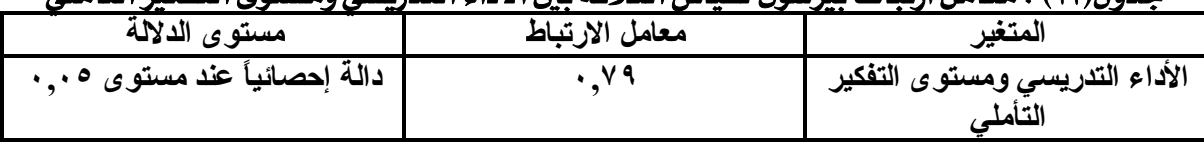

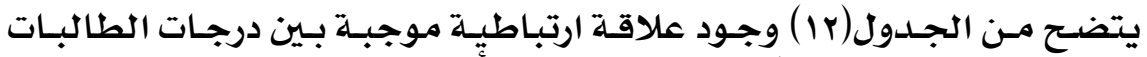

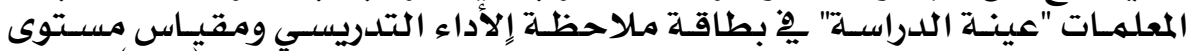

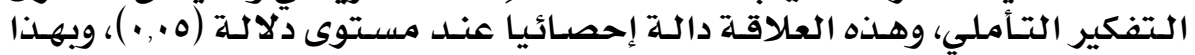

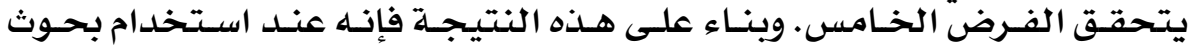

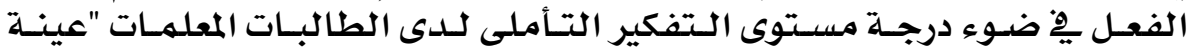

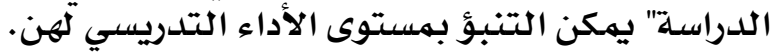

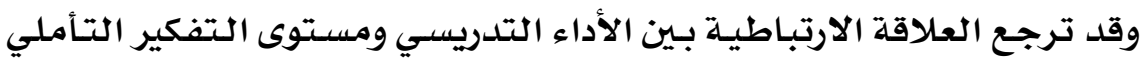

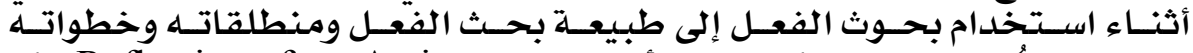

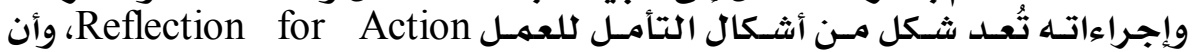

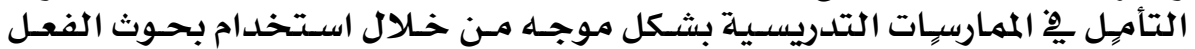

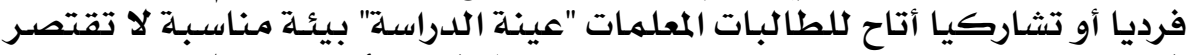

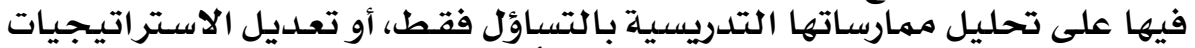

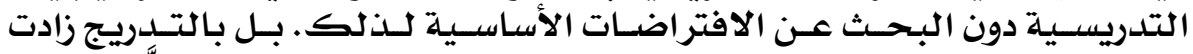

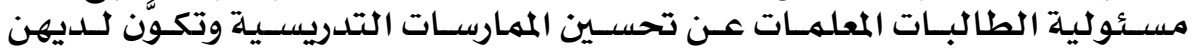

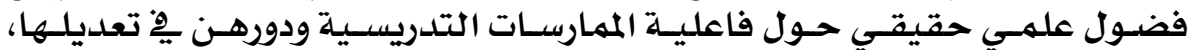

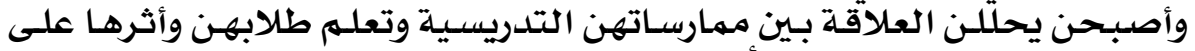

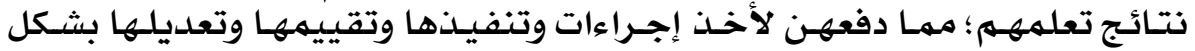

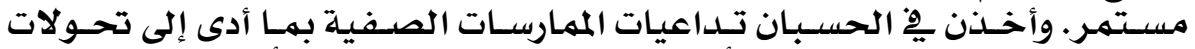

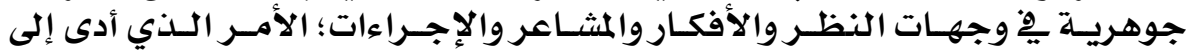

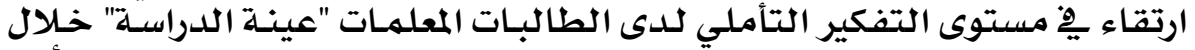

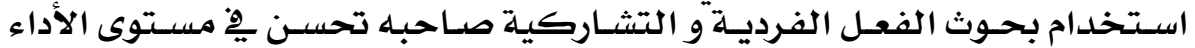
التدريسي لهن.

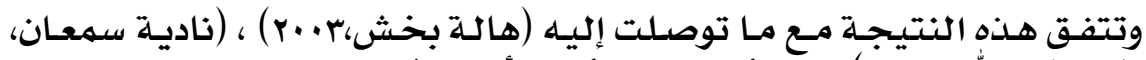

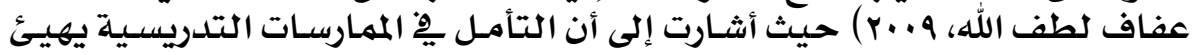




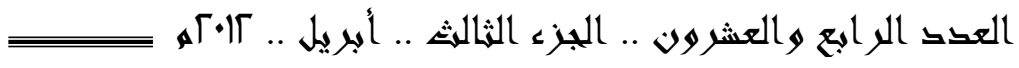

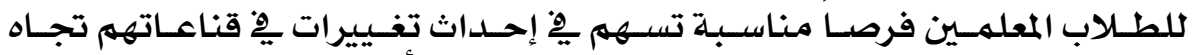

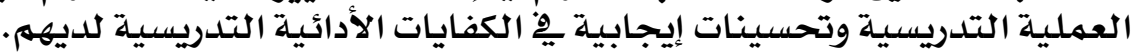

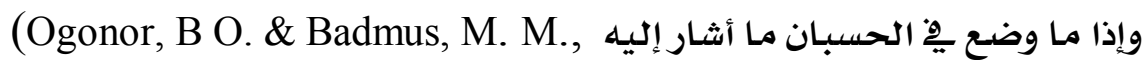

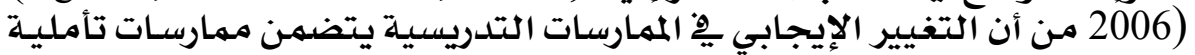

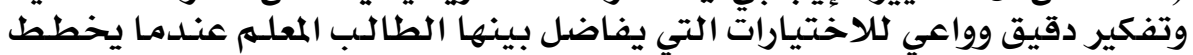

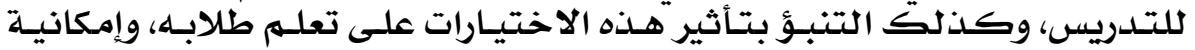

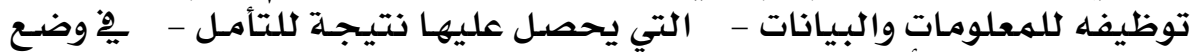

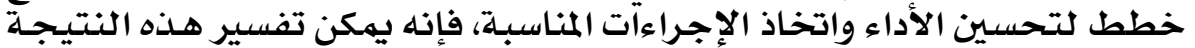

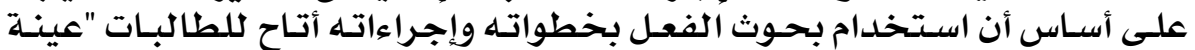

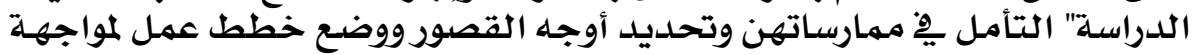

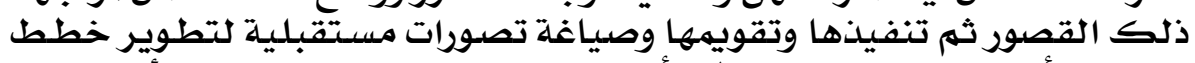

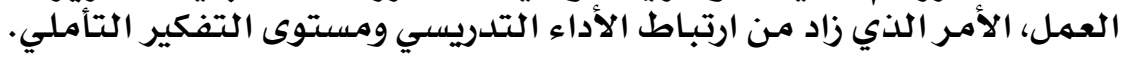

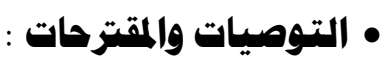

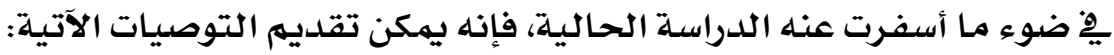

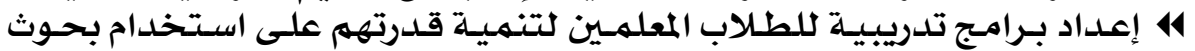

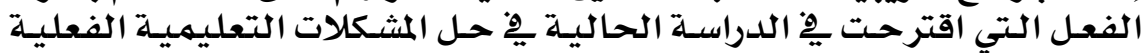

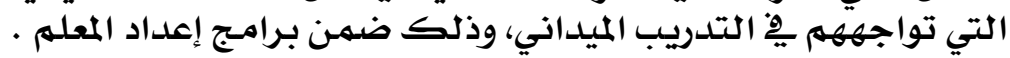

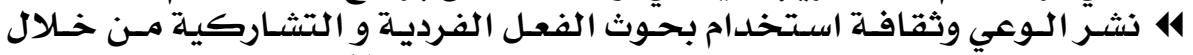

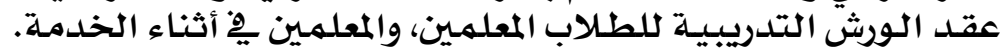

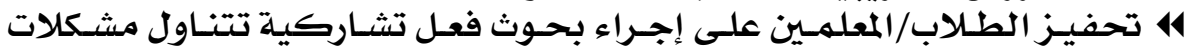

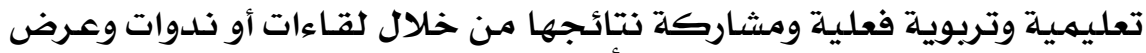

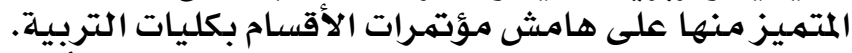

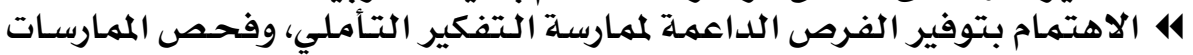

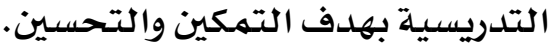

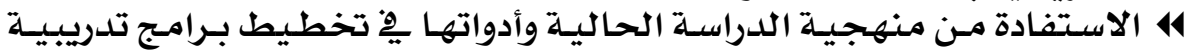

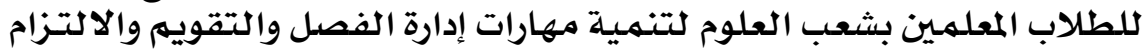

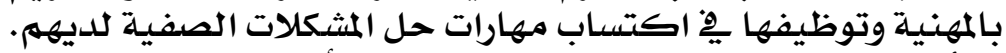

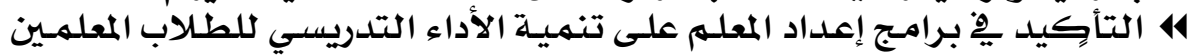

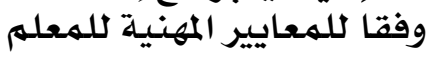

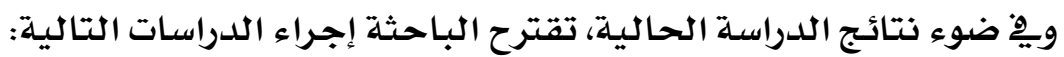

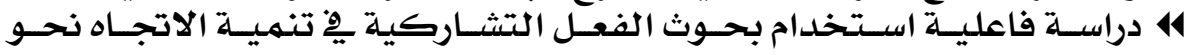
التدريس.

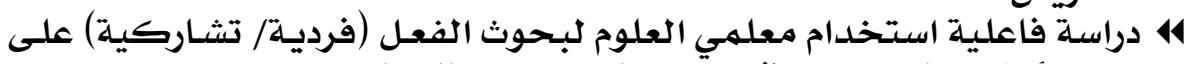

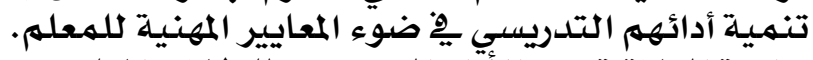

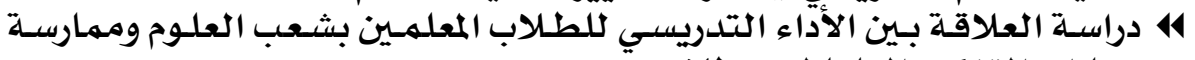

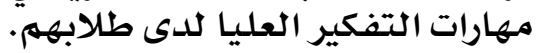

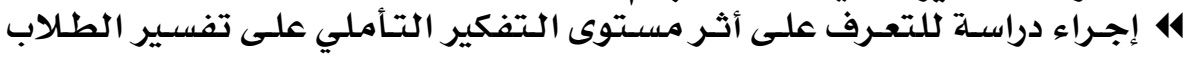

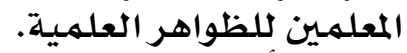

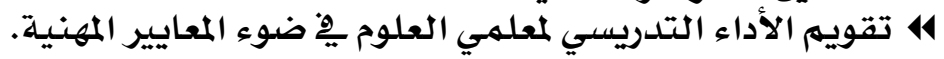




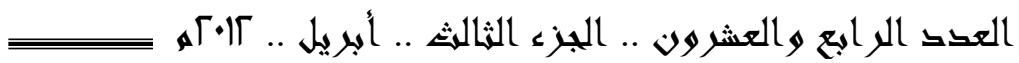

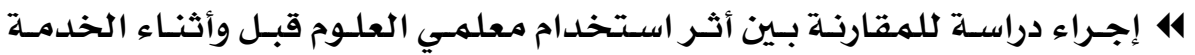

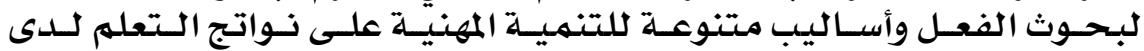

الطلاب.

•

ا. أحمد حسين اللقاني، على الجمل (r..r) : معجم المصطلحات التربوية ، القاهرة ، عالم

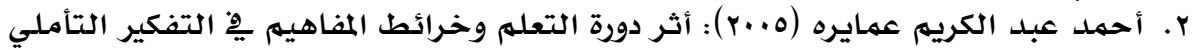

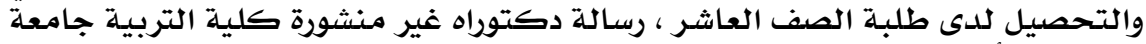

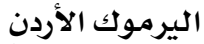

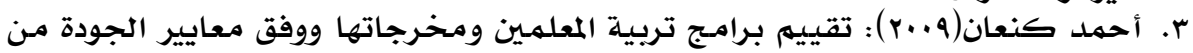

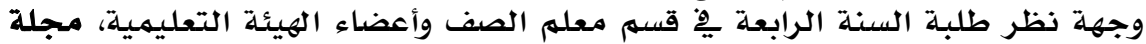

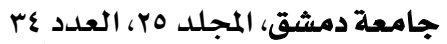

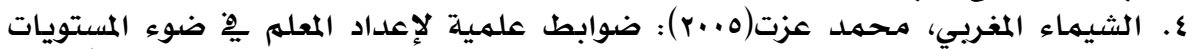

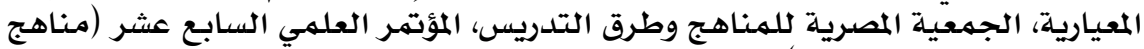

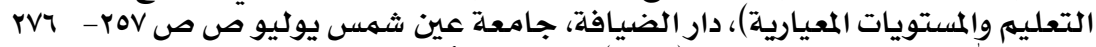

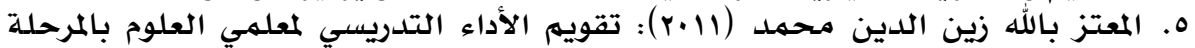

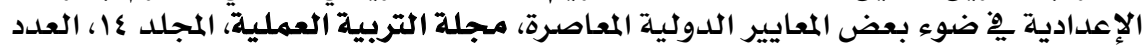

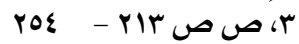

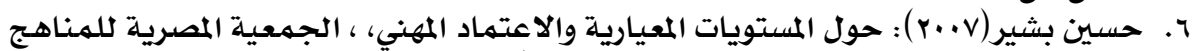

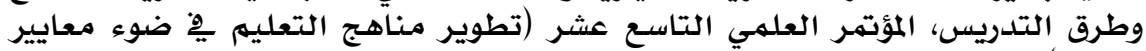

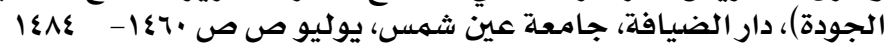

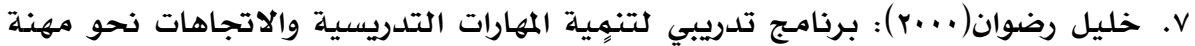

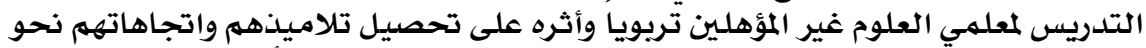

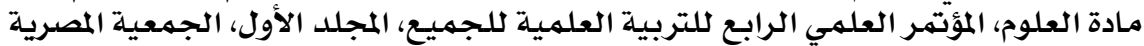

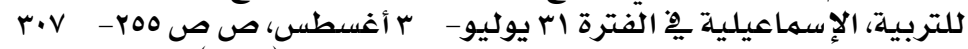

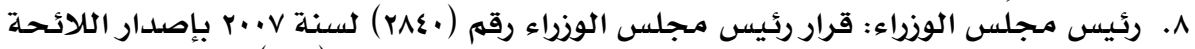

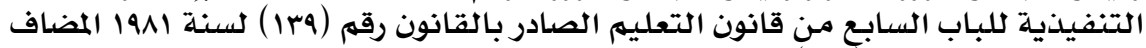

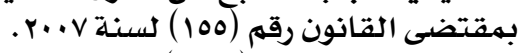

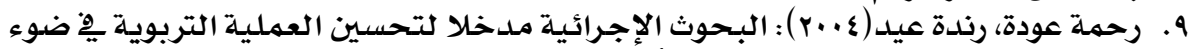

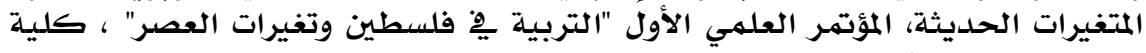

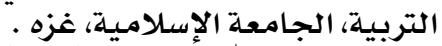

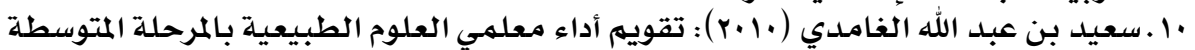

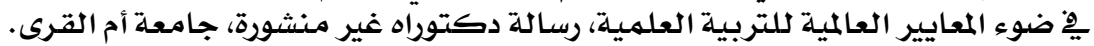

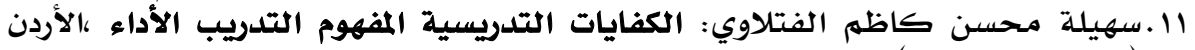

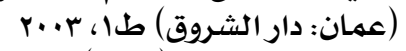

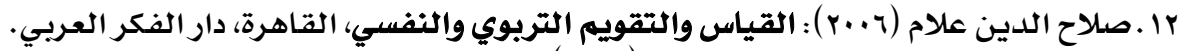

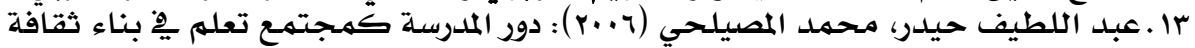

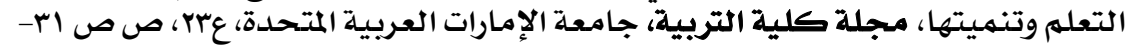

.01

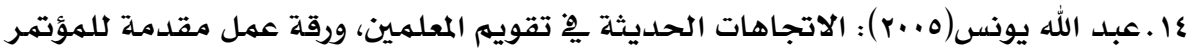

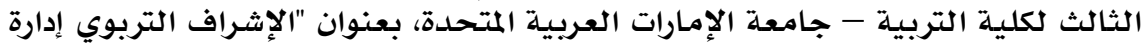
لجودة التعليه" يِّاِ الفترة 10 - 17 مارسي.

\section{Y०.}

\section{دواسات عربية في الثزبية وعام النفسي (ASEP)}




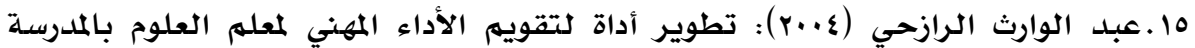

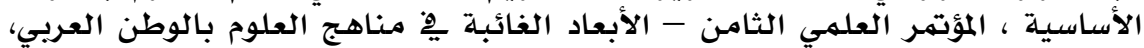

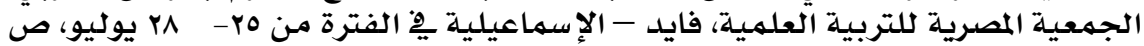

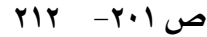

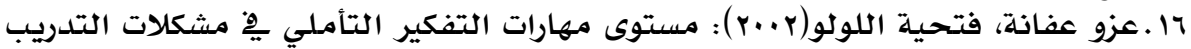

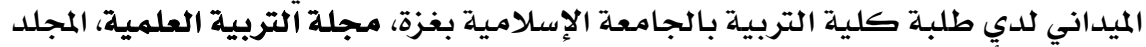

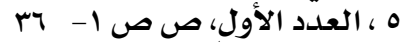

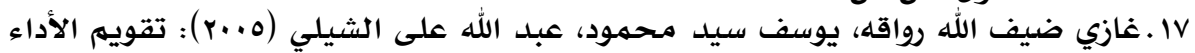

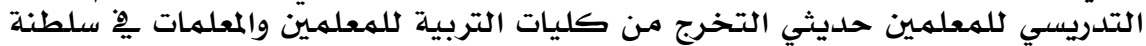

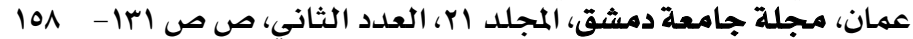

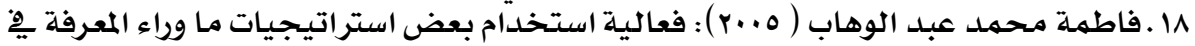

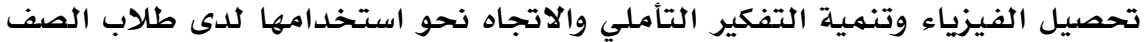

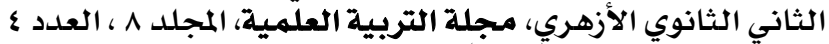

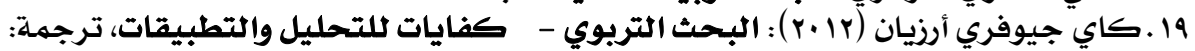

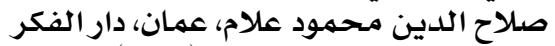

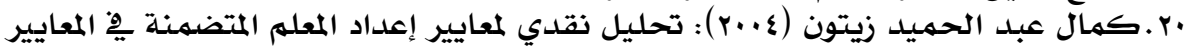

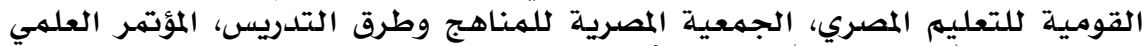

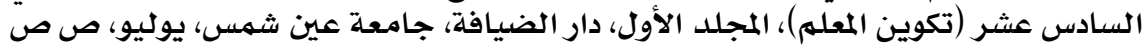
I 1 r $-11 r$

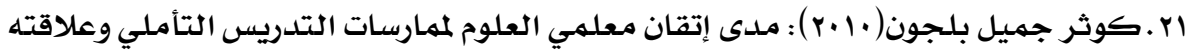

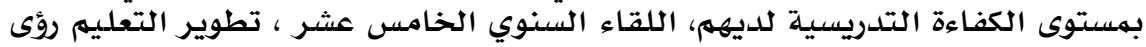

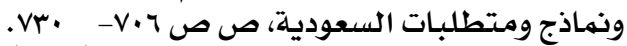

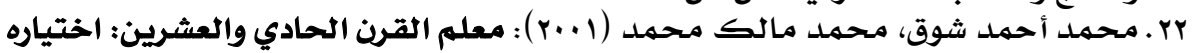

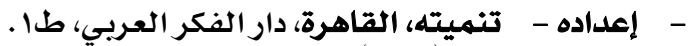

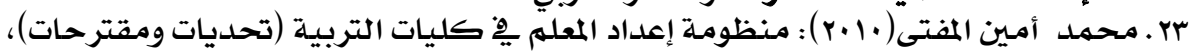

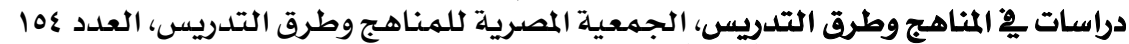

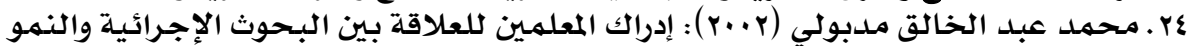

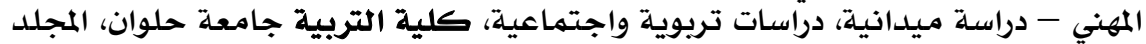

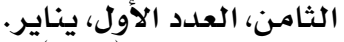

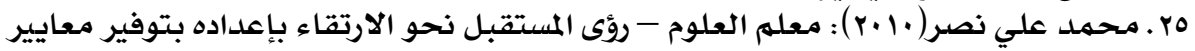

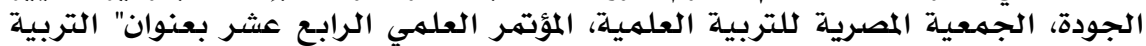

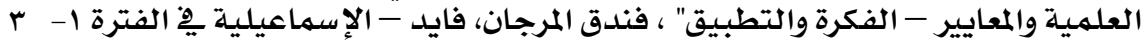

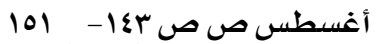

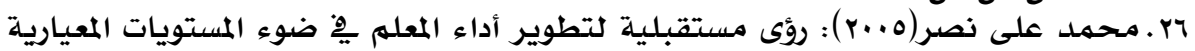

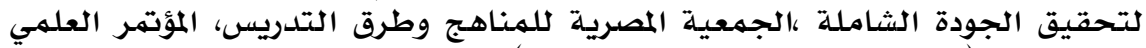

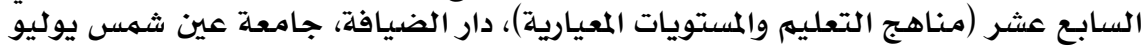
ص ص ص

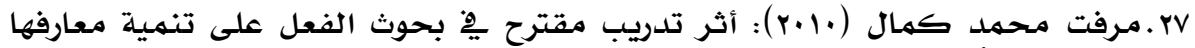

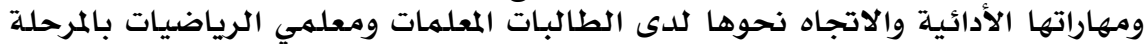

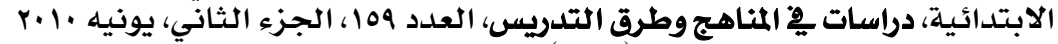

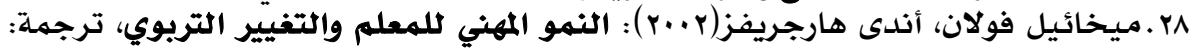

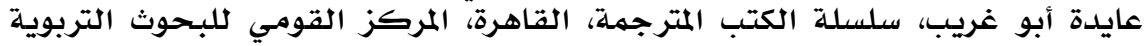
والتنهمية. 


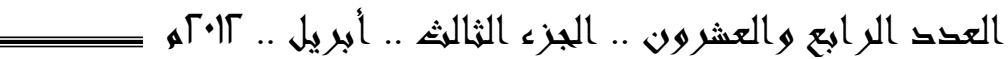

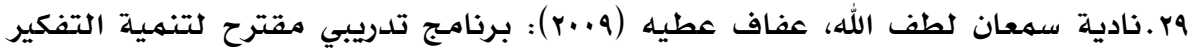

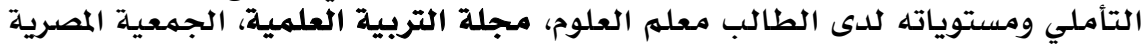

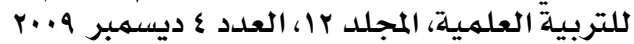

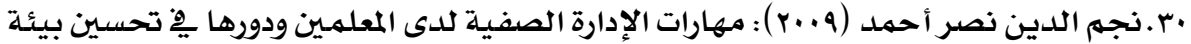

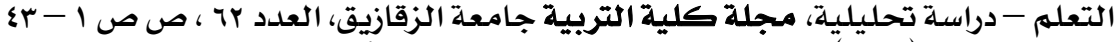

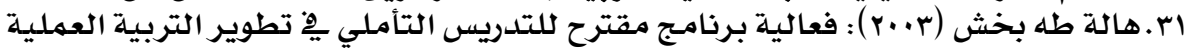

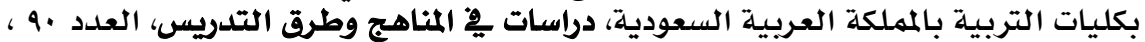

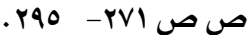

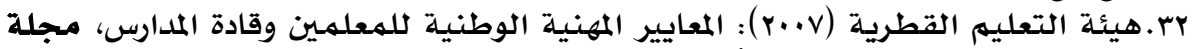

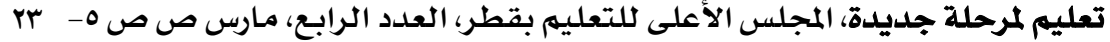

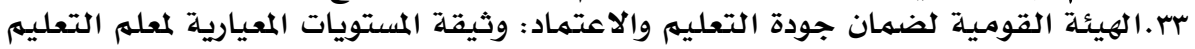

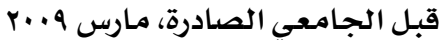

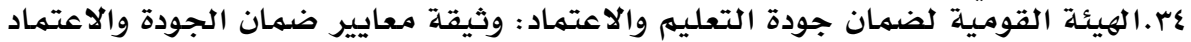

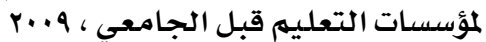

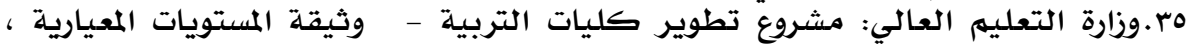

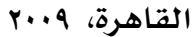

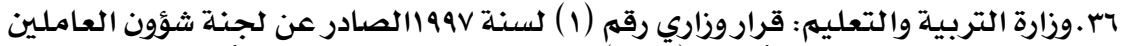

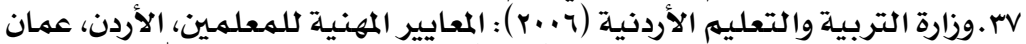

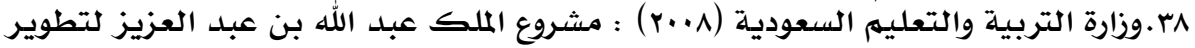
www.moe.gov.sa/quality/taqweem 8,htm.

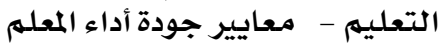

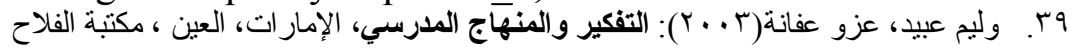

40. Ado, Kathryn (2013). Action research: professional development to help support and retain early career teachers, Educational Action Research, Volume 21, Number 2, 1 June, pp. 131-146(16)

41. Banegas, Dario; Pavese, Anahi; Velazquez, Aurelia; Velez, Sandra Maria (2013). Teacher Professional Development through Collaborative Action Research, Educational Action Research, , v21 n2 p185-201

42. Brownstein, Erica.; Allan, Elizabeth; Veal, William R. (2009): Alignment of the "2003 NSTA Standards for Science Teacher Preparation" with the NCATE Assessment System, Journal of Science Teacher Education, v20 n5 p403 413 Oct.

43. Buss, R. R. (2010). Efficacy for Teaching Elementary Science and Mathematics Compared to Other Content. School Science And Mathematics, 110(6), 290-297.

44. Campbell, D . ; Melenyzer, B.; Nettles, D . and Wyman, R . Portfolio and Performance Assessment in Teacher Education . Boston $\mathrm{M}$ Allyn and bacon .2000.

45. Council of Chief State School Officers. (2011, April). Interstate Teacher Assessment and Support Consortium (InTASC) Model Core Teaching Standards: A Resource for State Dialogue. Washington, DC: Author.

46. Crosswell, L. (2009). Classroom management: Developing your own approach to managing the classroom. In J. Millwater \& D. Beutel 


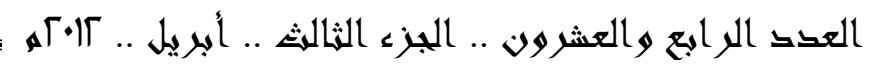

(Eds.), Stepping out into the real world of education (pp. 41-68). New South Wales, Australia: Pearson.

47. Darling-Hammond, L. \& J. Baratz-Snowden. (2005). A Good Teacher in Every Classroom: Preparing the Highly Qualified Teachers our Children Deserve. San Francisco, CA: John Wiley \& Sons.

48. Ferrance, E. (2000). Themes in Education: Action Research, The Education Alliance: Brown University, Providence, Rhode Island.

49. Firestone William, Mayrowetz David, Fairman Janet. (1998). Performance-Based Assessment and Instructional Change: The Effects of Testing in Maine and Maryland, Educational Evaluation \& Policy Analysis, vol. 20 no. 2 95-113

50. Gebhard, J.G. (2005). Awareness of teaching through action research: Examples, benefits, limitations. JALT Journal 27(1).

51. Glanz, J. (2003). Action research: an educational leader's guide to school improvement, second edition. Norwood, MA: ChristopherGordon.

52. Goh, P., \& Matthews, B. (2011). Listening to the Concerns of Student Teachers in Malaysia during Teaching Practice. Australian Journal Of Teacher Education, 36(3), 92-103.

53. Griffith, B. A., \& Frieden, G. (2000). Facilitating reflective thinking in counselor education. Counselor Education and Supervision, 40(2).

54. Harry S. Hertz (2001). Baldrige National Quality Program, National Institute of and technology, Web site:www.quality.nist-gov

55. Hendricks C.C.(2009). Improving Schools Through Action Research: A Comprehensive Guide for Educators (2nd Edition). Boston: Allyn \& Bacon.

56. Jaipal, Kamini; Figg, Candace (Mar 2011). Collaborative Action Research Approaches Promoting Professional Development for Elementary School Teachers, Educational Action Research, v19 n1 p59-72

57. Johnson, A. P. (2012). A short guide to action research $\left(4^{\text {th }}\right.$. ed.). New Jersey: Pearson Education

58. Kember, D., Leung, D., Jones, A., Loke, A. Y., et al. (2000). Development of a questionnaire to measure the level of reflective thinking. Assessment and Evaluation in Higher Education, 25(4), 380-395.

59. Kemmis, S., \& McTaggart, R.(2007). participatory action research http://www.corwin.com/upm-data/21157_Chapter_10.pdf

60. Keogh ,M. (2005). Factors influencing pre- service teachers' level of reflective thinking. Unpublished doctoral dissertation, Syracuse University.

61. Kim ,Y. (2005) . Cultivating reflective thinking: The effects of a reflective thinking tool on learners' learning performance and metacognitive awareness in the context of on- line learning. Unpublished Doctoral dissertation, The Pennsylvania State University. 


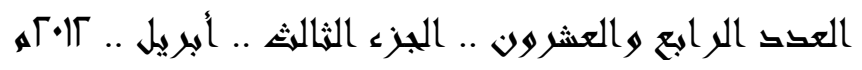

62. Kirkwood, M., \& Christie, D. (2006). The role of teacher research in continuing professional development. British Journal of Educational Studies, 54, 429-448.

63. Klieger, A. \& Yakobovitch, A. (2011). Science Teachers' Perception of Science Standards Implementation. Journal of Science Education and Technology, 20 (3), 286 - 299.

64. Koshy, Valsa (2005). Action Research for Improving Practice: A Practical Guide . Thousand Oaks, CA: Paul Chapman,

65. Kovalik ,S. and Olsen, K. (2010). Kid's Eye View of Science: A Conceptual Integrated Approach to Teaching Science K-6, first edition ,U.S.A : Sage

66. Kraft, N. P. (2002). Teacher research as a way to engage in critical reflection: A case study. Reflective Practice,3, 175-189.

67. Larrivee, Barbara (2008). Development of a tool to assess teachers' level of reflective practice. Reflective Practice Journal, 9(3), 341-360

68. Lee, Young Ah; Wang, Ye (2012). Searching for New Directions: Developing MA Action Research Project as a Tool for Teaching USChina Education Review, A 8 p697-709

69. Luk, J. (2008). Assessing teaching practicum reflections: Distinguishing discourse features of the "high" and "low" grade reports. System, 36, 624-641.

70. Leung, D. Y. P. \& Kember, D. (2003). The relationship between approaches to learning and reflection upon practice. Educational Psychology, 23(1), 61-71.

71. Mahardale, J., Neville, R., Jais, N. \& Chan, C.(2007) . Reflective thinking in a problem based English programmed: A study on the development of thinking in elementary students. www.pbl2008.com/pdf/0048.pdf

72. Manfra, M.M. (2009). The middle ground in action research: Integrating practical and critical inquiry. Journal of Curriculum \& Instruction, 3(1), 32-46.

73. Mertler, Craig A. (2011). Action Research: Improving Schools and Empowering Educators. Third Edition, SAGE Publications (CA)

74. National Staff Development Council. (NSDC) (2001). Training Manual: NSDC's Standards for Staff Development - revised. Oxford, $\mathrm{OH}$ : Author

75. New South Wales Institute of Teachers (2010). NSW Professional Teaching Standards http://www.nswteachers.nsw.edu.au/

76. Mills, G. E. (2011). Action research: A guide for the teacher researcher (4thed.). Boston: Pearson

77. Norton, L. S. (2009). Action Research in teaching \& learning-A practical guide to conducting pedagogical research in universities. London: Routledge 


$$
\text { العقد الر ابع والعشرون .. الجزء المثالمش .. أبريل .. Гا. مه }
$$

78. NSTA Standards for Science Teacher Preparation (2012) http://www.nsta.org/preservice/docs/2012NSTAPreserviceScienceStan dards.pdf

79. Ogonor, B O. \& Badmus, M. M. (2006).Reflective Teaching Practice among Student Teachers: The Case in a Tertiary Institution in Nigeria, Australian Journal of Teacher Education, Vol. 31: No. 2.

80. Onwuegbuzie, A.J., \& Dickinson, W.B. (2007). Mixed methods research and action research: a framework for the development of preservice and in-service teachers. Academic exchange. from http://asstudents.unco.edu/students/AE-xtra/2007/6/indxmain.html.

81. Parsons, R. D., \& Brown, K. S. (2002). Teacher as reflective practitioner and action researcher. Belmont, CA: Wadsworth/ Thomson Learning.

82. Phan ,H. (2008). Achievement goals, the classroom environment, 19. and reflective thinking: A conceptual framework. Electronic Journal of Research in Education Psychology. ISSN , 6 (3) , 571 602.http://www.investigacion-psicopedagogica.org/revista/articulos/16/ english/Art 16 269.pdf

83. Phan ,H. (2007) . An examination of reflective thinking, learning 20. approaches, and self- efficacy beliefs at the university of the South Pacific: A path analysis approach. Educational Psychology , 27 (6), $789-806$.

84. Phan, H. (2006). Examination of student learning approaches, reflective thinking, and epistemological beliefs: A latent variables approach, Electronic Journal of Research in Educational Psychology, No. 10, Vol. 4(3), 2006. ISSN:1696-2095. pp:577-610

85. Porter, A., Youngs, P., \& Odden, A. (2001). Advances in teacher assessments and uses. In V. Richardson (Ed.), Handbook of research on teaching ( $4^{\text {th }}$ ed., pp.259-297). Washington, DC: American Educational Research Association

86. Rawlinson , D., \& Little, M. (2004). Improving student learning through classroom action research. Florida Department of Education. Tallahassee: Author.

87. Reis-Jorge, J. M. (2005). Developing teachers' knowledge and skills as researchers: A conceptual framework. Asia-Pacific Journal of Teacher Education, 33,303-319.

88. Riel, Margaret. (2010). Understanding Action Research. Center for Collaborative Action Research, Pepperdine University. Accessed online http://cadres.pepperdine.edu/ccar/define.html.

89. Samuels ,M. \& Betts ,J. (2007) . Crossing the threshold from description to deconstruction and reconstruction: Using self- assessment to deepen reflection. Reflective Practice , 8 (2), $269-283$. 


$$
\text { العقد الر ابع والعشرون .. الجزء المثالمش .. أبريل .. Гا. مه }
$$

90. Schmuck, R. A. (Ed.). (2009). Practical action research: A collection of articles (2nd edition). Thousand Oaks, CA: Corwin Press.

91. Schneider, D. (2006) . Reflection. http://edutechwiki.unige.ch/en/Reflection

92. Semerci, C. (2007). "Developing a reflective thinking tendency scale for teacher and student teachers". Educational Science: Theory \& Practice, 7 (3), sep., 1369 - 1379

93. Sharp ,K. (2003) . Teacher Reflection: A perspective from the trenches. Theory into Practice, 42 (3), $243-247$.

94. Siebert, C. J. (2005). Promoting Pre-service Teachers' Success in Classroom Management by Leveraging a Local Union's Resources: A Professional Development School Initiative. Education, 125(3), 385392.

95. Smith, K. \& Sela, O. (2005). Action Research as a bridge between preservice teacher education and in-service professional development. The European Journal of Teacher Education, 28 (3), 293-311.

96. Stringer, E.T. (2007). Action Research. Los Angeles, (3rd ed.) CA: Sage.

97. Tok, S. (2010). The problems of teacher candidate's about teaching skills during teaching practice. Social and Behavioral Sciences. 2 (2), 4142-4146. http://www.sciencedirect.com/

98. Weichel, Mark (2003). A Study of Principals' Perceptions of State Standards in Nebraska, Connections, Vol. 4, February, pp 1-26, online http://www.nassp.org/portals/0/content/48345.pdf

99. Wenzlaff ,T. (1994) . Training the student to be a reflective practitioner. Education, 115 (2) , $278-287$.

100. Winter, R. (1989) Learning from Experience: principles and practice in action research. Lewes, Falmer.

101. Zeichner, L. M. (2003). Teacher research as professional development for P-12 educators in the USA. Educational Action Research, 11,301325.

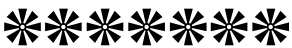

